MANNHEIM RESEARCH INSTITUTE For the ECONOMiCS OF AGING

\title{
AUSWIRKUNGEN DER FINANZKRISE AUF DIE PRIVATE ALTERSVORSORGE
}

\author{
Axel Börsch-Supan \\ Martin Gasche \\ Michael Ziegelmeyer
}

๑) $\boldsymbol{m e a - M a n n h e i m ~ R e s e a r c h ~ I n s t i t u t e ~ f o r ~ t h e ~ E c o n o m i c s ~ o f ~ A g i n g ~}$

L13, 17_D-68131 Mannheim_Phone +49 621 181-2773/1862_Fax +49 621 181-1863_www.mea.uni-mannheim.de 


\title{
Auswirkungen der Finanzkrise auf die private Altersvorsorge ${ }^{1}$
}

\author{
Axel Börsch-Supan \\ Martin Gasche \\ Michael Ziegelmeyer ${ }^{\ddagger}$
}

November 2009

\begin{abstract}
Zusammenfassung: Die starken Vermögensverluste einzelner Anlageklassen in 2008 durch die Finanz- und aufkommende Wirtschaftskrise führte zu einer Diskussion über die Risiken der kapitalgedeckten Altersvorsorge. Diese Studie quantifiziert die Höhe der Vermögensverluste und Renditeeinbußen durch die Finanz- und Wirtschaftskrise bei der kapitalgedeckten Altersvorsorge. Die Datenbasis bilden die SAVE Daten 2008. Die Effekte auf die Portfolios der Haushalte werden auf Basis der Vermögensbestände Ende 2007 und der beobachteten Renditeentwicklung in 2008 über verschiedene Anlageklassen abgeschätzt. Im Vergleich zum Vermögen im Referenzszenario ohne Krise ergeben sich durchschnittliche Finanzvermögensverluste von rund 3.000 Euro oder 8,5\%. Dies ist geringfügig weniger als die Verluste, die aus der Geldvermögensstatistik der Bundesbank abgeleitet werden können. Beschränkt man sich nur auf das Altersvorsorgevermögen, liegt der mittlere Verlust bei 3\%. Man kann diese Vermögensverluste differenziert nach Geburtsjahrgängen über das gesamte Erwerbsleben bis zum Rentenalter fortschreiben und in einen Renditeverlust umrechnen. Dies führt für die Geburtsjahrgänge 1940 bis 1990 zu Renditeeinbußen von maximal 0,1 Prozentpunkten für das Altersvorsorgevermögen und maximal 0,2 Prozentpunkten für das Finanzvermögen. Die größten Renditeverluste haben die gerade in die Rente eingetretenen und die rentennahen Jahrgänge, weil sie zum Zeitpunkt der Krise schon viel Vermögen angesammelt haben und deshalb auch die größten Verluste erleiden. Da der Renditerückgang durch den demographischen Wandel jedoch weit größer ist als der Renditerückgang durch die Finanzkrise, genießen diese Jahrgänge immer noch eine deutlich höhere Rendite als die jüngeren Jahrgänge.
\end{abstract}

JEL: G01, E27, G11, J26

Schlagwörter: private Altersvorsorge, Finanzkrise

\footnotetext{
${ }^{1}$ Wir danken Benedikt Alt und Julius Nick für ihre hervorragende Forschungsassistenz im Rahmen dieses Projekts. Das MEA ist ein Forschungsinstitut, das sich zu etwa 85\% aus Mitteln der öffentlichen Forschungsförderung finanziert. Wir danken vor allem der Deutschen Forschungsgemeinschaft, die das SAVE-Panel finanziert. Wir danken ebenso dem Land Baden-Württemberg und dem Gesamtverband der Deutschen Versicherungswirtschaft für die Grundfinanzierung des MEA.

‡ Mannheimer Forschungsinstitut Ökonomie und Demographischer Wandel (MEA); Universität Mannheim; L13,17; 68131 Mannheim; E-Mail: Gasche@mea.uni-mannheim.de; Ziegelmeyer@mea.uni-mannheim.de
} 


\section{Einleitung}

Die Finanzkrise hat wieder ins Bewusstsein gerückt, dass die Anlagen der privaten kapitalgedeckten Altersvorsorge mit Risiken behaftet und auch große Wertverluste nicht auszuschließen sind. In dieser Studie wird der Frage nachgegangen, wie und wie stark die private Altersvorsorge von der Finanzkrise betroffen ist, ob die Auswirkungen permanent oder vorübergehend sind und welche Personengruppen bezüglich der privaten Vorsorge vor allem unter den Effekten der Finanzkrise zu leiden haben.

Die Stärkung der kapitalgedeckten Altersvorsorge ist seit Längerem eine Forderung und seit 2001 auch Gegenstand der Politik in Deutschland, um den demographischen Herausforderungen für die Rentensysteme zu begegnen. Während das Risiko der umlagefinanzierten gesetzlichen Rente vor allem im Lohnsummenrisiko und damit zusammenhängend im demographischen Risiko besteht, ist das spezifische Risiko der kapitalgedeckten Rente das Kapitalmarktrisiko. Dieses ist mit der seit Herbst 2008 verschärften Finanzmarktkrise offen zutage getreten, nicht ohne Rufe nach einer „Restauration“ des Umlagesystems laut werden zu lassen, obwohl durch die Krise das Lohnsummenrisiko ebenfalls virulent wurde ${ }^{2}$ und obwohl für das Umlagesystem das demographische Risiko unverändert bestehen bleibt. Die Kapitaldeckung in der Altersvorsorge wird gerade als Mittel gesehen, um das demographische Risiko des Umlagesystems zu entschärfen, da für kapitalgedeckte Systeme die Geburtenrate bzw. das Größenverhältnis zwischen der Gruppe der Rentner und der Beitragzahler keine direkte Rolle spielt und weil mit der Kapitaldeckung die demographischen Lasten anders auf die Generationen verteilt werden können. Der Preis für die Risikoreduktion hinsichtlich der Demographie ist ein höheres Kapitalmarktrisiko für die gesamte Altersvorsorge.

Vor dem Hintergrund der aktuellen Krise stellt sich nun die Frage, wie groß das Kapitalmarktrisiko für die kapitalgedeckte Altersvorsorge im Allgemeinen ist; wie die aktuelle Krise Rendite und Risiko der kapitalgedeckten Altersvorsorge beeinflusst hat; wie groß die Verluste durch die Krise waren und ob sich durch die Krise die Sichtweise ändern sollte, dass ein Mischsystem aus Kapitaldeckung und Umlage den Herausforderungen der demographischen Entwicklung am besten gewachsen ist. Dies sind die Themen dieser Studie. Sie ist die „Schwesterstudie“ zu Börsch-Supan, Gasche, Wilke (2009), in der die Auswirkungen der Finanzkrise auf die Gesetzliche Rentenversicherung und die Rentner untersucht wurden.

\footnotetext{
${ }^{2}$ Vgl. Börsch-Supan, Gasche und Wilke (2009).
} 
Es wird sich zeigen, dass die private kapitalgedeckte Altersvorsorge und die gesetzliche umlagefinanzierte Altersvorsorge in ganz ähnlicher Weise und auch in ähnlichem Ausmaß von der Krise betroffen sind. Zwar sind die Risiken und die zugrunde liegenden Mechanismen der beiden Vorsorgearten zunächst sehr unterschiedlich: In der privaten Altersvorsorge beeinflusst das Kapitalmarktrisiko die Rendite der Kapitalanlage, während in der gesetzlichen Rente das Lohnsummenrisiko über die Rentenanpassungsformel in der Rentenhöhe seinen Ausdruck findet. Dennoch wirkt sich im Ergebnis ein derartig breiter Schock wie die derzeitige Finanzkrise auf beide Vorsorgewege sehr ähnlich aus.

Zunächst ist grundsätzlich zu betonen, dass durch die langfristige Ausrichtung der privaten Altersvorsorgeanlagen kurzfristige Renditeeinbrüche, wie sie durch die Finanzkrise zu beobachten sind, weniger stark zu Buche schlagen als allgemein verstanden wird. Um dies zu zeigen, schätzen wir die unmittelbaren Finanzvermögensverluste 2008 durch die Finanzkrise ab, indem wir die Vermögenspositionen der deutschen Haushalte Ende 2007 mit den beobachteten Renditen im Jahr 2008 fortschreiben - zum einen mit den tatsächlichen Renditen 2008 und zum zweiten mit den hypothetischen Renditen, die 2008 eingetreten wären, hätte es die Finanzkrise nicht gegeben. Diese Rechnung machen wir zunächst für das gesamte Finanzvermögen und dann getrennt für das Altersvorsorgevermögen, unter dem die Produkte der privaten Altersvorsorge zusammengefasst werden.

Im Ergebnis zeigt sich ein Finanzvermögensverlust von rund 3.000 Euro im Vergleich zum simulierten Vermögen 2008, das sich ohne Finanzkrise ergeben hätte. Der relative Vermögensverlust beläuft sich im Durchschnitt auf 8,5\%. Insbesondere sind diejenigen relativ stark betroffen, deren Aktienanteil im Portfolio groß war. Dies sind die Haushalte mit höheren Einkommen, größeren Vermögen und die Älteren. Die Verteilungsanalyse der Verluste zeigt, dass einige sehr stark von der Krise gebeutelt sind. So verlieren 14\% der Haushalte mindestens $10 \%$ ihres Finanzvermögens und 4,8\% der Haushalte müssen extreme Verluste von mindestens 25\% des Finanzvermögens hinnehmen.

Die Auswirkungen der Finanzkrise auf die Rendite der gesamten privaten Altersvorsorge über das gesamte Leben eines Versicherten sind demgegenüber gering, vor allem wenn die Renditeeinbrüche durch die Krise nur vorübergehend sind. Der Renditeverlust beträgt dann maximal 0,2 Prozentpunkte bei Betrachtung des gesamten Finanzvermögens. Dieser maximale Verlust ergibt sich bei den Rentnerjahrgängen und rentennahen Jahrgängen. Jüngere Kohorten 
sind weniger oder gar nicht betroffen. Die höhere Betroffenheit gemessen an den Renditeverlusten muss allerdings im Zusammenhang mit dem Renditeniveau gesehen werden. So ist die Gesamtrendite für diese älteren Jahrgänge grundsätzlich höher als für die jüngeren und diese älteren Jahrgänge weisen auch nach Berücksichtigung der Krise noch immer eine höhere Rendite auf als die Jüngeren.

Insgesamt zeigen sich weit reichende Parallelen zu den Auswirkungen der Finanzkrise auf die Gesetzliche Rentenversicherung. ${ }^{3}$ Die dort stattfindende Abwertung der Entgeltpunkte kann ebenfalls als Vermögensverlust interpretiert werden, der alle Jahrgänge permanent trifft, die zum Zeitpunkt der Krise im Erwerbsleben standen. Auch in der Gesetzlichen Rentenversicherung sind die Rentner und die rentennahen Jahrgänge am stärksten betroffen. Selbst die Größenordnung der Renditeverluste ist ähnlich. Wir zeigen, dass die Renditeeinbußen in der Gesetzlichen Rentenversicherung sogar etwas größer sind als die in der privaten Altersvorsorge im eigentlichen Sinne, jedoch niedriger als die Verluste im Gesamtfinanzvermögen.

Für viele mag dieses Ergebnis erstaunlich sein, war es doch ein massiver Einbruch auf den Aktienmärkten, der diese schwerste Finanz- und Wirtschaftskrise seit der Weltwirtschaftskrise einläutete. Die relativ geringen Auswirkungen auf die private Altersvorsorge beruhen auf zwei grundlegenden Eigenschaften der privaten Altersvorsorge. Zum einen machen Aktien nur einen geringen Anteil der Anlagen für die private Altersvorsorge aus. Dies zeigen wir im folgenden Abschnitt 2. Zum anderen werden selbst massive Schocks über die lange Zeit, in der Altersvorsorgevermögen akkumuliert wird, geglättet. Dies wird in Abschnitt 3 anhand eines stilisierten Beispiels verdeutlicht.

Im Abschnitt 4 werden dann auf Grundlage der SAVE-Daten für deutsche Haushalte Vermögensverluste bzw. Renditeeinbußen im Jahr 2008 kalkuliert. In einem zweiten Schritt wird gezeigt, wie sich die Vermögensverluste bzw. Renditeeinbußen im Jahr 2008 langfristig niederschlagen. Im Abschnitt 5 werden die durch die Finanzkrise erzeugten Renditeverluste für die gesamte private Altersvorsorge und das Finanzvermögen abgeschätzt. Die Studie schließt mit einem zusammenfassenden Fazit in Abschnitt 6.

\footnotetext{
${ }^{3}$ Vgl. Börsch-Supan, Gasche und Wilke (2009).
} 


\section{Finanzkrise und Renditen der privaten Vermögensanlagen}

Die Finanzkrise führte zu einem Wertverlust von Vermögenswerten. Die bedeutendsten Wertverluste hatten Aktienanlagen und Aktienfonds zu verzeichnen. Der Deutsche Aktienindex (DAX) verlor innerhalb eines Jahres über 40\% an Wert (Abbildung 1). Wenn das Portfolio eines Haushalts genau den Aktienindex abgebildet hätte, ergäbe sich buchmäßig im Jahr 2008 ein Vermögensverlust in dieser Höhe. Vermögensverluste können in Renditen umgerechnet werden. Als Rendite ausgedrückt entsprach der Einbruch des DAX einer negativen Verzinsung von -40\% im Jahr 2008.

Auch andere Anlageformen büßten an Rentabilität ein. Die Verluste waren jedoch höchst unterschiedlich. $\mathrm{Zu}$ Totalverlusten kam es nur in beschränktem Ausmaß, zum Beispiel wenn sich Schuldverschreibungen oder Zertifikate von Lehman Brothers in den Portfolios befanden oder strukturierte Wertpapiere (z.B. Asset Backed Securities), deren Wertverfall als Auslöser der Krise gelten kann. Dagegen konnten die in Deutschland am weitesten verbreiteten Sparanlagen aufgrund der zeitweise sehr angespannten Liquiditätssituation der Geschäftsbanken sogar eine Zunahme der Verzinsung verzeichnen. Auch die Umlaufrendite festverzinslicher Wertpapiere veränderte sich nur in geringem Maße. Schließlich war Deutschland im Gegensatz zu vielen anderen Ländern von einem Verfall der Immobilienpreise kaum betroffen, weil es in Deutschland vorher keine Immobilienpreisblase gegeben hat.

Haben die privaten Haushalte ihr Vermögen nicht direkt in primären Anlagen wie Aktien oder Schuldverschreibungen angelegt, sondern indirekt, indem sie ihr Vermögen Kapitalsammelstellen (z.B. Versicherungen oder Investmentfonds) überlassen haben, die ihrerseits das Kapital in bestimmten Wertpapiere wie Aktien, Schuldverschreibungen und Derivaten anlegen, dann hängt die Renditeentwicklung davon ab, wie stark im Portfolio dieser Kapitalsammelstellen die Anlagen vertreten waren, die besonders viel verloren haben. 


\section{Abbildung 1: Verzinsung privater Vermögensanlagen}
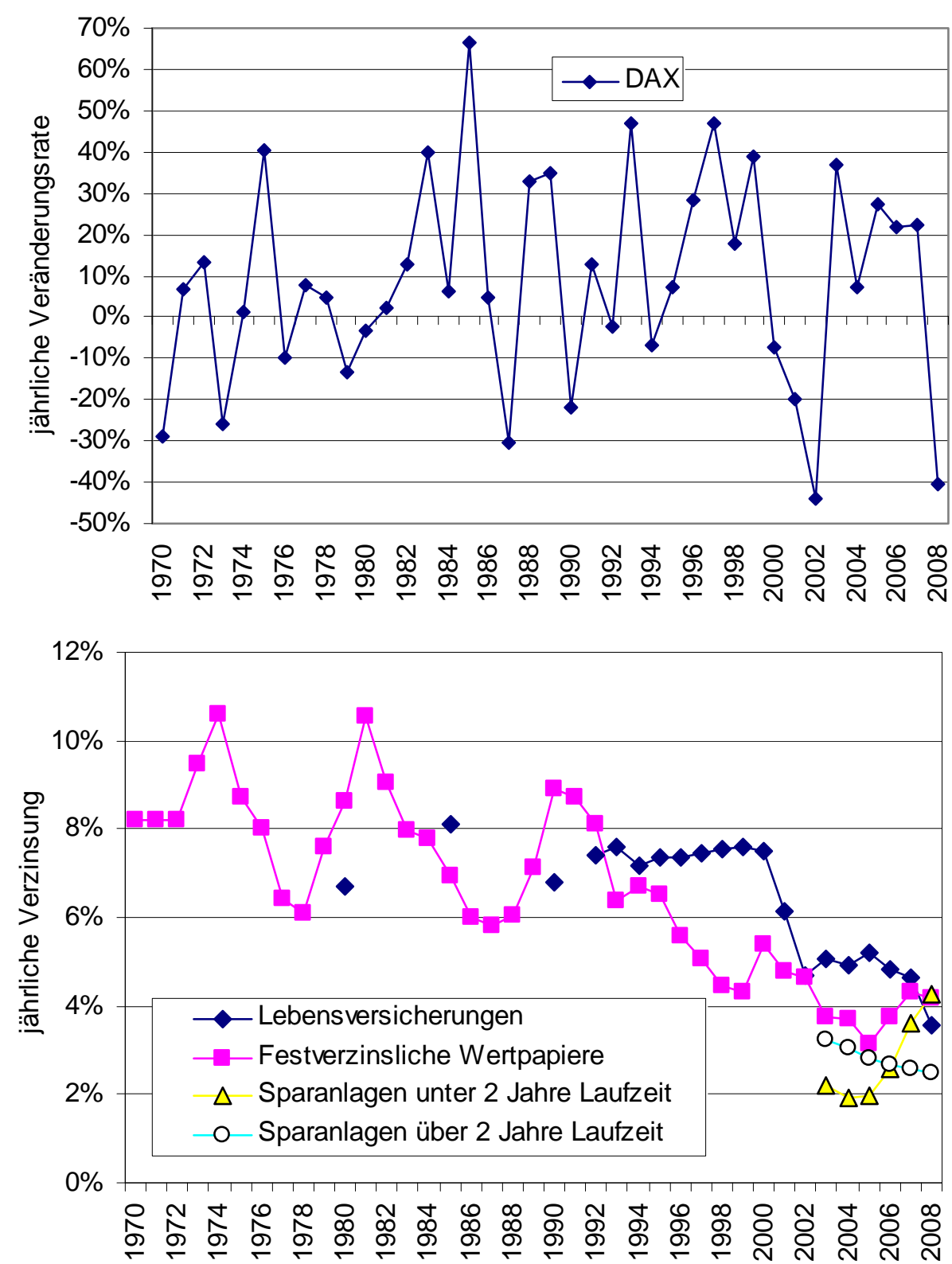

Quellen: GDV, Deutsche Bundesbank.

Zu diesen „sekundären Anlageformen“, also Anlagen z.B. in Versicherungen oder Fonds, zählen fast alle Altersvorsorgeprodukte. Das im Anlagevolumen nach wie vor am meisten verbreitete Altersvorsorgeprodukt ist die Kapitallebensversicherung. Die deutsche Lebensversicherungsbranche war nur zu einem sehr geringen Anteil in Asset Backed Securities und Credit Linked Notes (CLN) engagiert ${ }^{4}$, so dass die unmittelbaren Effekte der Subprimekrise auf die Lebensversicherungen als gering einzuschätzen sind. Im Zuge der Wertverluste auf dem Aktienmarkt mussten die Lebensversicherungen jedoch auch Wertverluste hinnehmen. Da die Lebensversicherungen zur Zeit der massiven Wertverluste am Aktienmarkt im Herbst

\footnotetext{
${ }^{4}$ Laut GDV waren es im September 2008 rund 1,7\% des Kapitalbestandes.
} 
2008 aber über 80 \% des rund 700 Mrd. EUR umfassenden Anlagekapitals in Zinstitel investiert hatten und weniger als $10 \%$ in Aktien, blieb ein massiver Kapitalschwund bei den Lebensversicherungen aus. Soweit es sich bei den von den Lebensversicherungen gehaltenen Zinstiteln um Staatspapiere handelte, ist sogar von einem Wertzuwachs des Bestandes auszugehen, weil in der Krise die Kurse der Staatspapiere wegen der starken Nachfrage gestiegen sind. Neu gezeichnete Staatstitel waren - als Kehrseite der Medaille - entsprechend niedriger verzinst. Problematischer war dagegen das Engagement der Lebensversicherungen (rund 30\% des Portfolios) in Bankschuldverschreibungen. Denn zum einen sanken die Kurse dieser Papiere (soweit überhaupt ein Preis festgestellt werden konnte), weil die Risikoprämien stiegen, zum anderen bestand bei Bankschuldverschreibungen ein Ausfallrisiko. Soweit es sich bei den Bankschuldverschreibungen um Pfandbriefe handelte, waren diese zwar durch Hypotheken und Staatstitel besichert, doch wenn der Handel mit diesen Papieren zum Erliegen gekommen wäre, hätte die Gefahr von Liquiditätsengpässen bestanden. Bei Versicherungen können allerdings kurzfristige Liquiditätsprobleme grundsätzlich nur dann auftreten, wenn die Sparraten der Versicherten geringer sind als die Auszahlungen, wenn eine Versicherung also Vermögen auflösen muss, um die Renten und Kapitalpolicen oder auch die Rückkaufwerte nach einer Stornierung auszuzahlen.

Insgesamt wurden die Lebensversicherungen als Altersvorsorge von der Finanzkrise relativ wenig beeinträchtigt: Die Nettoverzinsung der Kapitallebensversicherungen sank von 4,65\% im Jahr 2007 auf 3,55\% im Jahr 2008. ${ }^{5}$ In Abhängigkeit von der Dauer dieser niedrigeren Renditen und damit in Abhängigkeit von der Beeinträchtigung der Überschussbeteiligungen wird dies zu geringeren Ablaufleistungen führen, jedoch keinesfalls im Ausmaß eines vollständig in Aktien angelegten Vermögens.

Auch die fünf Durchführungswege der betrieblichen Altersvorsorge Direktzusage, Direktversicherung, Unterstützungskassen, Pensionskassen und Pensionsfonds sind von der Finanzkrise in unterschiedlichem Maß betroffen. Die Auswirkungen auf die Direktversicherungen entsprechen im Wesentlichen denen auf die Lebensversicherungen.

Direktzusagen bleiben direkt von der Finanzkrise unbeeinflusst; sie hängen aber von der Prosperität des Unternehmens ab, die indirekt über die allgemeine Wirtschaftentwicklung Schaden nehmen kann. Dies kann dann zu Kürzungen der Betriebsrenten führen. Bei der Un-

\footnotetext{
${ }^{5}$ Vgl. GDV (2009).
} 
ternehmensinsolvenz greift der Pensionssicherungsverein. Die grundsätzlichen Probleme der Direktzusagen, die letztlich einer Umlagefinanzierung recht ähnlich sind, bleiben zusätzlich bestehen.

Viele Direktzusagen wurden in den letzten Jahren von größeren Unternehmen in Pensionskassen und Pensionsfonds ausgelagert, damit sie bei den Unternehmensratings nicht herabgestuft werden. Für diese Durchführungswege gilt, dass sie vom Wertverlust der Anlagen voll getroffen werden. Pensionskassen sind an eine Höchstgrenze des Aktienengagements in Höhe von $35 \%$ gebunden. Zudem dürfen maximal $5 \%$ in Hedge-Fonds angelegt sein. Tatsächlich sind die Pensionskassen i.d.R. mit $70 \%$ bis $90 \%$ in Zinspapieren investiert. Die Aktienabhängigkeit ist aber größer als bei den Lebensversicherungen. Pensionsfonds gibt es in Deutschland erst seit 2002. Sie sind nicht an eine Mindestverzinsung gebunden, und für sie gilt auch kein Limit hinsichtlich der Aktienquote. Da die Finanzkrise die Aktienwerte stärker traf als die Zinstitel, dürften Pensionsfonds einem größeren Risiko ausgesetzt sein als z.B. Lebensversicherungen. Die OECD geht davon aus, dass Pensionsfonds in Deutschland 2008 durch die Finanzkrise Wertverluste von rund 8\% hinnehmen mussten. ${ }^{6}$

Die Betroffenheit der Riester-Renten hängt davon ab, ob die Verträge als Banksparpläne, als Fondssparpläne oder als Rentenversicherung abgeschlossen wurden. Grundsätzlich ist die Rückzahlung der Beiträge bei Riesterverträgen garantiert - dies entspricht also einer Nominalrendite von mindestens null. Die Einbußen waren bei Riester-Fonds am größten, da diese am stärksten von den Marktschwankungen abhängen. Für die Riester-Versicherung gelten die oben zur Lebensversicherung gemachten Aussagen. Die Verzinsung von RiesterBanksparplänen wird oft an die Verzinsung von Bundeswertpapieren und/oder den Euribor gekoppelt, so dass sich eine geringere Rendite bei den Bundeswertpapieren auch auf die Riester-Rente auswirken kann. Da hier aber ein gleitender Zinssatz (über mehrere Jahre) verwendet wird, können sich nur nachhaltige Zinsänderungen negativ auswirken. Für die RürupRente gibt es anders als bei Lebensversicherungen und Pensionskassen keine Anlagevorschriften. Auch hier kann man zwischen Versicherungsprodukten und fondsorientierten Produkten unterscheiden. Entsprechend gelten die oben jeweils gemachten Aussagen.

Insgesamt lässt sich also konstatieren, dass die typischen Altersvorsorgeprodukte in ihrem Wert bzw. ihrer Rendite weit weniger von der Finanzkrise betroffen waren als reine Aktien-

\footnotetext{
${ }^{6}$ Vgl. OECD (2009), S. 33, Figure 1.3.
} 
produkte. Deren Wertverlust von 40\% ist daher kein Gradmesser für den Effekt der Krise auf die private Altersvorsorge. Im Abschnitt 4 werden wir, ausgehend vom Portefeuille der deutschen Haushalte und den unterschiedlichen Verlustraten der einzelnen Anlageelemente abschätzen, wie sehr die Altersvorsorge typischer Haushalte von der Krise betroffen war.

\section{Finanzkrise und private Altersvorsorge: Grundsätzliche Anmerkungen zu langfristigen Kapitalanlagen}

Auch aus einem zweiten Grund kann der Einbruch des DAX um 40\% im Jahr 2008 kein Gradmesser für Altersvorsorgeprodukte sein. Denn Altersvorsorgeanlagen heben sich durch zwei Besonderheiten von typischen Einmalanlagen ab: Erstens ist die Altersvorsorge eine sehr langfristige Anlage, zweitens wird diese zumeist aufgrund eines Vertrages mit gleichmäßigen Ein- und Auszahlungen (Sparplan und Auszahlungsplan) durchgeführt. Wie sich diese beiden Merkmale Langfristigkeit und Gleichmäßigkeit auf die Rendite und das Risiko der Altersvorsorge auch vor dem Hintergrund der Finanzmarktkrise auswirken, wird im Folgenden in Form eines stilisierten Beispiels gezeigt.

\subsection{Risiko der kapitalgedeckten Altersvorsorge}

\section{Risikoreduktion durch Langfristigkeit der Anlage: der „Anlagehorizonteffekt“}

Kurzfristige Schwankungen der Vermögenspreise sind für die kapitalgedeckte Altersvorsorge insofern weniger relevant, weil die Altersvorsorge einen sehr langen Zeithorizont (Anlagezeitraum mind. 25 Jahre) aufweist. Über diesen werden kurzfristige Schwankungen geglättet. Bedeutender für die Altersvorsorge sind dagegen langfristige strukturelle Veränderungen am Kapitalmarkt, so genannte Kohortenschwankungen, wie sie beispielsweise von der demographischen Entwicklung oder vom technischen Fortschritt ausgelöst werden können.

Nachfolgend wird anhand von Beispielrechnungen gezeigt, wie sich der Anlagehorizont auf die Schwankungen der Rendite und damit auf das Risiko der Anlage auswirkt. Um die glättende Wirkung besonders deutlich zu machen, legen wir als Beispiel eine vollständig in Aktien investierte Anlage zugrunde, d.h. eine Anlage, die besonders stark, aber relativ kurzfristig durch die Krise getroffenen wurde. Ausgangspunkt ist zunächst eine Einmalanlage, d.h. ein bestimmter Anlagebetrag wird zu einem bestimmten Zeitpunkt eingezahlt und dann für eine vorgegebene Anlagedauer mit der tatsächlich realisierten und der unterstellten Entwicklung 
des DAX verzinst. ${ }^{7}$ Zugrunde gelegt werden die DAX-Jahresendstände seit $1970 .{ }^{8}$ Für zukünftige Jahre wird angenommen, dass der DAX mit seiner langjährigen durchschnittlichen Zuwachsrate von 8,15\% ${ }^{9}$ abzüglich eines Demographieabschlags wächst. Da die demographische Entwicklung zu einem langfristigen Rückgang der Kapitalrenditen führt, ${ }^{10}$ wird schließlich angenommen, dass dieser Abschlag bis zum Jahr 2050 kontinuierlich auf einen Prozentpunkt ansteigt, so dass die Verzinsung im Jahr 2050 7,15\% beträgt. Die Rendite am Ende des Anlagezeitraums wird dann dem jeweiligen Anlagezeitpunkt der Einmalanlage zugeordnet (vgl. Abbildung 2). Zur Vereinfachung wird von den Transaktionskosten der Anlage abgesehen.

In Abbildung 2 sind die jeweiligen Renditen für Anlagezeitpunkte von 1970 bis 2010 für verschiedene Anlagehorizonte (5 Jahre, 10 Jahre, 20 Jahre, 30 Jahre und 40 Jahre) dargestellt. ${ }^{11}$ Es ist leicht zu erkennen, dass die Renditeschwankungen umso größer sind, je kürzer die Laufzeit der Anlage ist. Umgekehrt variiert die Rendite weniger, je länger die Laufzeit gewählt wird. Damit ist die Wahl des Anlagezeitpunkts, das Timing der Anlage, umso unbedeutender, je länger die Laufzeit ist.

Trotzdem bleibt bei der Einmalanlage der Anlagezeitpunkt wichtig. Die 30-jährige Anlage im Jahr 1970 bringt z.B. noch eine Rendite von über $9 \%$, da der Ablauf des Anlagezeitraums direkt auf dem Höhepunkt der Internetblase im Jahr 2000 ist. Hätte man das Kapital nur zwei Jahre später angelegt, hätte man das Platzen der Blase im Jahr 2001 mitgemacht und nur eine Rendite von unter $6 \%$ erzielen können (Abbildung 2). Die Einmalanlage erbringt bei einer Anlage im Jahr 1999, dem Höhepunkt der Internetblase, die niedrigste Rendite.

Das Anlagerisiko - genauer gesagt das Risiko bei der Wahl des Anlagezeitpunkts oder kurz: das Timing-Risiko - kann man anhand der Standardabweichung der Renditekurve für unterschiedliche Anlagezeitpunkte (Abbildung 2) messen. Wie die Tabelle 1 zeigt, sinkt die Standardabweichung und damit das Anlagerisiko mit der Laufzeit: Bei einem Anlagezeitraum von 5 Jahren beträgt sie beispielsweise noch 9,13 und bei 30 Jahren nur noch 1,18. Entsprechend kann man festhalten, dass bei der Altersvorsorge, die typischerweise durch einen langen An-

\footnotetext{
${ }^{7}$ Es werden also keine DAX-Papiere gekauft, sondern es wird angenommen, dass die Wertentwicklung des nicht näher spezifizierten Altervorsorgekapitals der DAX-Entwicklung folgt.

${ }^{8}$ Vor 1987 zurückgerechnete Werte.

${ }^{9}$ Durchschnittliche Zuwachsrate zwischen 1970 und 2007.

${ }^{10}$ Vgl. dazu Börsch-Supan, Heiss, Ludwig und Winter (2003) oder Krüger und Ludwig (2007).

${ }^{11}$ Da für die Berechnungen die Jahresendstände des DAX verwendet werden, wird angenommen, dass die Anlage am Ende des jeweiligen Jahres gemacht wird.
} 
lagezeitraum gekennzeichnet ist, das Anlagerisiko reduziert wird. Durch die Langfristorientierung ist die Altersvorsorge also recht gut gegen Kurzfristschwankungen abgesichert.

Tabelle 1: Rendite und Risiko für verschiedene „Anlagestrategien“ im DAX

\begin{tabular}{|l|c|c|}
\hline & $\begin{array}{c}\text { Durchschnitt- } \\
\text { liche Rendi- } \\
\text { te }^{\mathbf{1 2}} \mathbf{1 9 7 0 - 2 0 1 0}\end{array}$ & $\begin{array}{c}\text { Standardabweichung } \\
\text { der Renditen 1970- } \\
\mathbf{2 0 1 0}\end{array}$ \\
\hline Einmalanlage 1 Jahr (=DAX ${ }^{\mathbf{1 3}}$ ) & 6,75 & 24,43 \\
\hline Einmalanlage 5 Jahre & 7,54 & 9,13 \\
\hline Einmalanlage 10 Jahre & 7,53 & 4,61 \\
\hline Einmalanlage 20 Jahre & 7,65 & 2,48 \\
\hline Einmalanlage 30 Jahre & 7,40 & 1,18 \\
\hline Einmalanlage 40 Jahre & 7,31 & 0,80 \\
\hline Sparplan 30 Jahre & 7,87 & 1,07 \\
\hline $\begin{array}{l}\text { Sparplan 30 Jahre und Auszah- } \\
\text { lungsplan 20 Jahre }\end{array}$ & 8,00 & 0,57 \\
\hline
\end{tabular}

Quelle: Eigene Berechnungen.

Abbildung 2: Rendite einer Einmalanlage in Abhängigkeit von der Laufzeit

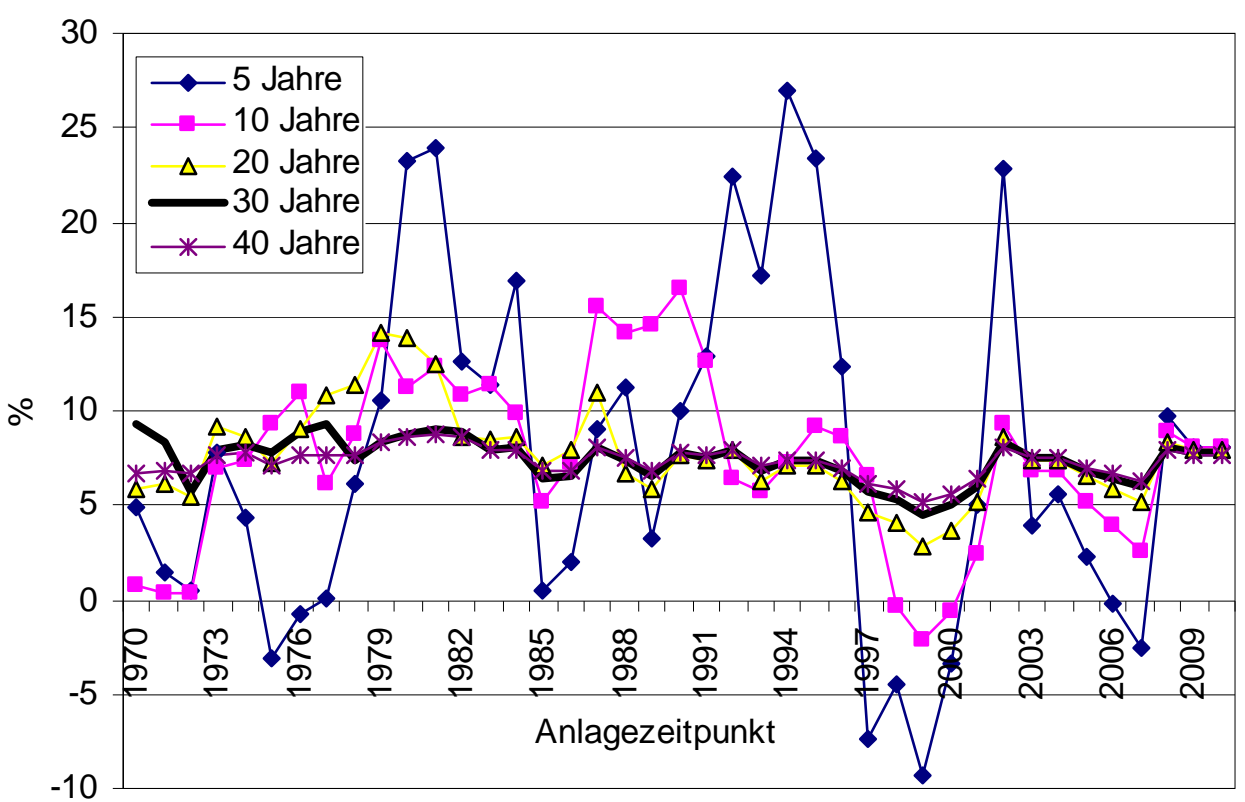

Quelle: Eigene Berechnungen.

\section{Risikoreduktion durch gleichmäßige Einzahlung: der „Durchschnittseffekt“}

Typische Altersvorsorgeprodukte sind nicht nur langfristig angelegt, sondern werden zumeist auch durch regelmäßige Einzahlungen über einen langen Zeitraum bedient. Dies können die Einzahlungen in einen klassischen Sparplans sein oder die Beiträge für eine Renten- oder Ka-

\footnotetext{
${ }^{12}$ Arithmetisches Mittel der Renditen für die verschiedenen Anlagestartzeitpunkte im Zeitraum zwischen 1970 und 2010.

${ }^{13}$ Mit Berücksichtigung der Finanzmarktkrise und DAX-Endständen 2008 von 4800, 2009 von 5600 und 2010 von 6057.
} 
pitallebensversicherung. In diesem Fall kommt zu dem im vorangegangenen Abschnitt beschriebenen Anlagehorizonteffekt noch der Durchschnittskosteneffekt (Cost-Average-Effekt) hinzu. Der Anleger kann sich hier den Umstand zu Nutze machen, dass für einen gleich bleibenden Betrag bei fallenden Kursen mehr Anteile und bei steigenden Kursen weniger Anteile gekauft werden können, so dass für den Betrachtungszeitraum der durchschnittliche Kaufpreis der Anteile unterhalb des durchschnittlichen Kurses liegt.

Dieses Argument wird oft herangezogen, um die Renditevorteile einer Cost-AverageAnlagestrategie zu begründen. Allerdings kann man zeigen, dass solche systematische Vorteile nur bei einer rückblickenden Betrachtung durch „ex-post-Normierung“ konstruiert werden können, für eine ex-ante festzulegende Anlagestrategie aber keine praktische Relevanz besitzen. ${ }^{14}$ Abgesehen von der Tatsache, dass man bei den hier gewählten Annahmen eher von einem „Durchschnittsrenditeeffekt“ sprechen müsste, weil annahmegemäß die (gleich hohen) Beiträge bzw. das angesparte Kapital im jeweiligen Jahr nach Maßgabe der DAXEntwicklung verzinst werden, ist für die Argumentation hier aber ein anderer Punkt entscheidend: Mit den über eine lange Zeit hinweg gleichmäßigen Einzahlungen in Form eines Sparplans oder einer regelmäßigen Prämie kann eine zusätzliche Risikoreduktion über eine weitere „Durchschnittsbildung“ erreicht werden, da die Rendite nicht nur über die gesamte Laufzeit gemittelt wird wie bei der Einmalanlage. Vielmehr wird vereinfacht gesprochen für jede Einzahlung eine Durchschnittsrendite vom jeweiligen Einzahlungszeitpunkt bis zum Anlageendzeitpunkt ermittelt und aus diesen Durchschnittsrenditen je Einzahlung dann die durchschnittliche Rendite für den Gesamtanlagebetrag abgeleitet. Damit wird das Problem des richtigen Einstiegszeitpunktes (Timing) auf einen langen Zeitraum ausgedehnt und somit die Renditeschwankungen weiter reduziert.

Dies zeigt Abbildung 3, der ein einfacher Sparplan mit einmaliger Auszahlung am Ende der Anlageperiode zugrunde liegt: Die entsprechende Renditekurve in Abhängigkeit vom Anlagebeginn weist im Vergleich zur Einmalanlage geringere Schwankungen auf; das Risiko wird reduziert. Die Standardabweichung für einen Anlagebeginn in einem Jahr im Zeitraum 1970 bis 2010 sinkt für einen 30-jährigen Anlagehorizont von 1,18 bei der Einmalanlage auf 1,07 bei regelmäßigen Einzahlungen über die gesamte Anlageperiode.

\footnotetext{
${ }^{14}$ Vgl. dazu ausführlich Langer und Nauhauser (2003).
} 
Natürlich bleibt auch hier eine Sensibilität der Rendite gegenüber einem starken Renditeeinbruch am Ende der Laufzeit bestehen, allerdings in abgemilderter Form. So kommt es genauso wie bei der Einmalanlage beim Anlagebeginn 1971 und 1972 zu einem Renditeeinbruch, weil auch bei einem Sparplan ein Kapitalwertverlust am Ende der Laufzeit nicht mehr geglättet werden kann, indem zu einem späteren Zeitpunkt Anlagen getätigt werden, die diesen Renditeeinbruch nicht mitgemacht haben. Insbesondere schlagen die Wertverluste 2001 und 2002 bei einem Sparplan, der in diesen Jahren ausläuft, voll durch. Die Rückgänge im Anlagezeitraum davor konnten aber im Vergleich zur Einmalanlage besser aufgefangen werden, so dass in diesen Fällen der Renditeeinbruch etwas geringer ausfällt als bei der Einmalanlage (Abbildung 3).

Werden nicht nur die Einzahlungen, sondern auch die Auszahlungen über eine längere Zeit verteilt (Auszahlungsplan), wird auch das Problem des richtigen Ausstiegszeitpunkts auf einen Zeitraum ausgedehnt und somit eine weitere Risikoreduktion erreicht. Ein Auszahlungsplan ist typisch für Rentenversicherungen und manche Sparpläne. Abbildung 3, der ein 20 Jahre andauernder gleichmäßiger Auszahlungsplan zugrunde liegt, ${ }^{15}$ zeigt, dass die Standardabweichung sich bei einem kombinierten Sparplan und Auszahlungsplan nochmals reduziert. Im Vergleich zum 30-jährigen Sparplan sinkt die Standardabweichung des Sparplans plus Auszahlungsplans von 1,07 auf 0,57 (Abbildung 3 und Tabelle 1).

Damit bleibt festzuhalten, dass die kapitalgedeckte Altervorsorge ihre relativ geringe Anfälligkeit gegenüber Verzinsungsschwankungen vor allem aus ihrem langfristigen Anlagehorizont schöpft. Dies gilt selbst für Anlagen mit einer einmaligen Ein- und Auszahlung. Eine zusätzliche Risikoreduktion aufgrund einer Art Durchschnittskosten- oder Durchschnittsrenditeneffekt kann dadurch erreicht werden, dass auch die Einzahlungen bzw. Auszahlungen gleichmäßig über eine lange Zeit erfolgen. Die dadurch erzeugte Risikoreduktion ist jedoch geringerer als der Effekt eines langfristigen Anlagehorizonts.

\footnotetext{
${ }^{15}$ Unterstellt wurde eine Auszahlung des jeweiligen angesammelten Kapitals in gleich hohen Annuitäten über 20 Jahre.
} 


\section{Abbildung 3: Rendite der Einmalanlage über 30 Jahre und des Sparplans im Vergleich (der „Durchschnittseffekt“)}

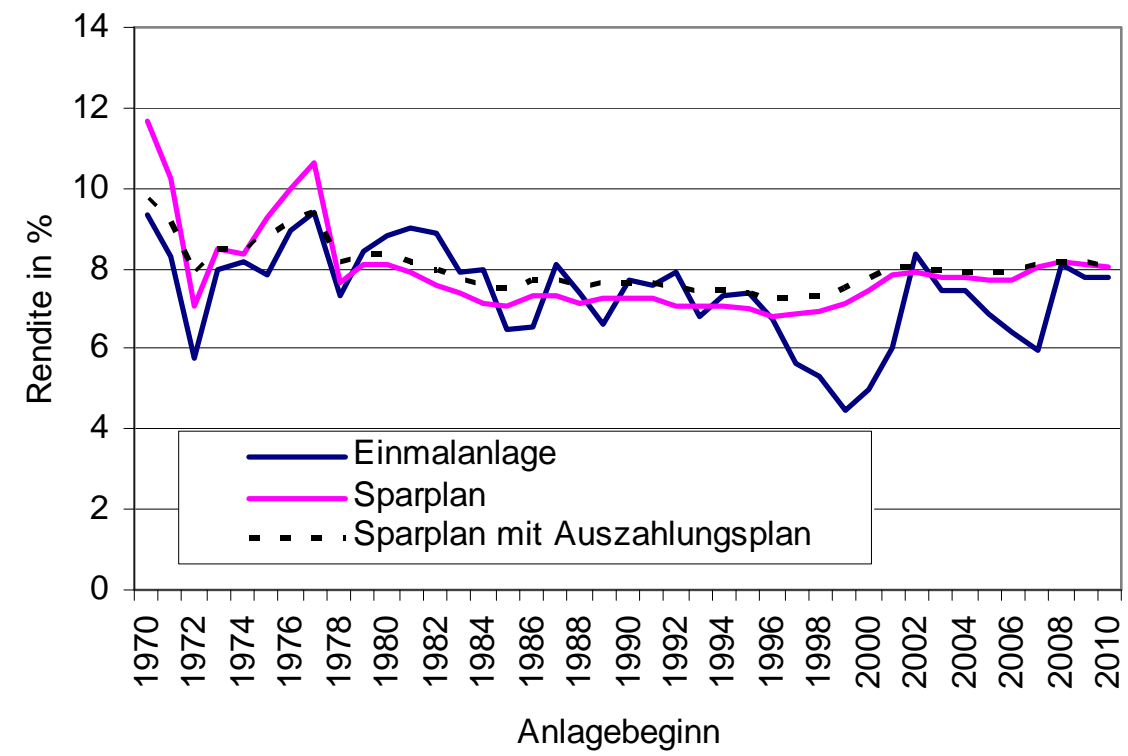

Quelle: Eigene Berechnungen.

\subsection{Auswirkungen der Finanzkrise auf die Rendite der kapitalgedeckten Altersvorsorge}

In diesem Abschnitt werden diese grundsätzlichen Überlegungen auf die konkreten Wertverluste durch die Finanzkrise 2008/2009 angewendet. Dazu wird angenommen, dass das Altersvorsorgekapital mit regelmäßigen Beiträgen (zum Beispiel in Form eines Sparplans) angelegt und mit der Entwicklung des DAX verzinst wird. Zugrunde gelegt werden die DAXJahresendstände seit $1970 .{ }^{16}$ Die Anlage erstreckt sich über einen Zeitraum von 30 Jahren. Von Kosten wird zur Vereinfachung abgesehen.

Für die abzuleitenden Befunde ist die Wahl des Vergleichsszenarios nicht unkritisch. So kann die relevante Alternative eine Situation ohne Finanzkrise sein. Möglich wäre allerdings auch, dass die Finanzkrise nichts anderes ist als ein „normaler“ zyklischer Ausschlag“ nach unten, auf den wieder eine starke Gegenbewegung nach oben folgt, ähnlich wie nach dem Platzen der Internetblase 2001 der Boom bis 2007 folgte. Damit zusammenhängend ist für die Auswirkungen der Finanzkrise die Frage von großer Bedeutung, inwieweit die Finanzkrise langfristige strukturelle Auswirkungen auf die Kapitalverzinsung hat oder ob es sich nur um ein vorübergehendes Ereignis ohne langfristige Nachwirkungen handelt. Langfristige und gravierende Auswirkungen der derzeitigen Finanzkrise auf die kapitalgedeckte Altersvorsorge kann es geben, wenn es zu einer strukturellen Reduktion der Kapitalverzinsung kommt, namentlich

\footnotetext{
${ }^{16}$ Vor 1987 zurückgerechnete Werte.
} 
dass die Kapitalzinsen nach dem Schock der Finanzmarktkrise nicht mehr auf ihren alten Pfad zurückkehren, sondern aufgrund von Regulierungen, Risikoaversion usw. auf einen niedrigeren Pfad einschwenken. Die derzeitigen Regulierungsansprüche, eine größere Risikoaversion z.B. von Pensionsfondsverwaltern und die derzeit feststellbaren protektionistischen Tendenzen sowie die Anzeichen, dass die Finanzkrise das Potentialwachstum der Volkswirtschaft negativ beeinflusst hat, könnten dafür sprechen, dass sich langfristig das Umfeld für die Kapitalerträge verändert hat. Die fortschreitende Globalisierung mit hohen Renditeerwartungen und auch die historischen Beispiele der Renditeentwicklung nach einer Krise sprechen allerdings dagegen.

Um all diese möglichen Effekte der Finanzkrise auf die Altersvorsorge grundsätzlich zu veranschaulichen, werden im Folgenden für die DAX-Entwicklung nach 2007 vier Szenarien unterstellt:

- Szenario 1: Ohne Finanzkrise (Referenzszenario): Der DAX stagniert 2008 auf dem Jahresendstand 2007. Ab 2009 nimmt er mit der historischen durchschnittlichen Wachstumsrate zwischen 1970 und 2007 von rund 8,15 \% zu. Um die Auswirkungen der demographischen Entwicklung auf die Kapitalrendite abzubilden wird im Zeitverlauf ein langfristiger gradueller Rückgang der Wachstumsrate des DAX unterstellt: Von 8,15\% bis auf 7,15 \% im Jahr 2050.

- Szenario 2: Mit Finanzkrise und Rückkehr auf den alten Pfad der Kapitalverzinsung: Der DAX sinkt im Jahr 2008 auf 4800 Punkte (-40 \%), steigt im Jahr 2009 auf 5600 Punkte und entwickelt sich danach mit den im Szenario 1 unterstellten Wachstumsraten. ${ }^{17}$

- Szenario 3: Mit Finanzkrise und Einschwenken auf einen neuen Pfad der Kapitalverzinsung: Der DAX sinkt im Jahr 2008 auf 4800 Punkte, steigt im Jahr 2009 auf 5600 Punkte und entwickelt sich danach mit den im Szenario 1 unterstellten Wachstumsraten abzüglich einem Prozentpunkt. Damit soll den möglicherweise durch die Finanzmarktkrise ausgelösten strukturellen, renditedämpfenden Faktoren (Risikoaversion, Regulierungen, Protektionismus) Rechnung getragen werden.

- Szenario 4: Mit Finanzkrise und anschließendem Aktienboom: Der DAX sinkt im Jahr 2008 auf 4800 Punkte, steigt im Jahr 2009 auf 5600 Punkte, 2010 auf 8000 Punkte und bis Ende 2011 auf den DAX-Stand ohne Krise. Danach entwickelt er sich mit den im Szenario 1 unterstellten Wachstumsraten.

Die Auswirkungen der Finanzmarktkrise zeigen sich als erstes und am stärksten für den Anlagebeginn Ende 1978, da der 30-jährige Sparplan Ende des Jahres 2008 abläuft. Die Rendite für diesen Anlagezeitpunkt ist für alle Krisenszenarien (Szenarien 2 bis 4) rund 2,6 Prozentpunkte geringer als ohne Finanzmarktkrise (7,7\% im Vergleich zu 10,3\%). Der Verlust ist für

\footnotetext{
${ }^{17}$ Dies bedeutet mit Blick auf den DAX ausgedrückt in Punkten, dass der DAX dauerhaft niedrigere Werte aufweist als im Szenario 1.
} 
den Anlagezeitpunkt 1978 deshalb am stärksten, da für diese Anlage die Finanzkrise voll durchschlägt, sie aber nicht von der unterstellten Gegenbewegung im Jahr 2009 (DAX steigt von 4800 auf 5600 Punkte) profitieren kann.

Im Szenario 2 liegen für die folgenden 30 Anlagestartzeitpunkte die Renditen niedriger als ohne Krise, wobei sich der Abstand zum Szenario 1 allmählich schließt (Abbildung 4). Nach 2009 sind die Renditen wieder identisch. Das allmähliche Schließen der Renditelücke ist auf die Eigenschaft des Sparplans zurückzuführen, da zunehmend Einlagen für die Bildung der Durchschnittsrendite relevant sind, die nach der Finanzmarktkrise getätigt wurden. Bei einer Einmalanlage würde es dagegen zum Anlagezeitpunkt 2009 zu einem sprunghaften Renditeanstieg auf das Niveau ohne Krise kommen. Der renditedämpfende Effekt durch die Finanzmarktkrise kann verringert werden, wenn zusätzlich zum Sparplan auch ein Auszahlungsplan vereinbart wird. Hier greift der oben angesprochene Durchschnittseffekt, der die Auswirkungen der Finanzkrise weiter glättet (Abbildung 5).

Die Rendite im Szenario 3 weicht von Szenario 2 ab, sobald sich die strukturelle Verschiebung der Kapitalmarktzinskurve nach unten bemerkbar macht. Die Renditedifferenz zum Szenario ohne Finanzkrise fällt höher aus und die Renditelücke schließt sich nicht, da im Szenario 3 annahmegemäß von einem langfristigen, strukturellen Effekt ausgegangen wird, der dauerhaft zu einer Renditeeinbuße von 1 Prozentpunkt führt. Im Szenario 2 sind dagegen die Auswirkungen der Finanzmarktkrise ab dem Anlagezeitpunkt 2008 ausgestanden. Dies bedeutet allerdings gleichzeitig, dass bis zum Jahr 2038, dem Jahr in dem die Anlage aus 2008 ausläuft, die Finanzkrise nachwirkt.

Im Szenario 4 kommt es nur für drei Anlagestartjahre (1978 bis 1980) zu Renditeeinbußen. Danach hat der auf die Krise folgende Boom die negativen Effekte der Finanzkrise wieder kompensiert, teilweise sogar überkompensiert. Anlagen um den Zeitpunkt der Finanzkrise rentieren sich nach 30 Jahren aufgrund des Boomeffekts sogar besser als im Szenario ohne Krise. 

Abbildung 4: Auswirkungen der Finanzkrise auf die Rendite eines Sparplans mit 30-
jähriger Laufzeit für unterschiedliche Szenarien

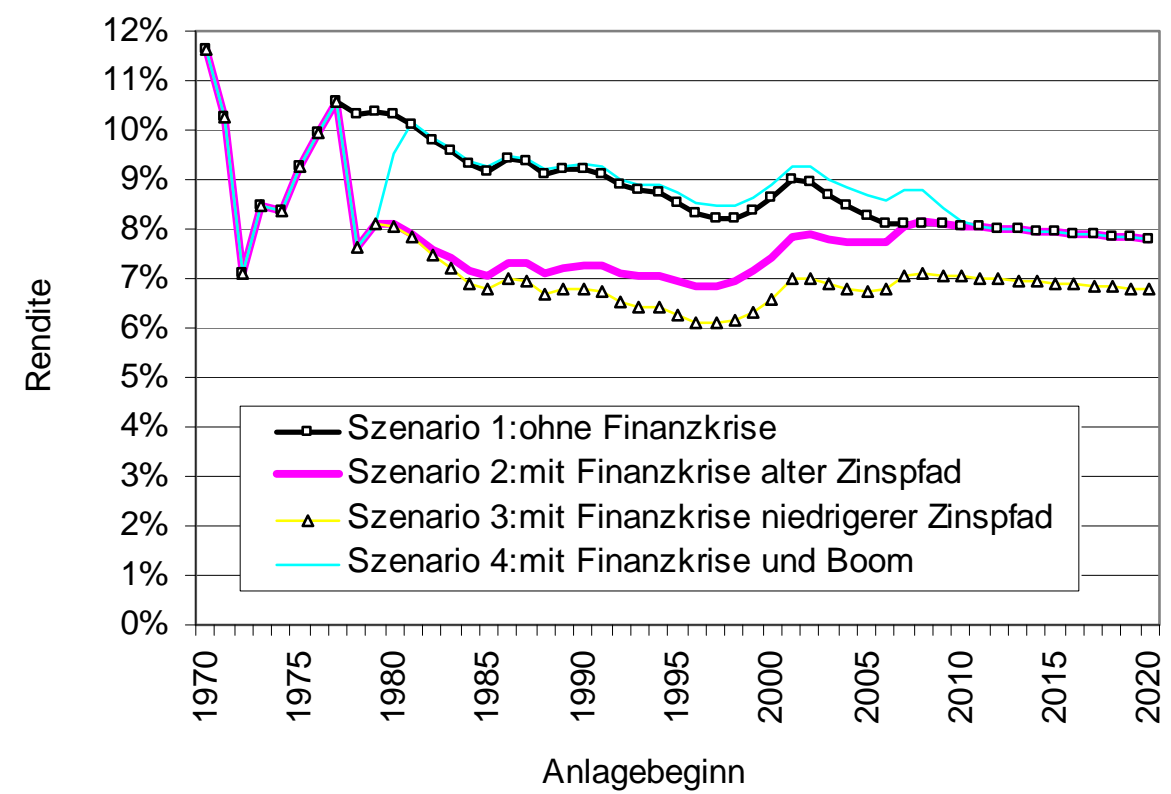

Quelle: Eigene Berechnungen.

Abbildung 5: Auswirkungen der Finanzmarktkrise auf die Rendite eines Sparplans mit 30-jähriger Laufzeit und auf die Rendite eines Sparplans mit Auszahlungsplan

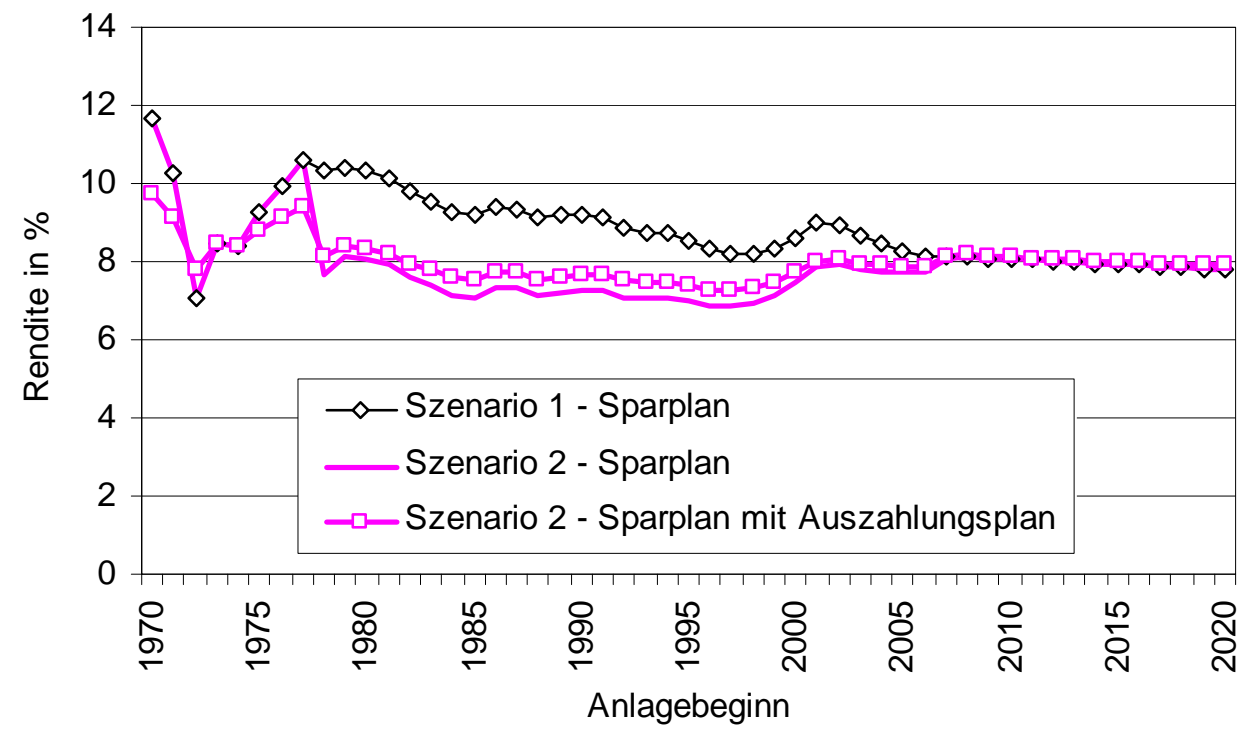

Quelle: Eigene Berechnungen.

Fazit: Die Finanzmarktkrise, charakterisiert durch einen Preisverfall der Kapitalanlagen, schlägt sich in einem Renditeverlust der kapitalgedeckten Altersvorsorge nieder, auch dann, wenn nach der Krise der alte Pfad der Kapitalverzinsung wieder erreicht wird. Zwar ist der Renditeverlust nur vorübergehend, er weist aber eine hohe Persistenz auf, da er bei einer gan- 
zen „Altersvorsorgegeneration“ auftritt. Diese Aussage gilt nicht, wenn nach der Krise ein „Aufholprozess“ stattfindet, wenn also auf die Krise ein Boom folgt, der dafür sorgt, dass die Vermögenswerte wieder das Niveau erreichen, das sie ohne Krise gehabt hätten.

Mit den vier Szenarien ist eine große Bandbreite der Renditeentwicklung abgebildet. Was die Renditeentwicklung in der privaten Altersvorsorge ist, ist die Lohnentwicklung in der Gesetzlichen Rentenversicherung, da sich die Renten an den Löhnen orientieren. In der „SchwesterStudie“ zur Gesetzlichen Rentenversicherung sind wir davon ausgegangen, dass die Lohnwachstumsraten nach einem Einbruch durch die Finanzkrise wieder auf ihr altes Niveau zurückkehren. Dies entspricht hier dem Szenario 2. Ein Überschießen der Löhne nach der Krise, was dem Szenario 4 entsprechen würde, ist eher unwahrscheinlich. Auch eine strukturelle Reduktion der Löhne (analog zu Szenario 3 bei den Renditen) wurde nicht angenommen. Hinsichtlich der Lohnentwicklung wurde also ein mittleres Szenario unterstellt. Um eine Vergleichbarkeit mit der Schwester-Studie zu gewährleisten, wird im folgenden Abschnitt 4 für die Renditeentwicklung qualitativ das Szenario 2 unterstellt. Die Renditen kehren also nach einem Einbruch wieder auf das Niveau zurück, das sie annahmegemäß ohne Krise gehabt hätten. Dies kann genauso wie die analoge Annahme für die Lohnentwicklung als mittleres Szenario angesehen werden.

\section{Auswirkungen der Finanzkrise auf das Vermögen deutscher Haushalte}

Nach den grundsätzlichen Überlegungen werden nun die konkreten Auswirkungen der Finanzkrise auf das Vorsorgevermögen deutscher Haushalte unter Verwendung des SAVEDatensatzes betrachtet. Die seit 2001 erhobene und ab 2005 auf jährlicher Basis durchgeführte SAVE Befragung ist eine repräsentative Panelumfrage mit dem Ziel, das Spar- und Portfolioverhalten deutscher Privathaushalte genauer zu analysieren. Neben soziodemographischen Merkmalen findet in jedem Befragungsjahr eine detaillierte Erfassung der Vermögenswerte eines Haushaltes statt. ${ }^{18}$ Für diese Untersuchung werden der Vermögensbestand der SAVEHaushalte und die Vermögenszusammensetzung Ende 2007 aus der SAVE Befragung 2008 zugrunde gelegt. Die Stichprobe von 2.608 befragten Haushalten im Jahr 2008 wird auf die wiederbefragten Haushalte in 2009 beschränkt. Dies reduziert die Stichprobengröße auf 2.222 befragte Haushalte und stellt sicher, dass die Vergleichbarkeit zu den in 2009 direkt erfassten

\footnotetext{
${ }^{18}$ Vgl. Börsch-Supan, Coppola, Essig, Eymann, und Schunk (2009).
} 
Vermögensverlusten gewahrt bleibt. ${ }^{19}$ Der SAVE Datensatz wurde ferner, um Verzerrungen durch Item-Nonresponse zu vermeiden, durch ein multiples Imputationsverfahren imputiert. ${ }^{20}$ Alle Ergebnisse basieren auf den fünf multiplen imputierten und nach dem Mikrozensus 2008 gewichteten Daten.

Der Vermögensbestand der SAVE-Haushalte und die Vermögenszusammensetzung Ende 2007 werden in zwei Szenarien fortgeschrieben. ${ }^{21}$ Im Referenzszenario werden die Vermögenswerte anhand der erwarteten Renditeentwicklung ohne Finanzkrise auf das Jahr 2008 hochgerechnet. Im Krisenszenario werden die Vermögenswerte des Jahres 2007 mit der tatsächlich realisierten Wertentwicklung des Jahres 2008 fortgeschrieben. Die Differenz zwischen den Vermögensbeständen mit und ohne Krise im Jahr 2008 gibt einen Eindruck über den Vermögensverlust durch die Finanzkrise. Die Ergebnisse werden differenziert nach Alter, Einkommensklassen und Vermögensklassen dargestellt. Zunächst wird eine Kurzfristbetrachtung vorgenommen, also die Wirkungen der Krise auf den Vermögensbestand für den Zeitraum zwischen Ende 2007 und Ende 2008. Danach werden die langfristigen Effekte dargestellt, indem der Vermögensbestand über 2008 hinaus fortgeschrieben wird.

\subsection{Vermögenspositionen deutscher Haushalte vor der Finanzkrise}

\subsubsection{Gesamtes Bruttovermögen}

Im Folgenden wird zwischen Geldvermögen und Altersvorsorgevermögen unterschieden. Zum Geldvermögen zählen Sparanlagen im weiten Sinne, Bausparverträge, Aktien und Fonds sowie festverzinsliche Wertpapiere und sonstige Wertpapiere. Zum Altersvorsorgevermögen gehören Kapitallebensversicherungen, betriebliche Altersvorsorgeverträge, Riester- oder Rürup-Renten sowie weitere private Rentenversicherungsverträge. Da diese Einteilung nicht völlig trennscharf ist und bestimmte Geldvermögensarten auch für die Altersvorsorge dienen können, genauso wie umgekehrt Kapitallebensversicherungen bei Fälligkeit auch zum Konsum in jungen Jahren eingesetzt werden können, werden alle Vermögenskategorien betrachtet. Geldvermögen und Altersvorsorgevermögen zusammen ergeben das Finanzvermögen. Das Bruttovermögen setzt sich aus Finanzvermögen und Immobilienvermögen zusammen.

Das Geldvermögen der SAVE-Haushalte belief sich Ende des Jahres 2007 auf durchschnittlich knapp 24.800 Euro je Haushalt, das Altersvorsorgevermögen auf 11.400 Euro und das

\footnotetext{
${ }^{19}$ Vgl. Börsch-Supan, Bucher-Koenen, Gasche und Ziegelmeyer (2009).

${ }^{20}$ Vgl. Schunk (2008) und Ziegelmeyer (2009).

${ }^{21}$ Ähnlich gehen Benz et al. (2009) auf Grundlage von EVS-Daten vor.
} 
Immobilienvermögen auf 126.400 Euro je Haushalt. Das Immobilienvermögen macht also den weitaus größten Teil des gesamten Bruttovermögens aus. Nach Alter differenziert zeigt sich, dass das Vermögen in jungen Jahren gering ist und dann zunimmt. Erwartungsgemäß erreicht das Altersvorsorgevermögen bei der Altersgruppe der 51- bis 60-Jährigen sein Maximum. Das Immobilienvermögen und das Geldvermögen sind dagegen in der Altersklasse der 60- bis 71-Jährigen am größten (Abbildung 6). Differenziert nach Einkommen ergibt sich mit zunehmenden Einkommen ein steiler Anstieg der Vermögensgrößen bis auf ein Geldvermögen von durchschnittlich über 50.000 Euro, ein Altersvorsorgevermögen von 28.000 Euro und ein Immobilienvermögen von über 250.000 Euro im 5. Quintil. Die Zusammensetzung des Geldvermögens und des Altersvorsorgevermögens wird im Folgenden näher analysiert.

\section{Abbildung 6: Bruttovermögen deutscher Haushalte nach Altersklassen Ende 2007}

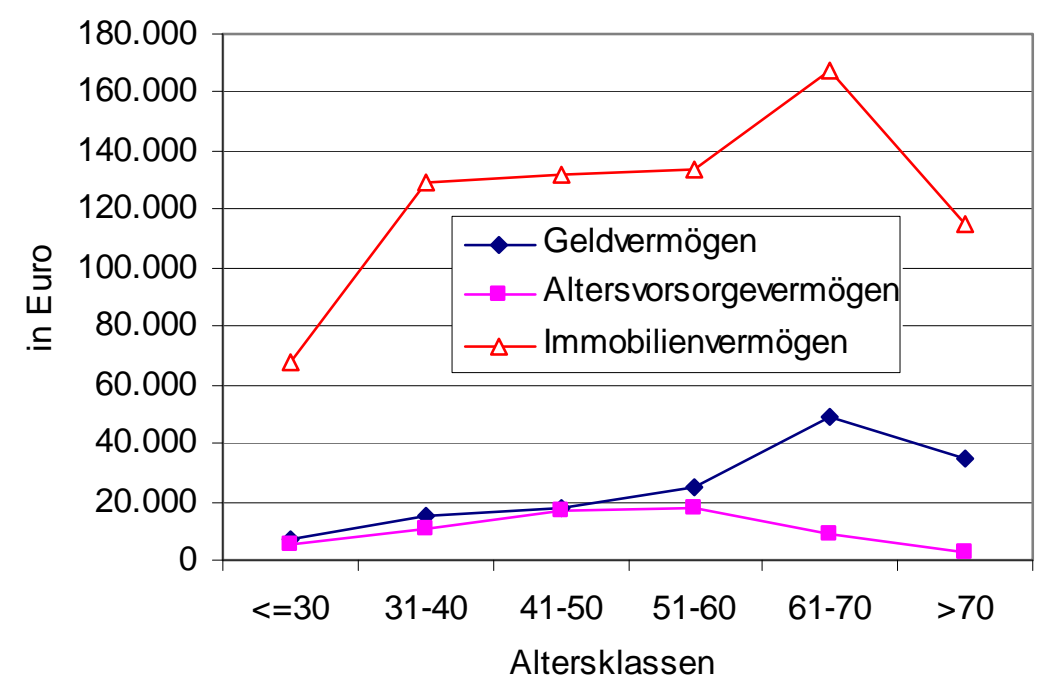

Quelle: SAVE, eigene Berechnung.

\subsubsection{Geldvermögen}

Differenziert man das Geldvermögen nach Altersgruppen, zeigt sich das typische mit dem Alter ansteigende Profil. Erst im Rentenalter, wenn die Ersparnisse zur Erhöhung des Alterseinkommens aufgelöst werden, sinkt der Vermögensbestand wieder (Abbildung 7). Sparanlagen machen in allen Altersklassen den größten Teil des Geldvermögens aus. Während sie bei den Jungen und Alten einen Anteil von nahezu 50\% am Geldvermögen haben, sind in den mittleren Altersklassen riskantere Anlagen wie Aktien und Fonds von etwas größerer Bedeutung (Abbildung 8). 
Abbildung 7: Geldvermögen deutscher Haushalte nach Altersklassen Ende 2007

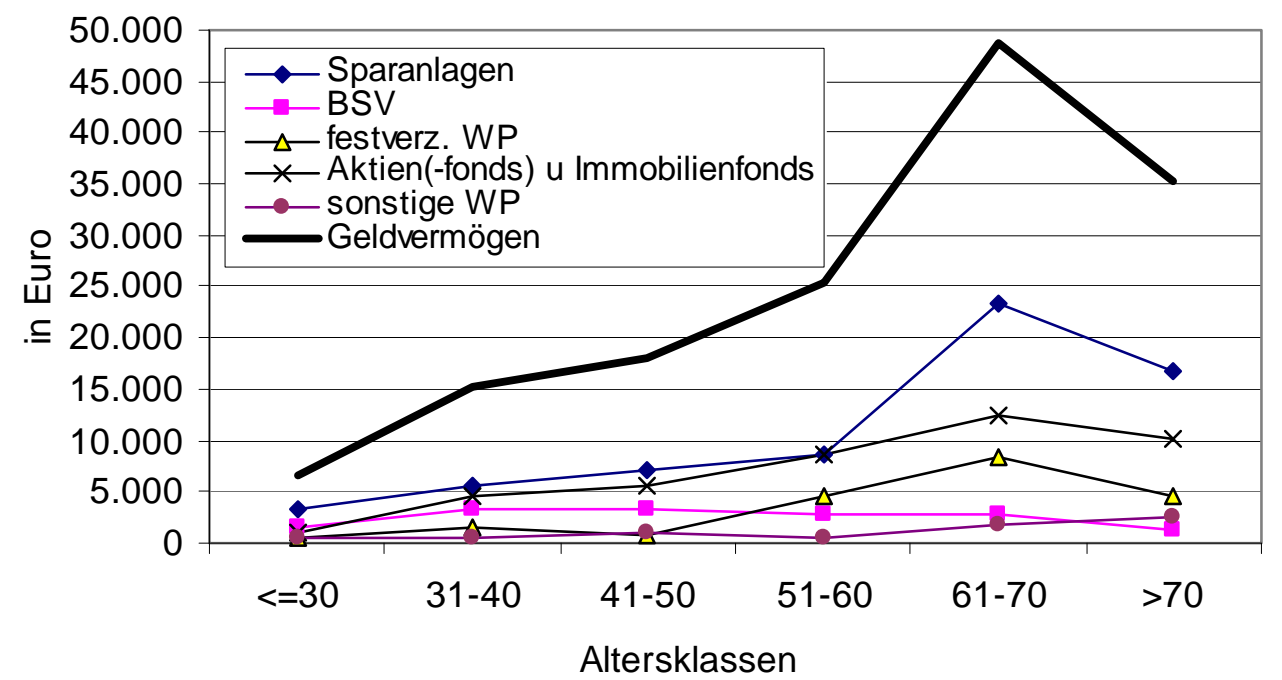

BSV: Bausparverträge, WP: Wertpapiere.

Quelle: SAVE, eigene Berechnung.

Abbildung 8: Geldvermögensstruktur nach Altersklassen Ende 2007

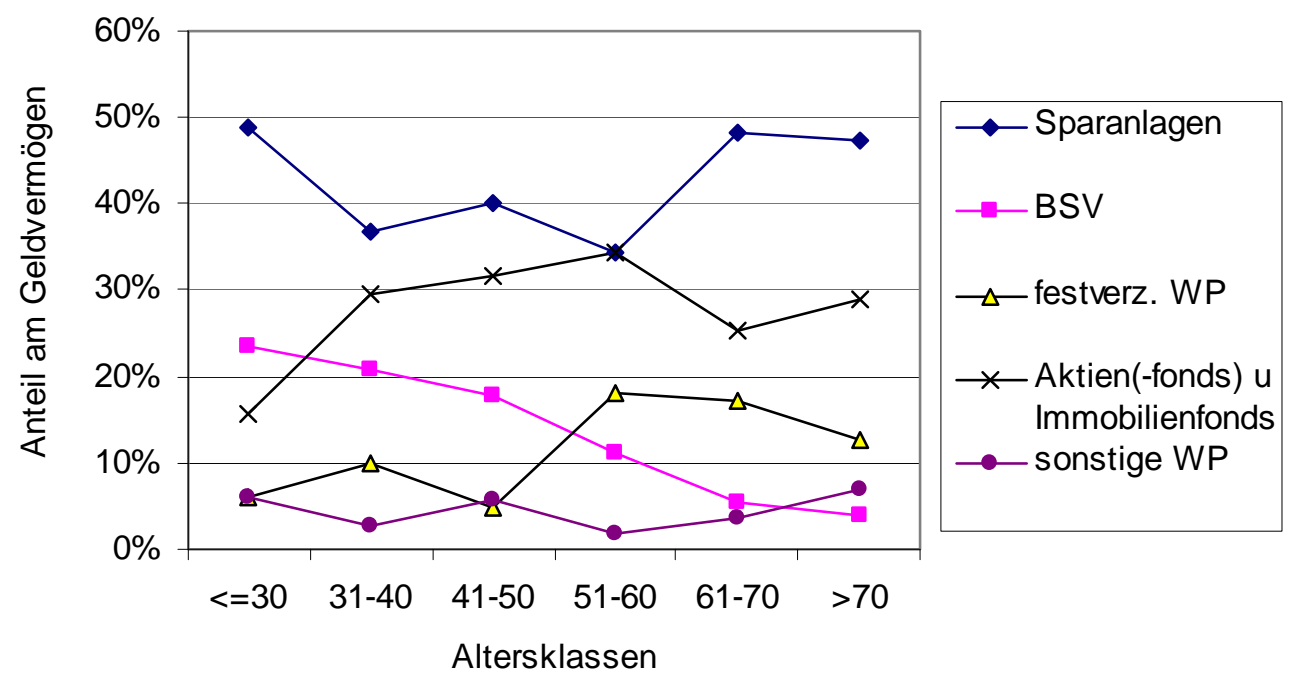

BSV: Bausparverträge, WP: Wertpapiere.

Quelle: SAVE, eigene Berechnung.

Differenziert nach Einkommensklassen steigt der Bruttogeldvermögensbestand mit den Einkommen an und erreicht über 50.000 Euro im fünften Quintil (Abbildung 9). Die Bedeutung der Sparanlagen nimmt mit den Einkommen deutlich ab und die Bedeutung der riskanteren Aktien- und Fonds-Anlagen deutlich zu. Im fünften Einkommensquintil sind die Aktien und Fonds mit nahezu 40\% sogar die bedeutendste Anlageform (Abbildung 10). 
Abbildung 9: Geldvermögen deutscher Haushalte nach Einkommensquintilen Ende 2007

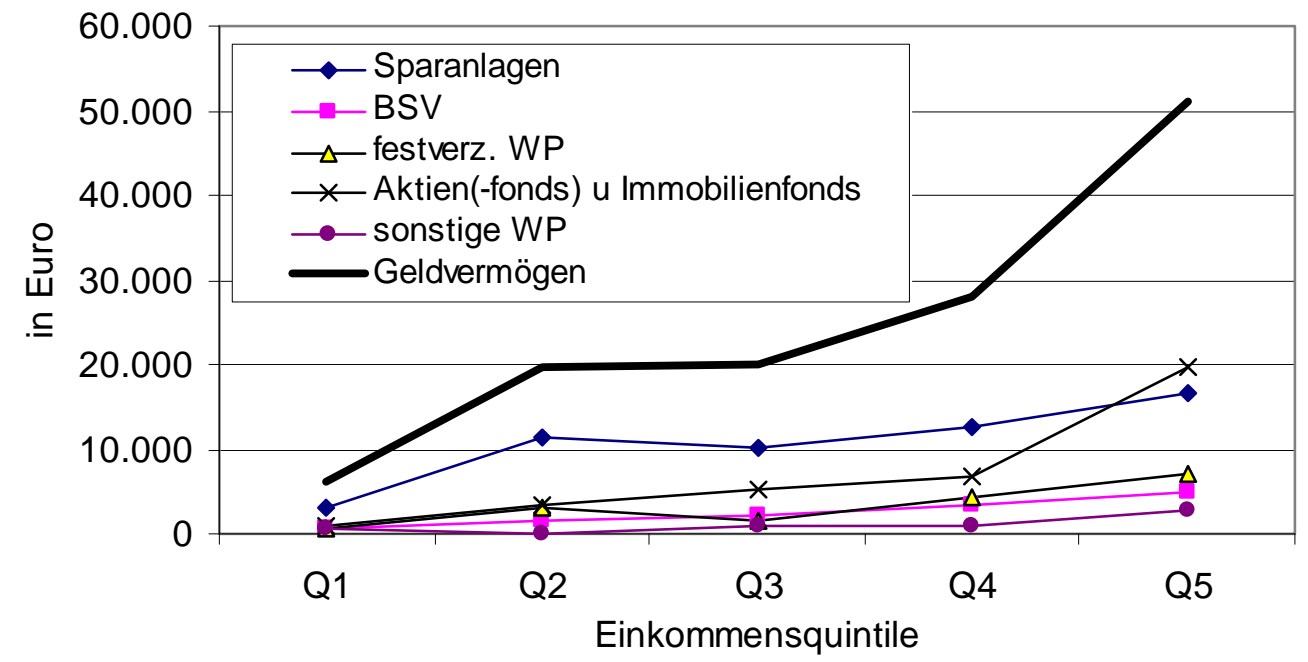

BSV: Bausparverträge, WP: Wertpapiere.

Quelle: SAVE, eigene Berechnung.

\section{Abbildung 10: Geldvermögensstruktur nach Einkommensquintilen Ende 2007}

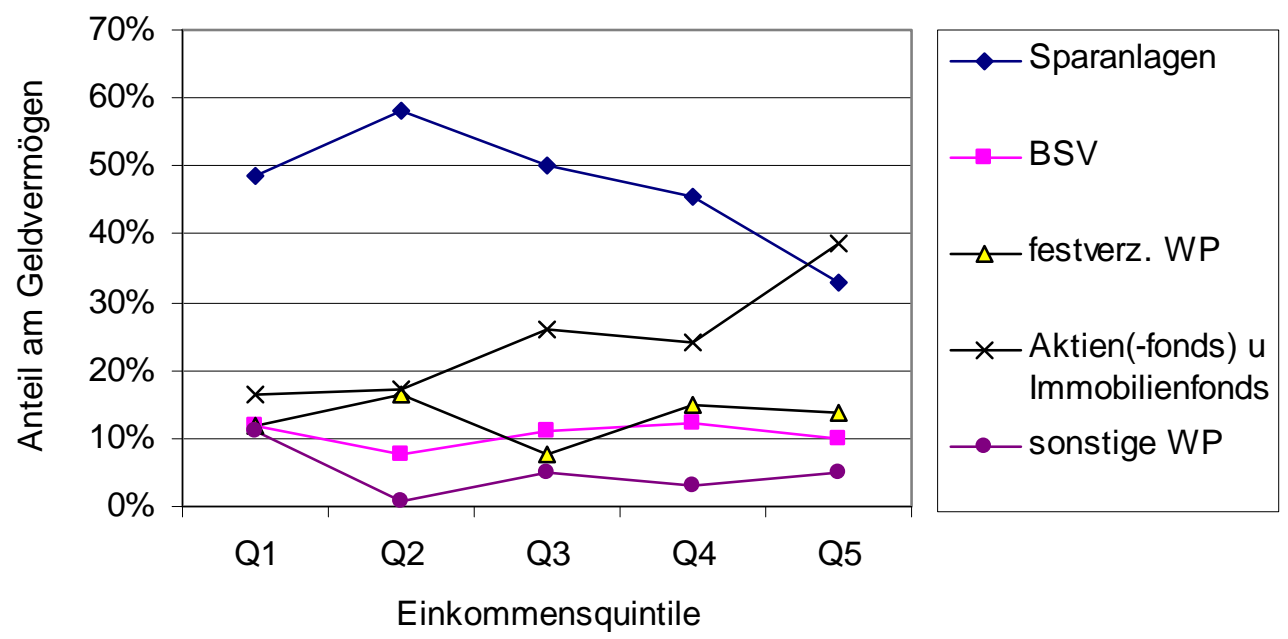

BSV: Bausparverträge, WP: Wertpapiere.

Quelle: SAVE, eigene Berechnung.

Nach Vermögensklassen differenziert - ausgedrückt in Quintilen des Nettogesamtvermögens - stellt man einen sehr steilen Anstieg des Vermögens vor allem im letzten Quintil fest (Abbildung 11), was auf eine hohe Disparität der Vermögensverteilung hindeutet. Auch hier ist der Aktienanteil im 5. Quintil am größten. Überraschenderweise ist aber auch unter den 20\% der Haushalte mit dem größten Vermögen die Sparanlage die wichtigste Anlageform (Abbildung 12). 
Abbildung 11: Geldvermögen deutscher Haushalte nach Vermögensquintilen Ende 2007

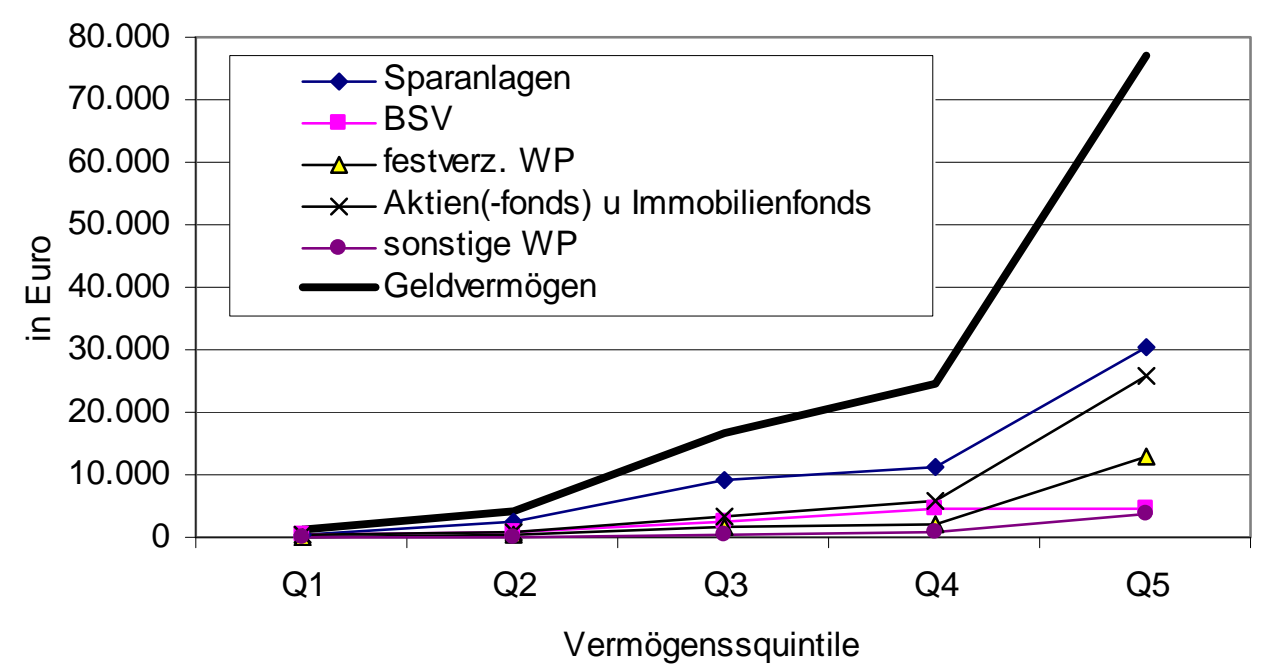

BSV: Bausparverträge, WP: Wertpapiere.

Quelle: SAVE, eigene Berechnung.

\section{Abbildung 12: Geldvermögensstruktur nach Vermögensquintilen Ende 2007}

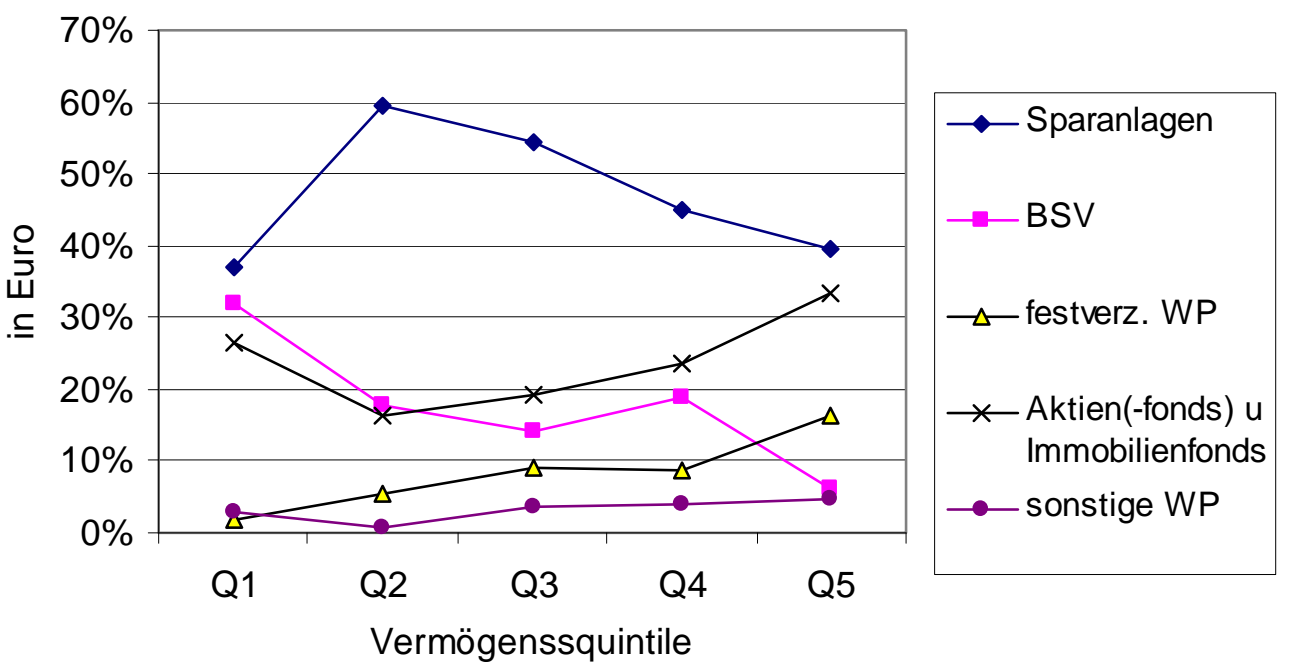

BSV: Bausparverträge, WP: Wertpapiere.

Quelle: SAVE, eigene Berechnung.

\subsubsection{Altersvorsorgevermögen}

Das Altersvorsorgevermögen zeigt differenziert nach Alter, Einkommen und Vermögen ein ähnliches Bild wie das Geldvermögen. Zunächst steigt es mit dem Alter der Versicherten an, bevor es bei den über 60-Jährigen erwartungsgemäß sinkt (Abbildung 13). Mit dem Einkommen und Vermögen ergibt sich ein stetiger Anstieg (Abbildungen 14 und 15). Im Vergleich zum Geldvermögen weist das Altersvorsorgevermögen allerdings durchweg ein geringeres Volumen auf. Selbst im höchsten Einkommensquintil und im höchsten Vermögensquintil wird ein durchschnittliches Altersvorsorgevermögen von 30.000 Euro nicht überschritten. Am 
bedeutendsten sind unabhängig von Alter, Einkommen und Vermögen die Kapitallebensversicherungen. Riester-Renten haben insgesamt noch ein geringes Volumen, da es die Altersvorsorge in Form der Riester-Rente erst seit 2002 gibt und mithin relativ wenig Zeit war, um Vermögen aufzubauen. In Zukunft dürfte die Bedeutung der Riester-Rente allerdings zunehmen.

\section{Abbildung 13: Altersvorsorgevermögen deutscher Haushalte nach Altersklassen Ende 2007}

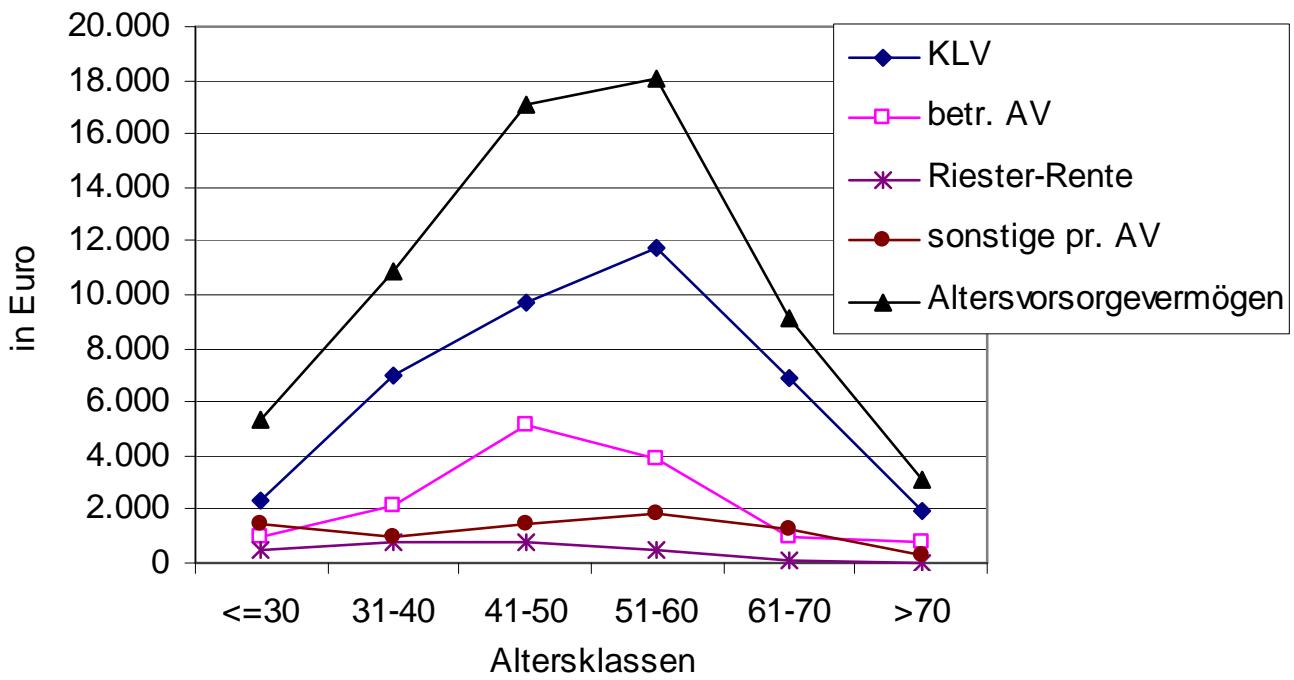

KLV: Kapitallebensversicherung, betr. AV: betriebliche Altersvorsorge. Quelle: SAVE, eigene Berechnung.

Abbildung 14: Altersvorsorgevermögen deutscher Haushalte nach Einkommensquintilen Ende 2007

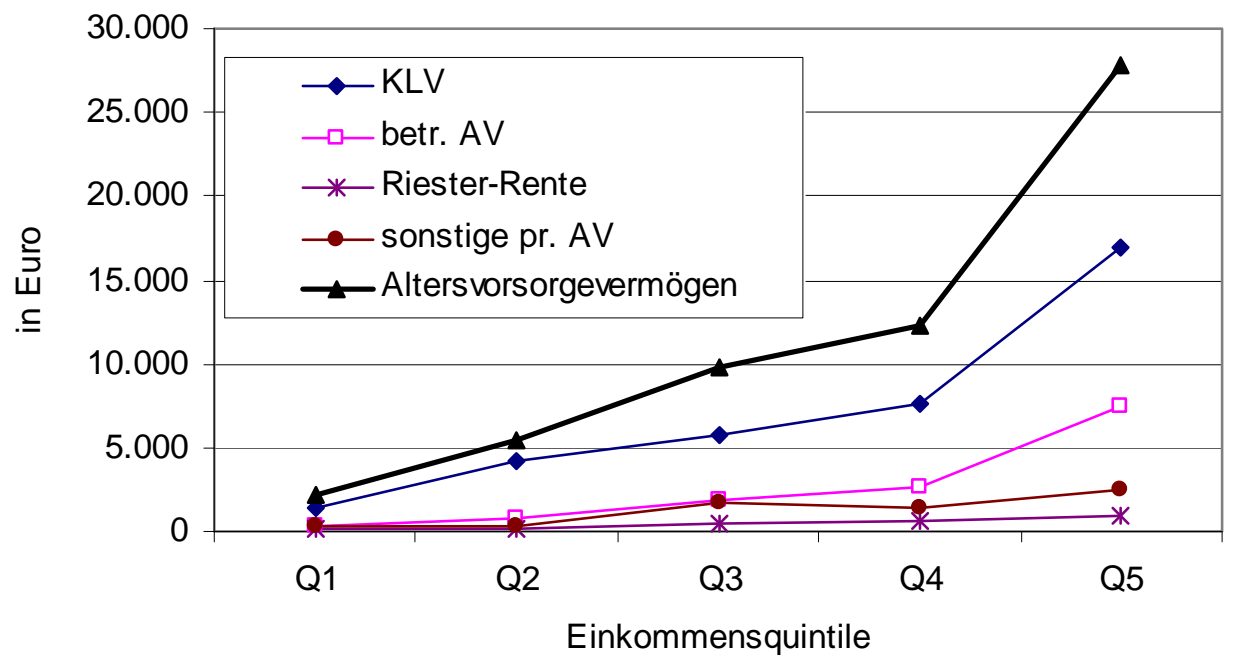

KLV: Kapitallebensversicherung, betr. AV: betriebliche Altersvorsorge.

Quelle: SAVE, eigene Berechnung. 
Abbildung 15: Altersvorsorgevermögen deutscher Haushalte nach Vermögensquintilen Ende 2007

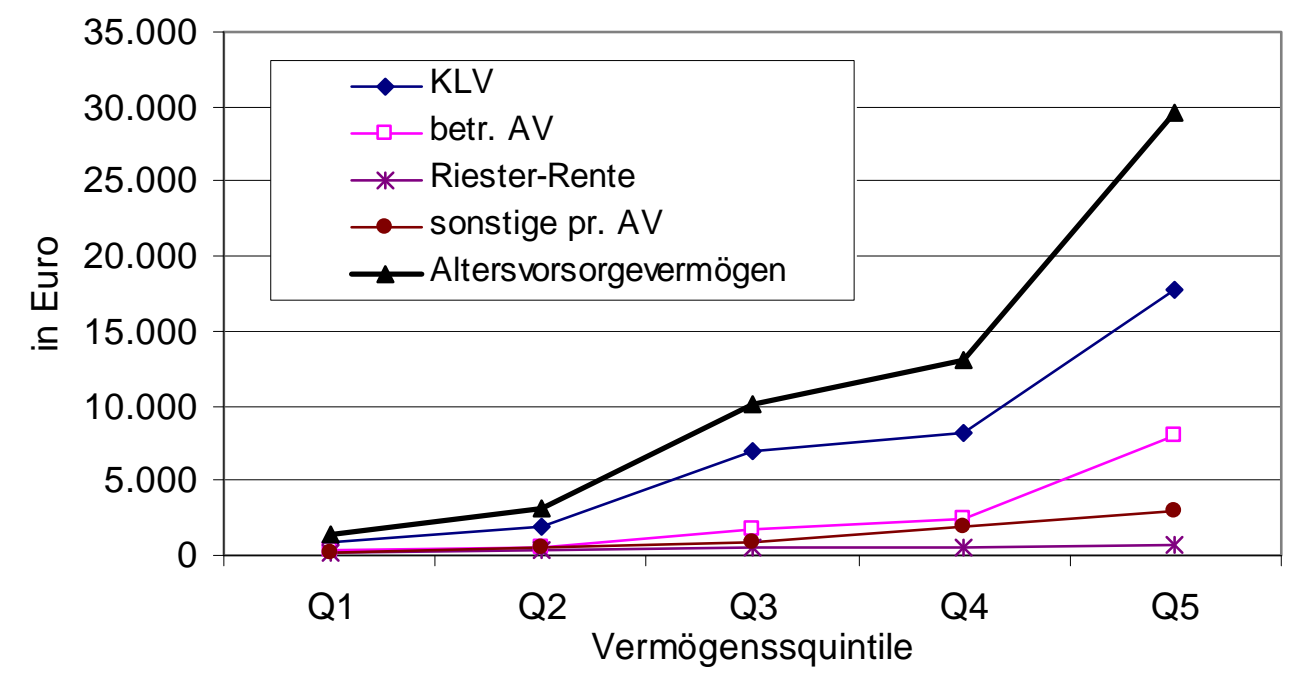

KLV: Kapitallebensversicherung, betr. AV: betriebliche Altersvorsorge. Quelle: SAVE, eigene Berechnung.

\subsection{Kurzfristige Auswirkungen der Finanzkrise im Jahr 2008}

\subsubsection{Annahmen für die Simulationsrechnungen}

In einem ersten Schritt werden nun die Auswirkungen der Finanzkrise im Jahr 2008 für das Geldvermögen und das Altersvorsorgevermögen abgeschätzt. Dazu wird die tatsächlich im Jahr 2008 beobachtete Renditeentwicklung der einzelnen Anlageformen, also mit Finanzkrise, mit einer Referenzsituation ohne Finanzkrise verglichen. Die Renditedifferenz bzw. die Vermögensdifferenz gibt die Auswirkungen der Finanzkrise wieder. Betrachtet werden wieder die SAVE-Haushalte differenziert nach Alter, Einkommen und Vermögen. Entscheidend für die Renditeentwicklung und die Höhe der Vermögensverluste ist dabei die Portfoliozusammensetzung des Jahres 2007. Dieses Portfolio wird bis Ende 2008 fortgeschrieben. In den Simulationsrechnungen wird also unterstellt, dass die Portfoliostruktur des Jahres 2007 im Jahr 2008 beibehalten worden ist.

Die Tatsache, dass die Portfoliostruktur des Jahres 2007 konstant gehalten wird, kann sowohl eine Unterschätzung als auch eine Überschätzung der Verluste implizieren. Eine Überschätzung läge dann vor, wenn die Haushalte rechtzeitig die Portfoliostruktur so angepasst hätten, dass die Vermögensverluste minimiert werden. Eine Unterschätzung gäbe es dann, wenn die Haushalte z.B. beim Kursminimum verkauft und bei steigenden Kursen nicht wieder eingestiegen wären. 
Für die Berechnungen werden die in Tabelle 2 aufgeführten Renditeannahmen verwendet. ${ }^{22}$ Für Aktienanlagen wird als Rendite die DAX-Entwicklung im Jahr 2008 von -40\% unterstellt. Die Renditen der Sparanlagen basieren auf Daten der Deutschen Bundesbank, welche die Effektivzinssätze der deutschen Banken für Einlagen privater Haushalte mit einer Laufzeit von bis zu zwei Jahren und einer Laufzeit von über zwei Jahren ausweisen. Die Bundesbank stellt außerdem Daten über die Bestandsvolumina der Einlagen privater Haushalte zur Verfügung. Diese wurden genutzt, um eine gewichtete Rendite für die Gesamtkategorie Sparanlagen zu errechnen. Hierbei wurden die durchschnittlichen Jahreszinssätze jeweils mit ihrem Anteil an den Gesamteinlagen gewichtet. Für die festverzinslichen Wertpapiere werden die „Umlaufrenditen festverzinslicher Wertpapiere inländischer Emittenten“ verwendet. Als Rendite sowohl für die Kapitallebensversicherungen als auch für die betrieblichen Lebensversicherungen wird die Nettoverzinsung der Lebensversicherungen herangezogen. Diese ist von 4,65\% im Jahr 2007 auf 3,55\% im Jahr 2008 gesunken. ${ }^{23}$ Die Verzinsung der Riester-Verträge wurde als gewichtetes arithmetisches Mittel der Renditen der Riester-Vertragsarten - Versicherungsvertrag, Fondsvertrag und Banksparvertrag - verwendet. Somit richten sich Versicherungsverträge nach der Wertentwicklung von Lebensversicherungen, Banksparverträge nach der Verzinsung von Sparanlagen und Investmentfondsverträge nach der Entwicklung der Aktien- und Immobilenfonds. Die Gewichtung erfolgte mit dem Anteil der jeweiligen Vertragsart an der Gesamtzahl der Riester-Verträge. ${ }^{24}$ Für die Renditen von Bausparverträgen werden einheitlich 2\% p.a. unterstellt. Für die Rendite der sonstigen betrieblichen Altersvorsorge wurde die von der OECD angegebene Wertentwicklung bei den Pensionsfonds von -8\% für 2008 verwendet. $^{25}$ Für 2007 wird eine mit den Kapitallebensversicherungen identische Verzinsung unterstellt. Mangels Daten wird angenommen, dass sich die sonstigen Wertpapiere mit der gleichen Rendite entwickeln wie die festverzinslichen Wertpapiere, und für sonstige Altersvorsorge wird die gleiche Verzinsung wie für die Kapitallebensversicherung unterstellt.

\footnotetext{
${ }^{22}$ Grundsätzlich lässt die grobe Einteilung in Vermögensklassen in SAVE nur eine schematische Darstellung der Renditeentwicklung zu. Die vielen Detailregelungen, die die Verzinsung von verschiedenen Anlageformen beeinflussen, konnten nicht berücksichtigt werden. Auch liegen uns für bestimmte Vermögenskategorien kaum zuverlässige Informationen über die Rendite bzw. Verlustentwicklung 2008 vor.

${ }^{23}$ Vgl. GDV (2009). Die Nettoverzinsung errechnet sich aus den Bruttoerträgen minus Aufwendungen (inklusive Abschreibungen) für die Kapitalanlagen im Verhältnis zum mittleren Kapitalanlagenbestand des Jahres. Bei der Nettoverzinsung der Kapitalanlagen werden sämtliche Erträge und Aufwendungen auf Kapitalanlagen berücksichtigt. In die Berechnung einbezogen sind damit auch Erträge und Verluste aus dem Abgang von Kapitalanlagen sowie Abschreibungen auf Wertpapiere und Investmentanteile.

${ }_{24}$ Die Nominalwertgarantie der Riester-Verträge wurde insofern außer Acht gelassen, dass sich als Durchschnittsrendite in einem Jahr auch negative Werte ergeben dürfen.

${ }^{25}$ Vgl. OECD (2009); S. 33, Figure 1.3.
} 
Insgesamt wurden bei der Renditeentwicklung für die Vermögenskategorien der SAVE-Daten eher pessimistische Annahmen getroffen, was insbesondere auf die Rendite der Kategorien Aktien(-fonds) und Immobilienfonds und auf die Riester-Verträge zutrifft. ${ }^{26}$ Insofern sind die berechneten Vermögensverluste ebenfalls eher als pessimistisch einzustufen.

Tabelle 2: Angenommene Renditen in den Simulationsrechnungen

\begin{tabular}{|c|c|c|c|c|c|c|}
\hline & Sparanlagen & BSV & $\begin{array}{c}\text { festverz. } \\
\text { WP } \\
\end{array}$ & $\begin{array}{l}\text { Aktien(-fonds) u } \\
\text { Immobilienfonds }\end{array}$ & $\begin{array}{c}\text { sonstige } \\
\text { WP }\end{array}$ & $\begin{array}{c}\text { Durchschnitt } \\
\text { SAVE-HH } \\
\end{array}$ \\
\hline $\begin{array}{l}2007 \\
2008 \text { ohne }\end{array}$ & $3,26 \%$ & $2,00 \%$ & $4,30 \%$ & $22,29 \%$ & $4,30 \%$ & $8,71 \%$ \\
\hline $\begin{array}{l}\text { Finanzkrise } \\
2008 \text { mit }\end{array}$ & $3,00 \%$ & $2,00 \%$ & $4,30 \%$ & $0,00 \%$ & $4,30 \%$ & $2,26 \%$ \\
\hline \multirow[t]{2}{*}{ Finanzkrise } & $3,66 \%$ & $2,00 \%$ & $4,19 \%$ & $-40,37 \%$ & $4,19 \%$ & $-9,09 \%$ \\
\hline & KLV & betr. LV & $\begin{array}{c}\text { sonst. } \\
\text { Betr. AV }\end{array}$ & Riester-Rente $^{27}$ & $\begin{array}{c}\text { sonstige } \\
\text { pr. AV }\end{array}$ & $\begin{array}{c}\text { Durchschnitt } \\
\text { SAVE-HH }\end{array}$ \\
\hline $\begin{array}{l}2007 \\
2008 \text { ohne }\end{array}$ & $4,65 \%$ & $4,65 \%$ & $4,65 \%$ & $7,74 \%$ & $4,65 \%$ & $4,78 \%$ \\
\hline $\begin{array}{l}\text { Finanzkrise } \\
2008 \text { mit }\end{array}$ & $4,65 \%$ & $4,65 \%$ & $4,65 \%$ & $3,75 \%$ & $4,65 \%$ & $4,62 \%$ \\
\hline Finanzkrise & $3,55 \%$ & $3,55 \%$ & $-8,00 \%$ & $-4,29 \%$ & $3,55 \%$ & $1,15 \%$ \\
\hline
\end{tabular}

Quelle: Eigene Annahmen auf Grundlage von Daten der Deutschen Bundesbank, des GDV und der OECD.

\subsubsection{Renditeeinbußen 2008}

Da sich die Finanzkrise vor allem auf die Renditen von Aktienanlagen und Fonds ausgewirkt hat, ist zu erwarten, dass diejenigen Haushalte am stärksten negativ betroffen sind, deren Portfolio einen hohen Anteil dieser Anlagen enthält. Über alle SAVE-Haushalte ergibt sich im Jahr 2008 durch die Finanzkrise eine durchschnittliche Rendite der Geldvermögensanlagen von -9,1\%. Ohne Finanzkrise hätten sie eine Rendite von 2,3\% erzielen können. Die Finanzkrise ist also für eine Renditedifferenz von -11,4 Prozentpunkten verantwortlich. Das Altersvorsorgevermögen ist insgesamt weniger betroffen: Das Altersvorsorgevermögen erzielte 2008 im Durchschnitt noch eine positive Rendite von 1,7\%. Ohne Krise hätte die Rendite aber 4,6\% betragen. Die Renditedifferenz beträgt somit -2,9 Prozentpunkte für den Durchschnitt aller Haushalte. Für das gesamte Finanzvermögen (Geldvermögen plus Altersvorsorgevermögen) ergibt sich insgesamt eine Renditedifferenz von -8,7 Prozentpunkten.

Differenziert man die SAVE-Haushalte nach Altersklassen, beträgt die Renditedifferenz beim Geldvermögen im Vergleich zur Referenzsituation ohne Finanzkrise zwischen -6 Prozentpunkte und -14 Prozentpunkte (Abbildung 16). Wie zu vermuten war, entspricht die

\footnotetext{
${ }^{26}$ Auch der angenommene Wert von -8\% für die sonstigen Betriebsrenten wird teilweise als zu pessimistisch erachtet; Vgl. GVG (2009), S. 17.

${ }^{27}$ Es wird angenommen, dass die mit der Riester-Rente verbundene Beitragsgarantie nicht in jedem Jahr gilt. Entsprechend kann es zu negativen Renditen in einzelnen Jahren kommen.
} 
Struktur der Renditeverluste in etwa dem Aktienanteil im Portfolio der Haushalte. Der Aktienanteil bei den 51- bis 60-Jährigen ist am größten. Entsprechend sind dort die höchsten Verluste festzustellen. Das gleiche Bild zeigt sich, wenn man die Haushalte nach Einkommensund Vermögensquintilen differenziert (Abbildungen 17 und 18).

Beim Altersvorsorgevermögen sind die Verlusttreiber die geringere Verzinsung bei den Lebensversicherungen und der Renditeeinbruch bei den Riester-Renten, soweit diese fondsgebunden sind, sowie die betriebliche Altersvorsorge. Da die Riester-Renten und die betriebliche Altersvorsorge am Altersvorsorgevermögen aber nur einen geringen Teil ausmachen, schlägt die negative Entwicklung auf dem Aktienmarkt nicht so stark durch.

Abbildung 16: Renditeverlust im Vergleich zur Referenzsituation ohne Finanzkrise nach Altersklassen im Jahr 2008

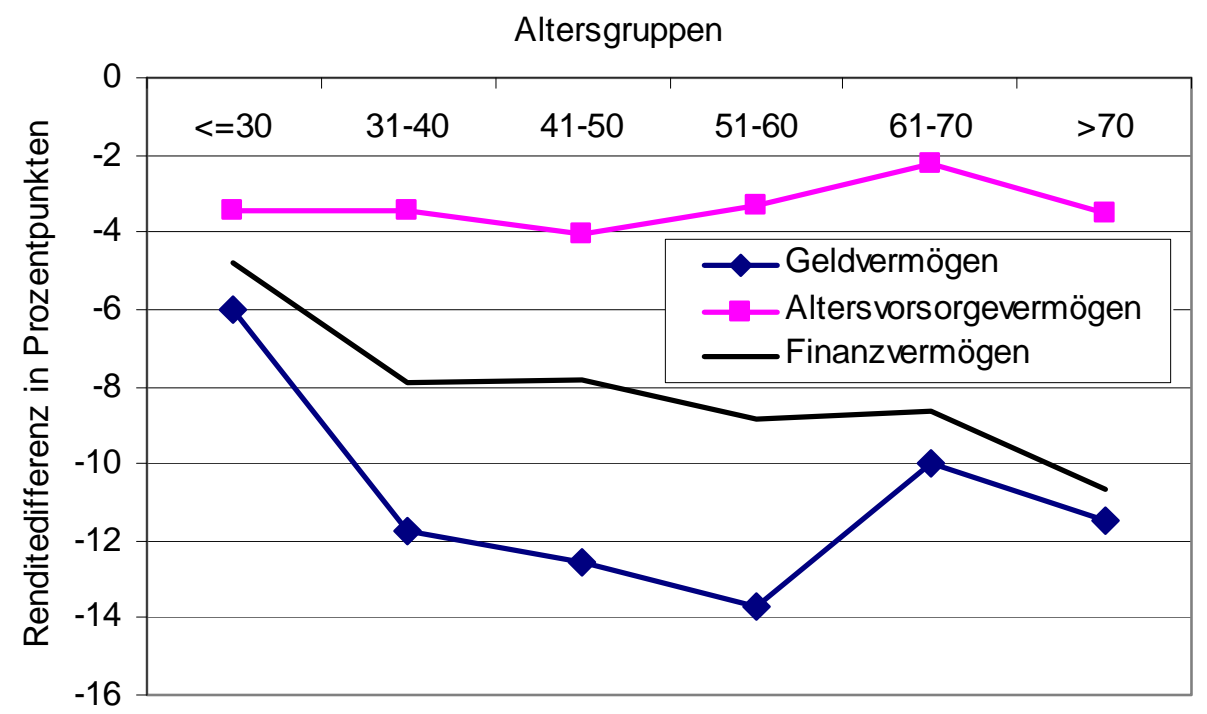

Quelle: SAVE, eigene Berechnung. 
Abbildung 17: Renditeverlust im Vergleich zur Referenzsituation ohne Finanzkrise nach Einkommensquintilen im Jahr 2008

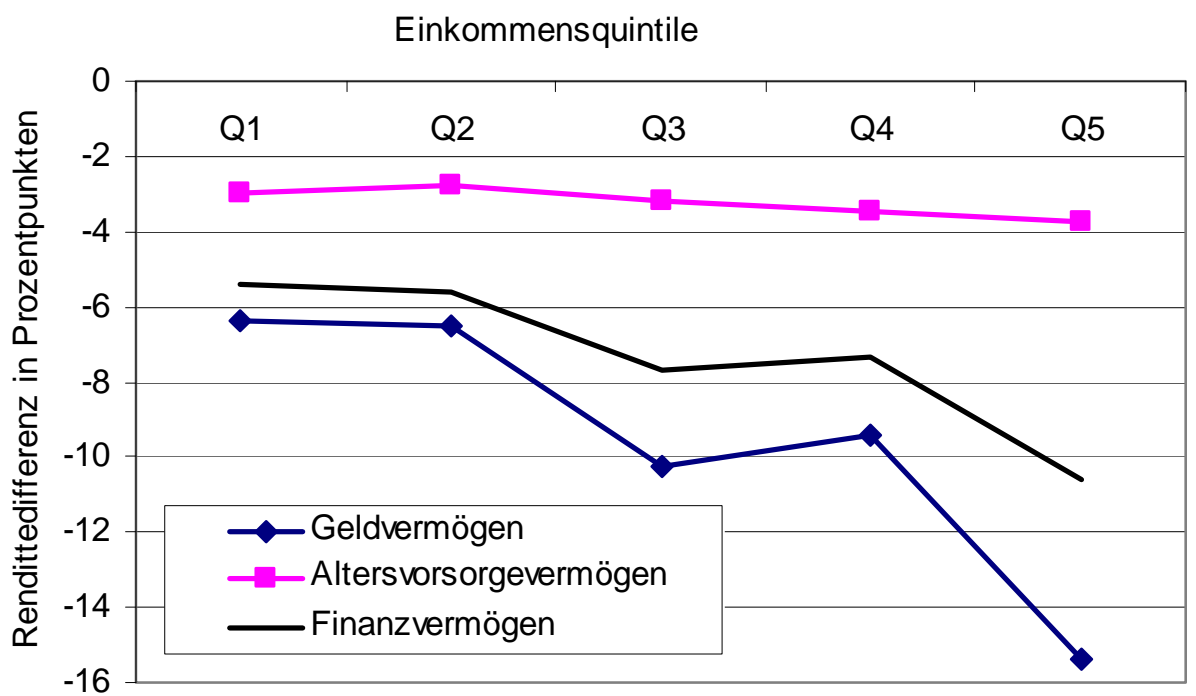

Quelle: SAVE, eigene Berechnung. Abbildung 18: Renditeverlust im Vergleich zur Referenzsituation ohne Finanzkrise
nach Vermögensquintilen im Jahr 2008

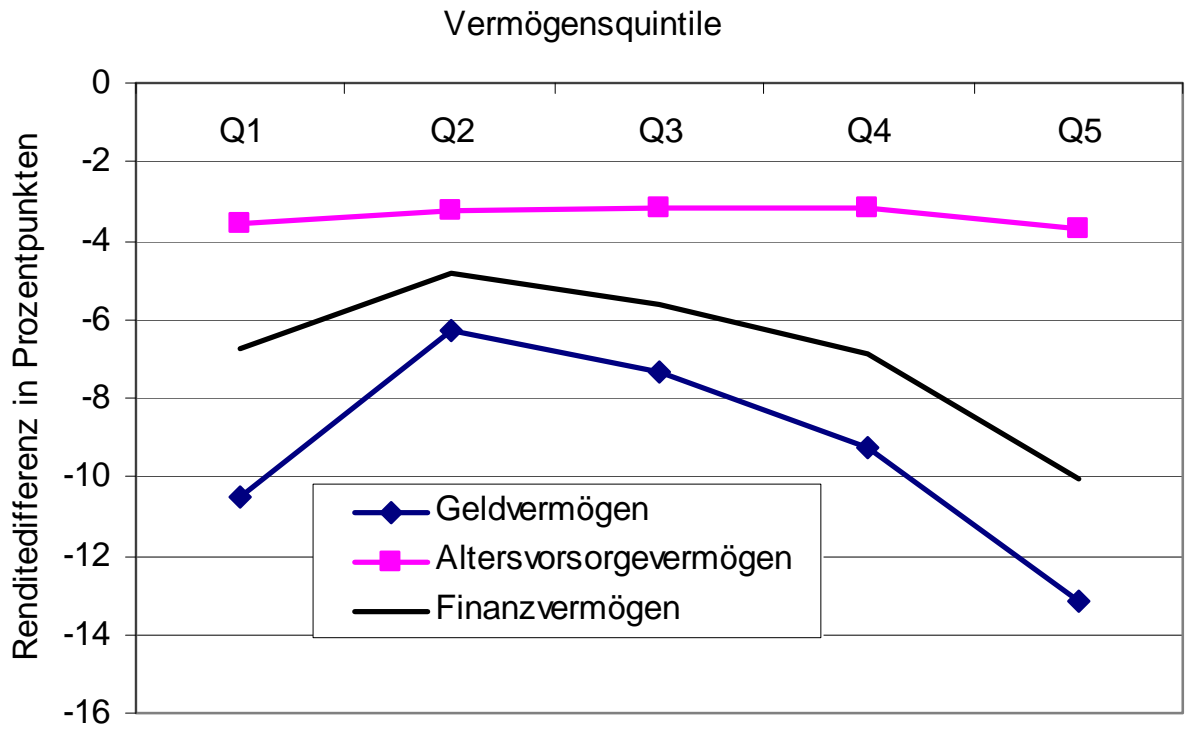

Quelle: SAVE, eigene Berechnung.

\subsubsection{Absolute Vermögensverluste 2008}

Drückt man die Renditeeinbußen nun in Eurobeträgen aus, ergibt sich für den Durchschnitt aller Haushalte eine Einbuße von 2.824 Euro beim Geldvermögen und von 335 Euro beim Altersvorsorgevermögen im Vergleich zur errechneten Referenzsituation in 2008 ohne Krise. Kalkuliert man die Verluste nicht im Vergleich zum simulierten Vermögen 2008, sondern im Vergleich zum tatsächlichen Vermögensbestand 2007, ergibt sich ein Geldvermögensverlust 
von 2.264 Euro (Tabelle 3). Das Altersvorsorgevermögen hat indes im Vergleich zum Stand Ende 2007 um 191 Euro zugenommen, woraus sich ein Gesamtverlust für das Finanzvermögen von 2.072 Euro ergibt. Vergleicht man dieses Ergebnis mit den Verlustangaben, die in SAVE 2009 bei der Frage nach den Verlusten durch die Finanzkrise gemacht wurden, ergibt sich eine gute Übereinstimmung. Der Durchschnitt der angegebenen Vermögensverluste lag dort bei rund 2.500 Euro. ${ }^{28}$ Da die Haushalte in der Befragung explizit nach Verlusten gefragt wurden, müsste man zur Verbesserung der Vergleichbarkeit die hier vorgenommenen Simulationsrechnungen um die möglichen positiven Renditeentwicklungen - beispielsweise wenn ein Haushalt nur Sparanlagen hatte - bereinigen. Betrachtete man demzufolge in den Simulationsrechnungen nur die Haushalte mit Verlusten, würde sich der durchschnittliche Vermögensverlust auf Simulationsbasis fast gänzlich dem Verlust der Umfrage in Höhe von 2.500 Euro annähern. Gleichwohl sind diese Werte aus der Befragung, da es sich dort um Selbsteinschätzungen der Befragten handelt, nicht direkt mit den hier berechneten Werten vergleichbar.

\subsubsection{Relative Vermögensverluste 2008}

Der durchschnittliche relative Vermögensverlust über alle Haushalte kann auf zwei verschiedene Arten berechnet werden. Erstens können die Verluste aller Haushalte aufsummiert und anschließend durch die Summe des Finanzvermögens (oder nur des Geld- bzw. Altersvorsorgevermögens) aller Haushalte geteilt werden. Zweitens kann für jeden Haushalt individuell die Verlustquote berechnet und anschließend der Durchschnitt über alle Verlustquoten gebildet werden. Sind die Verlustquoten für Haushalte mit einem niedrigen Finanzvermögen geringer als für Haushalte mit einem hohen Finanzvermögen, so erhält man bei der ersten Berechnungsart einen höheren durchschnittlichen Verlustanteil. Umgekehrt stellt sich das Bild dar, wenn die Verlustquoten für Haushalte mit einem niedrigeren Finanzvermögen höher sind als für Haushalte mit einem hohen Finanzvermögen. Dann ergibt sich über die zweite Berechnungsmethode ein höherer durchschnittlicher Verlustanteil.

Auf Basis der ersten Berechnungsart erhält man einen durchschnittlichen Verlust relativ zum Finanzvermögen von 8,5\% (Tabelle $3 \mathrm{a})^{29}$, wenn man die Verluste im Vergleich zum simulierten Vermögen 2008 betrachtet. Bezieht man die Verluste nicht auf dieses kalkulierte Vermögen, sondern auf das am Ende 2007 tatsächlich vorhandene Vermögen, erhält man entspre-

\footnotetext{
${ }^{28}$ Vgl. Börsch-Supan, Bucher-Koenen, Gasche und Ziegelmeyer (2009).

${ }^{29}$ Die so berechneten relativen Verlustanteile entsprechen in etwa den oben aufgezeigten Renditedifferenzen in Prozentpunkten.
} 
chend geringere Verlustanteile. Der relative Vermögensverlust bezogen auf alle Haushalte beläuft sich dann auf 5,7\%. (Tabelle 3b).

Wird die Kalkulation der Verlustquoten durch die zweite oben beschriebene Berechnungsart durchgeführt, so reduzieren sich die Verlustanteile auf 4,25\% des Finanzvermögens im Vergleich zum Referenzvermögen in 2008 und auf 1,81\% im Vergleich zum Vermögen Ende 2007. Der Unterschied in den beiden Berechnungsarten basiert auf dem Umstand, dass Haushalte mit geringerem Vermögen gar nicht oder nur in geringer Weise von Vermögensverlusten betroffen sind. Da die Haushalte mit geringem Vermögen bei der zweiten Berechnungsart mit dem gleichen Gewicht eingehen wie Haushalte mit hohem Vermögen, drücken die geringen Verlustquoten der Niedrigvermögenshaushalte die durchschnittliche Quote nach unten. Dies passiert bei der ersten Kalkulationsart nicht.

Die simulierte Verlustquote auf Basis der zweiten Berechnungsmethode von durchschnittlich 1,81\% über alle Haushalte liegt unter den aus tatsächlichen Verlustangaben der SAVE Befragung 2009 ableitbaren Verlustanteilen. Dort kann man feststellen, dass die Haushalte im Durchschnitt eine Verlustquote von 3,6\% ihres Finanzvermögens haben. ${ }^{30}$ Da in der hier vorgenommenen Simulation die Portfolios mancher Haushalte auch positive Renditen im Vergleich zu ihrem Vermögen Ende 2007 erzielen, reduzieren diese Haushalte den durchschnittlichen Vermögensverlust. Werden Haushalte mit positiven Renditen ausgeschlossen, um die Vergleichbarkeit zu den Selbstauskünften über Vermögensverluste herzustellen (dort werden nur Verluste erfasst), dann erhöht sich der durchschnittliche Verlustanteil auf 3,3\% und liegt nun sehr nah am Selbstauskunftswert von 3,6\%.

Unabhängig von der Berechnungsweise der Verluste zeigt sich, dass die absoluten Verluste mit dem Einkommen, dem Vermögen und dem Alter zunehmen. Dies gilt weitgehend auch für die relativen Vermögensverluste (Tabelle 3). Hier spiegeln sich die Portfolioanteile von Vermögenswerten mit hohen Wertverlusten in den Verlustanteilen wider.

\footnotetext{
${ }^{30}$ Vgl. Börsch-Supan, Bucher-Koenen, Gasche und Ziegelmeyer (2009).
} 
Tabelle 3a: Kalkulierte absolute und relative Vermögensverluste durch die Finanzkrise

\begin{tabular}{|c|c|c|c|c|c|c|}
\hline \multicolumn{7}{|c|}{ Verluste im Vergleich zum simulierten Vermögen 2008} \\
\hline $\begin{array}{l}\text { Verluste ab- } \\
\text { solut in Euro }\end{array}$ & \multicolumn{3}{|c|}{ Verluste absolut in Euro } & \multicolumn{3}{|c|}{ Verlustanteile in \% } \\
\hline $\begin{array}{l}\text { Alters- } \\
\text { klassen }\end{array}$ & $\begin{array}{l}\text { Geld- } \\
\text { vermögen }\end{array}$ & $\begin{array}{l}\text { Altersvorsorge- } \\
\text { vermögen }\end{array}$ & $\begin{array}{l}\text { Finanz- } \\
\text { vermögen }\end{array}$ & $\begin{array}{l}\text { Geld- } \\
\text { vermögen }\end{array}$ & $\begin{array}{l}\text { Altersvorsorge- } \\
\text { vermögen }\end{array}$ & $\begin{array}{l}\text { Finanz- } \\
\text { vermögen }\end{array}$ \\
\hline$<=30$ & -405 & -145 & -550 & $-5,9 \%$ & $-2,6 \%$ & $-4,4 \%$ \\
\hline $31-40$ & -1.793 & -320 & -2.113 & $-11,5 \%$ & $-2,8 \%$ & $-7,8 \%$ \\
\hline $41-50$ & -2.260 & -579 & -2.840 & $-12,4 \%$ & $-3,2 \%$ & $-7,9 \%$ \\
\hline $51-60$ & -3.476 & -480 & -3.956 & $-13,4 \%$ & $-2,5 \%$ & $-8,8 \%$ \\
\hline $61-70$ & -4.882 & -202 & -5.084 & $-9,8 \%$ & $-2,1 \%$ & $-8,6 \%$ \\
\hline$>70$ & -4.042 & -111 & -4.153 & $-11,2 \%$ & $-3,4 \%$ & $-10,6 \%$ \\
\hline Gesamt & -2.824 & -335 & -3.159 & $-11,1 \%$ & $-2,8 \%$ & $-8,5 \%$ \\
\hline $\begin{array}{l}\text { Einkommens- } \\
\text { quintile }\end{array}$ & $\begin{array}{l}\text { Geld- } \\
\text { vermögen }\end{array}$ & $\begin{array}{l}\text { Altersvorsorge- } \\
\text { vermögen }\end{array}$ & $\begin{array}{l}\text { Finanz- } \\
\text { vermögen }\end{array}$ & $\begin{array}{l}\text { Geld- } \\
\text { vermögen }\end{array}$ & $\begin{array}{l}\text { Altersvorsorge- } \\
\text { vermögen }\end{array}$ & $\begin{array}{l}\text { Finanz- } \\
\text { vermögen }\end{array}$ \\
\hline Q1 & -396 & -43 & -439 & $-6,3 \%$ & $-1,9 \%$ & $-5,1 \%$ \\
\hline Q2 & -1.287 & -110 & -1.397 & $-6,4 \%$ & $-1,9 \%$ & $-5,4 \%$ \\
\hline Q3 & -2.069 & -235 & -2.304 & $-10,1 \%$ & $-2,3 \%$ & $-7,5 \%$ \\
\hline Q4 & -2.638 & -351 & -2.989 & $-9,2 \%$ & $-2,7 \%$ & $-7,2 \%$ \\
\hline Q5 & -7.866 & -952 & -8.817 & $-15,1 \%$ & $-3,3 \%$ & $-10,8 \%$ \\
\hline Gesamt & -2.824 & -335 & -3.159 & $-11,1 \%$ & $-2,8 \%$ & $-8,5 \%$ \\
\hline $\begin{array}{l}\text { Vermögens- } \\
\text { quintile }\end{array}$ & $\begin{array}{l}\text { Geld- } \\
\text { vermögen }\end{array}$ & $\begin{array}{l}\text { Altersvorsorge- } \\
\text { vermögen }\end{array}$ & $\begin{array}{l}\text { Finanz- } \\
\text { vermögen }\end{array}$ & $\begin{array}{l}\text { Geld- } \\
\text { vermögen }\end{array}$ & $\begin{array}{l}\text { Altersvorsorge- } \\
\text { vermögen }\end{array}$ & $\begin{array}{l}\text { Finanz- } \\
\text { vermögen }\end{array}$ \\
\hline Q1 & -146 & -41 & -187 & $-10,3 \%$ & $-2,9 \%$ & $-6,6 \%$ \\
\hline Q2 & -267 & -93 & -360 & $-6,2 \%$ & $-2,8 \%$ & $-4,7 \%$ \\
\hline Q3 & -1.244 & -271 & -1.514 & $-7,2 \%$ & $-2,6 \%$ & $-5,5 \%$ \\
\hline Q4 & -2.288 & -348 & -2.635 & $-9,1 \%$ & $-2,5 \%$ & $-6,8 \%$ \\
\hline Q5 & -10.214 & -927 & -11.141 & $-12,9 \%$ & $-3,0 \%$ & $-10,1 \%$ \\
\hline Gesamt & -2.824 & -335 & -3.159 & $-11,1 \%$ & $-2,8 \%$ & $-8,5 \%$ \\
\hline
\end{tabular}

Quelle: SAVE, eigene Berechnung. 
Tabelle 3b: Kalkulierte absolute und relative Vermögensverluste durch die Finanzkrise

\begin{tabular}{|c|c|c|c|c|c|c|}
\hline \multicolumn{7}{|c|}{ Verluste im Vergleich zum tatsächlichen Vermögen 2007} \\
\hline \multirow[b]{2}{*}{ Altersklassen } & \multicolumn{3}{|c|}{ Verluste absolut in Euro } & \multicolumn{3}{|c|}{ Verlustanteile in \% } \\
\hline & $\begin{array}{l}\text { Geld- } \\
\text { vermögen }\end{array}$ & $\begin{array}{l}\text { Altersvorsorge- } \\
\text { vermögen }\end{array}$ & $\begin{array}{l}\text { Finanz- } \\
\text { vermögen }\end{array}$ & $\begin{array}{l}\text { Geld- } \\
\text { vermögen }\end{array}$ & $\begin{array}{l}\text { Altersvorsorge- } \\
\text { vermögen }\end{array}$ & $\begin{array}{l}\text { Finanz- } \\
\text { vermögen }\end{array}$ \\
\hline$<=30$ & -241 & 97 & -144 & $-3,6 \%$ & $1,8 \%$ & $-1,2 \%$ \\
\hline $31-40$ & -1.478 & 179 & -1.299 & $-9,7 \%$ & $1,6 \%$ & $-5,0 \%$ \\
\hline $41-50$ & -1.901 & 206 & -1.694 & $-10,6 \%$ & $1,2 \%$ & $-4,8 \%$ \\
\hline $51-60$ & -2.940 & 353 & -2.586 & $-11,6 \%$ & $2,0 \%$ & $-6,0 \%$ \\
\hline $61-70$ & -3.689 & 224 & -3.465 & $-7,6 \%$ & $2,4 \%$ & $-6,0 \%$ \\
\hline$>70$ & -3.218 & 32 & -3.186 & $-9,2 \%$ & $1,0 \%$ & $-8,3 \%$ \\
\hline Gesamt & -2.264 & 191 & -2.072 & $-9,1 \%$ & $1,7 \%$ & $-5,7 \%$ \\
\hline $\begin{array}{l}\text { Einkommens- } \\
\text { quintile }\end{array}$ & $\begin{array}{l}\text { Geld- } \\
\text { vermögen }\end{array}$ & $\begin{array}{l}\text { Altersvorsorge- } \\
\text { vermögen }\end{array}$ & $\begin{array}{l}\text { Finanz- } \\
\text { vermögen }\end{array}$ & $\begin{array}{l}\text { Geld- } \\
\text { vermögen }\end{array}$ & $\begin{array}{l}\text { Altersvorsorge- } \\
\text { vermögen }\end{array}$ & $\begin{array}{l}\text { Finanz- } \\
\text { vermögen }\end{array}$ \\
\hline Q1 & -231 & 58 & -173 & $-3,8 \%$ & $2,6 \%$ & $-2,1 \%$ \\
\hline Q2 & -773 & 143 & -629 & $-4,0 \%$ & $2,6 \%$ & $-2,5 \%$ \\
\hline Q3 & -1.615 & 215 & -1.400 & $-8,0 \%$ & $2,2 \%$ & $-4,7 \%$ \\
\hline Q4 & -1.969 & 214 & -1.755 & $-7,0 \%$ & $1,7 \%$ & $-4,4 \%$ \\
\hline Q5 & -6.848 & 335 & -6.513 & $-13,4 \%$ & $1,2 \%$ & $-8,2 \%$ \\
\hline Gesamt & -2.264 & 191 & -2.072 & $-9,1 \%$ & $1,7 \%$ & $-5,7 \%$ \\
\hline $\begin{array}{l}\text { Vermögens- } \\
\text { quintile }\end{array}$ & $\begin{array}{l}\text { Geld- } \\
\text { vermögen }\end{array}$ & $\begin{array}{l}\text { Altersvorsorge- } \\
\text { vermögen }\end{array}$ & $\begin{array}{l}\text { Finanz- } \\
\text { vermögen }\end{array}$ & $\begin{array}{l}\text { Geld- } \\
\text { vermögen }\end{array}$ & $\begin{array}{l}\text { Altersvorsorge- } \\
\text { vermögen }\end{array}$ & $\begin{array}{l}\text { Finanz- } \\
\text { vermögen }\end{array}$ \\
\hline Q1 & -119 & 21 & -98 & $-8,6 \%$ & $1,6 \%$ & $-3,6 \%$ \\
\hline Q2 & -165 & 53 & -112 & $-3,9 \%$ & $1,6 \%$ & $-1,5 \%$ \\
\hline Q3 & -832 & 190 & -642 & $-5,0 \%$ & $1,9 \%$ & $-2,4 \%$ \\
\hline Q4 & -1.730 & 254 & -1.475 & $-7,0 \%$ & $1,9 \%$ & $-3,9 \%$ \\
\hline Q5 & -8.500 & 443 & -8.057 & $-11,0 \%$ & $1,5 \%$ & $-7,5 \%$ \\
\hline Gesamt & -2.264 & 191 & -2.072 & $-9,1 \%$ & $1,7 \%$ & $-5,7 \%$ \\
\hline
\end{tabular}

Quelle: SAVE, eigene Berechnung.

\subsubsection{Verlustverteilung}

Mit dem SAVE Datensatz können nicht nur die mittleren Verluste für unterschiedliche Alters-

Einkommens- und Vermögensgruppen simuliert, sondern auch die individuellen Verluste je Haushalt berechnet werden, was anschließend eine Analyse der Verlustverteilung ermöglicht. So erleiden 24,3\% der SAVE Haushalte Verluste von mindestens 5\% ihres Finanzvermögens in 2008, wenn der Verlust als Differenz zwischen dem simulierten Finanzvermögen Ende 2008 mit und ohne Krise berechnet wird. Mindestens 10\% ihres Finanzvermögens verlieren 14,4\% aller Haushalte. Extreme Verluste von mindestens 25\% des Finanzvermögens müssen dagegen nur 4,8\% der Haushalte hinnehmen. 
Differenziert nach Altersklassen stellt man fest, dass die jüngste Altersgruppe bis einschließlich 30 Jahre am wenigsten häufig Verluste von mindestens 25\% und 10\% hinnehmen muss und beim 5\%-Niveau nur die Altersgruppe ab 71 Jahren einen geringeren Wert aufweist (Abbildung 19). Ferner steigen extreme Verluste von mindestens 25\% mit dem Alter von 3,1\% (Altersklasse bis 30 Jahre) auf 8,7\% (Altersklasse ab 71 Jahre) an. Uneinheitlicher stellt sich das Bild bei Verlusten von mindestens 10\% und 5\% dar. Zwar kann man auch bei Vermögensverlusten von mindestens 10\% einen leichten Trend mit dem Alter von 9,2\% auf 16,2\% feststellen, jedoch durchbricht vor allem die Altersgruppe von 31 bis 40 Jahren mit einer Betroffenheit von 16,7\% das Bild. Die höhere Betroffenheit dieser Altersgruppe spiegelt sich auch beim 5\%-Verlustniveau wider. Hier sind in der Altersgruppe von 31 bis 40 Jahren 30,6\% der Haushalte von Verlusten von mindestens 5\% betroffen, während der Anteil bei den anderen Altersklassen grob um die 25\% schwankt.

Einheitlich stellt sich dagegen das Bild über Einkommens- und Vermögensklassen dar (Abbildungen 20 und 21). Ein fast linearer Anstieg von 9,7\% auf 41,6\% betroffener Haushalte mit mindestens 5\% Verlusten findet man über die Einkommensquintile. Bei einem Verlust von mindestens 10\% steigt der Anteil von 4,6\% im untersten Quintil auf 26,5\% im obersten, wohingegen der Unterschied beim 25\%-Niveau sich von 2,3\% auf 6,6\% erstreckt. Ebenso beobachtet man auch über die Vermögensquintile den Gradienten von arm zu reich. Hier fällt jedoch der deutliche Anstieg der Betroffenheitsquote vom vierten auf das fünfte Quintil vor allem in Bezug auf das 5\%-Niveau und 10\%-Niveau auf. Der Grad der Betroffenheit vom untersten zum obersten Quintil nimmt zu: beim 5\%-Niveau von 11,6\% auf 39,6\%, beim 10\%Niveau von $4,5 \%$ auf $27,1 \%$ und beim $25 \%$-Niveau von $0,4 \%$ auf $7,7 \%$.

Soll eine Vergleichbarkeit zu den Selbstauskünften der SAVE Befragten zu ihren Vermögensverlusten hergestellt werden ${ }^{31}$, so empfiehlt es sich - wie bereits oben durchgeführt - das simulierte Vermögen mit Finanzkrise Ende 2008 mit dem tatsächlichen Vermögen Ende 2007 zu vergleichen. Betroffen von Vermögensverlusten von mindestens 5\% sind dann noch 16,7\% der Haushalte. Mindestens 10\% Verlust müssen immerhin 11,4\% der Haushalte einstecken und mit mindestens 25\% Verlust haben 4,4\% der Haushalte zu kämpfen. Diese Zahlen liegen höher als die Selbstauskünfte der SAVE Befragten über ihre Vermögensverluste in 2008. Beispielsweise erlitten nach den Selbstauskünften nur 9,3\% aller befragten Haushalte Verluste von über 10\% ihres Finanzvermögens. Diese Diskrepanz von in diesem Fall etwa 2 Prozent-

\footnotetext{
${ }^{31}$ Vgl. Börsch-Supan, Bucher-Koenen, Gasche und Ziegelmeyer (2009).
} 
punkten liegt vor allem daran, dass bei einigen Haushalten das Wissen um die eigenen Verluste fehlt. Dies zeigt sich auch am geringen Anteil der Haushalte von etwa 20\%, die überhaupt angeben, von Vermögensverlusten betroffen zu sein. Mit Blick auf die extremen Vermögensverluste gibt es dagegen einen Unterschied zu den Selbstauskünften, der entgegengesetzt wirkt: Im Rahmen der Selbstauskünfte gaben 2\% der Haushalte an, Finanzvermögensverluste von mindestens 50\% erlitten zu haben. In den Simulationsrechnungen sind dagegen die Vermögensverluste annahmegemäß auf den maximal möglichen relativen Vermögensverlust von -40\% - für den Fall, dass der Haushalt ausschließlich Aktien gehalten hat - beschränkt. Deshalb kann durch die Simulationsrechnungen nicht die individuelle Betroffenheit einzelner Haushalte zur Gänze abgebildet werden, da es in der Realität Haushalte geben kann, die Vermögenswerte besessen haben, deren Wert sich im Laufe des Jahres 2008 um weit mehr als 40\% reduziert hat (z.B. Lehman-Zertifikate, Aktien deutscher Banken, Aktien von Rohstoffunternehmen, chinesische oder russische Aktien).

\section{Abbildung 19: Anteil der Haushalte mit Verlusten im Vergleich zur Referenzsituation ohne Finanzkrise im Jahr 2008 von mind. 5\%, 10\% und 25\% ${ }^{\text {a) }}$ nach Altersklassen}

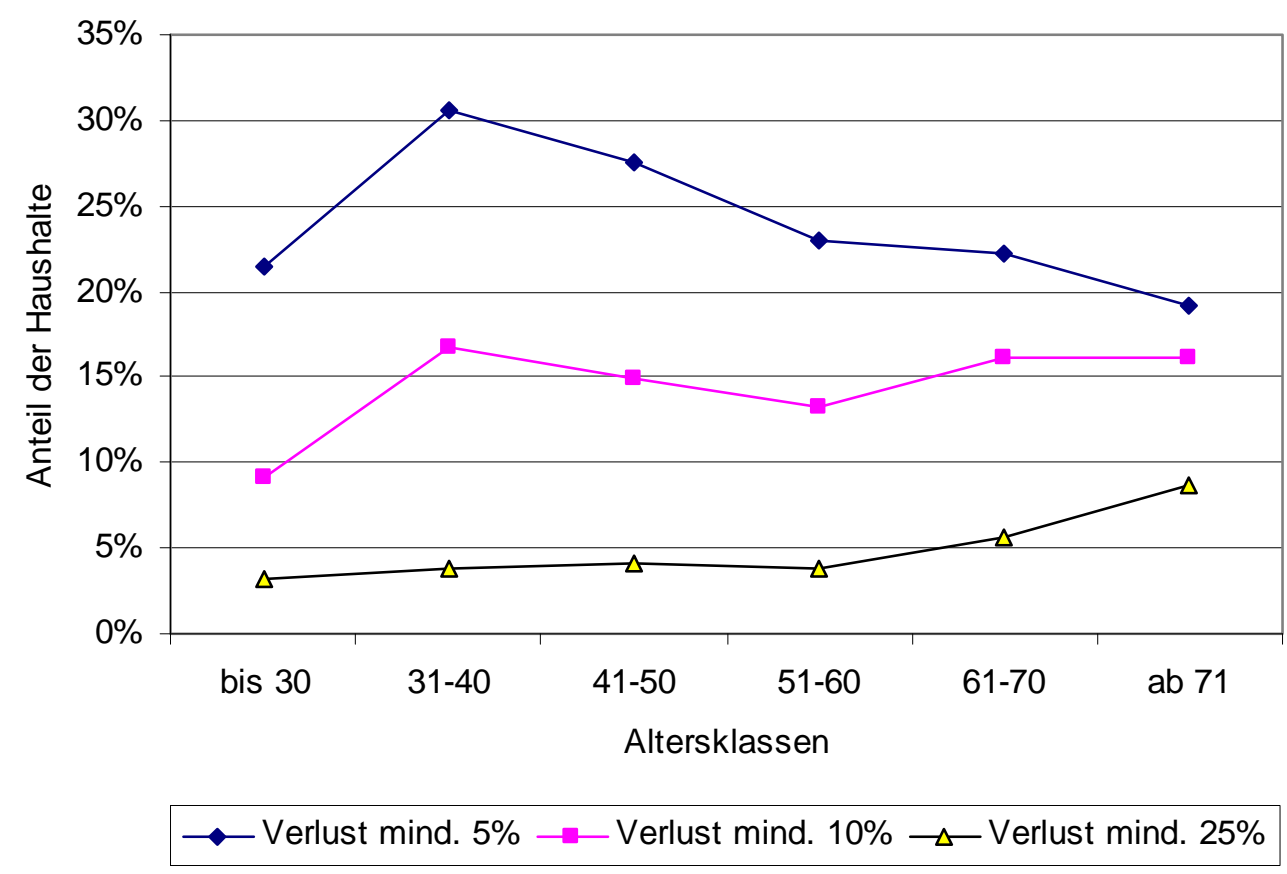

\footnotetext{
a) Verluste in \% des Finanzvermögens.

Quelle: SAVE, eigene Berechnung.
} 
Abbildung 20: Anteil der Haushalte mit Verlusten im Vergleich zur Referenzsituation ohne Finanzkrise im Jahr 2008 von mind. 5\%, 10\% und 25\% ${ }^{\text {a) }}$ nach Einkommensquintilen

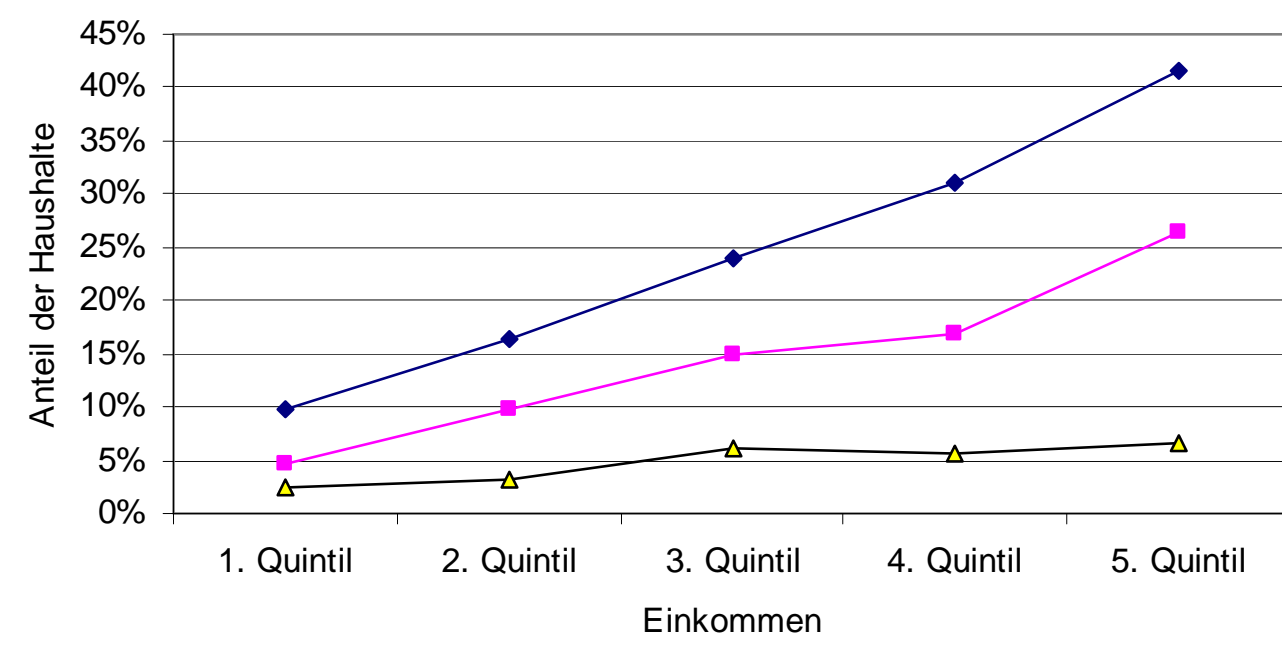

$\neg \multimap$ Verlust mind. $5 \% \rightarrow-$ Verlust mind. $10 \% \multimap-$ Verlust mind. $25 \%$

a) Verluste in \% des Finanzvermögens.

Quelle: SAVE, eigene Berechnung.

Abbildung 21: Anteil der Haushalte mit Verlusten im Vergleich zur Referenzsituation ohne Finanzkrise im Jahr 2008 von mind. 5\%, 10\% und 25\% ${ }^{\text {a) }}$ nach Vermögensquintilen

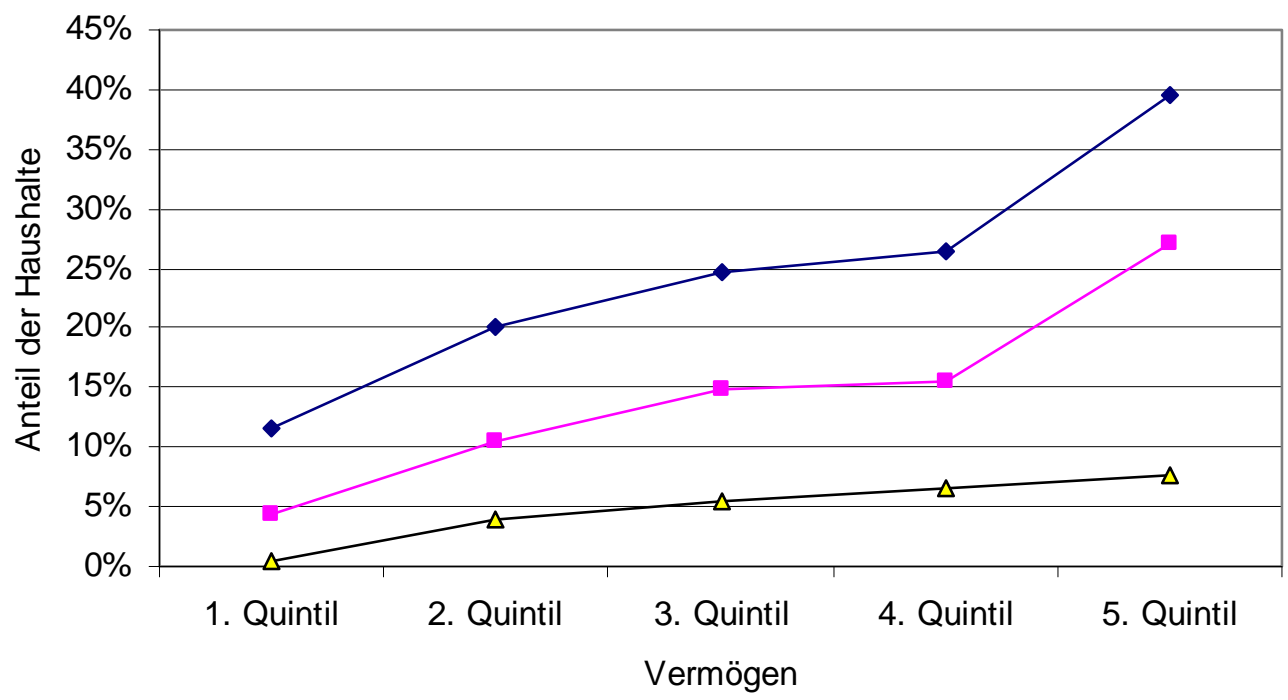

$\neg$ Verlust mind. 5\% —-Verlust mind. 10\% $\neg-$ Verlust mind. $25 \%$

a) Verluste in \% des Finanzvermögens.

Quelle: SAVE, eigene Berechnung.

Insgesamt zeigt sich somit sowohl bei den Selbstauskünften wie auch bei den in dieser Studie simulierten Verlusten für das Jahr 2008, dass die Haushalte im Mittel nur in einem relativ geringen Umfang von Vermögensverlusten betroffen sind. Dennoch gibt es Haushalte, die die 
Krise durch Vermögensverluste recht stark in Mitleidenschaft zieht. Der Grad der Betroffenheit schwankt dabei stark mit dem Alter, dem Einkommen und Vermögen der Haushalte.

\subsection{Kurzfristige Auswirkungen der Finanzkrise im Jahr 2008 unter Berücksichtigung von Vermögensumschichtungen}

Durch die Tatsache, dass für die Simulationsrechnungen die Portfoliostruktur Ende 2007 angenommen wurde, blieben implizit mögliche aktive Umschichtungen, die es gerade aufgrund der Finanzkrise gegeben haben könnte, unberücksichtigt. Zum Beispiel könnten die Haushalte riskante Vermögenswerte verkauft und in weniger riskanten Anlagen wieder angelegt haben. Um einen Eindruck von diesem „Umschichtungseffekt“ zu bekommen, wird nun für die Berechnungen des Vermögens 2008 die in SAVE 2009 angegebene Portfoliostruktur für Ende des Jahres 2008 zugrunde gelegt (Tabelle 4). Konkret wird bei den Berechnungen wie folgt vorgegangen: Die tatsächlichen Vermögenssummen (Geldvermögen, Altersvorsorgevermögen, Finanzvermögen) Ende 2007 werden gemäß der Portfoliostruktur Ende 2008 fiktiv auf die einzelnen Vermögensklassen verteilt. Dann wird dieses neu aufgeteilte Vermögen Ende 2007 in gleicher Weise wie oben für das Jahr 2008 mit den realisierten Renditen für die einzelnen Vermögenskategorien fortgeschrieben, also eine Vermögenswert für Ende 2008 kalkuliert. Der Vergleich der kalkulierten Vermögenswerte 2008 bei Zugrundelegung der unterschiedlichen Portfoliostrukturen kann Anhaltspunkte über die Effekte von Vermögensumschichtungen geben.

Hätte die Portfoliostruktur Ende des Jahres 2008 für das Vermögen 2007 gegolten, dann wären die Vermögensverluste geringer ausgefallen. Der Geldvermögensverlust hätte anstatt 2.824 Euro nur 2.109 Euro betragen. Die Differenz von 715 Euro könnte man nun so interpretieren, dass die Haushalte durch Vermögensumschichtungen einen Verlust in dieser Höhe hätten verhindern können, wenn sie die Portfoliostruktur 2007 in Richtung Portfoliostruktur Ende 2008 geändert hätten. Die tatsächliche aus den Umschichtungen resultierende Reduktion des Verlustes in 2008 hängt stark vom Zeitpunkt der Umschichtung ab. Wurden die Umschichtungen hauptsächlich im Oktober 2008 durchgeführt, wie die Statistiken des Bundesverbandes Investment und Asset Management e. V. in Bezug auf Publikumsfonds zeigen, dann hatten die Umschichtungen kaum verlustmindernde Wirkung, da die Verluste größtenteils an ihrem Tiefpunkt realisiert wurden. Freilich kann der Umschichtungseffekt so allenfalls annähernd ermittelt werden, weil die Portfoliostruktur 2008 sich von derjenigen 2007 
nicht nur aufgrund von Umschichtungen unterscheidet, sondern auch die Ersparnis in 2008, das Auflösen von Ersparnis sowie Wertänderungen eine Rolle gespielt haben könnten.

Tabelle 4: Portfoliostruktur: Anteil der Vermögensklassen Ende 2007 und Ende 2008

\begin{tabular}{l|ccccc} 
Geldvermögen & Sparanlagen & BSV & $\begin{array}{c}\text { festverzinsliche } \\
\text { Wertpapiere }\end{array}$ & $\begin{array}{c}\text { Aktien(-fonds) u } \\
\text { Immobilienfonds }\end{array}$ & $\begin{array}{c}\text { sonstige Wert- } \\
\text { papiere }\end{array}$ \\
\hline \hline Ende 2007 & $43,2 \%$ & $10,4 \%$ & $13,4 \%$ & $28,8 \%$ & $4,3 \%$ \\
Ende 2008 & $48,1 \%$ & $10,1 \%$ & $13,2 \%$ & $22,2 \%$ & $6,3 \%$ \\
\hline $\begin{array}{l}\text { Altersvorsorge- } \\
\text { vermögen }\end{array}$ & KLV & betr. LV & $\begin{array}{c}\text { sonst. Betr. } \\
\text { Altersvorsorge }\end{array}$ & Riester-Rente & $\begin{array}{c}\text { sonstige priv. } \\
\text { Altersvorsorge }\end{array}$ \\
\hline \hline Ende 2007 & $62,2 \%$ & $9,3 \%$ & $13,4 \%$ & $4,1 \%$ & $11,0 \%$ \\
Ende 2008 & $57,7 \%$ & $11,4 \%$ & $16,6 \%$ & $4,4 \%$ & $10,0 \%$
\end{tabular}

Quelle: SAVE, eigene Berechnungen.

Beim Altersvorsorgevermögen wäre der Verlust durch die Finanzkrise mit der Portfoliostruktur 2008 sogar größer ausgefallen als mit der Portfoliostruktur 2007, weil die betriebliche Altersvorsorge, die durch die Finanzkrise relativ starke Renditeeinbußen erlitten hat, Ende 2008 ein größeres Gewicht besaß als Ende 2007. Grundsätzlich dürften aber beim Altersvorsorgevermögen Umschichtungen bei der Portfoliostrukturänderung eine geringere Rolle spielen als beim Geldvermögen. Beim Altersvorsorgevermögen überwiegt also eindeutig der Effekt der zusätzlichen Ersparnis den Umschichtungseffekt. Die untergeordnete Rolle von Umschichtungen wird durch SAVE 2009 bestätigt, wo direkt nach den Umschichtungen gefragt wurde und nur $8 \%$ der Haushalte angaben, diesbezüglich aktiv geworden zu sein. ${ }^{32}$ Der gesamte Finanzvermögensverlust hätte sich bei der Portfoliostruktur 2008 auf 2.488 Euro beschränkt und nicht 3.159 Euro betragen (Tabelle 5).

\footnotetext{
${ }^{32}$ Vgl. Börsch-Supan, Bucher-Koenen, Gasche und Ziegelmeyer (2009).
} 
Tabelle 5: Absolute und relative Vermögensverluste für verschiedene Portfoliostrukturen

\begin{tabular}{|c|c|c|c|c|c|c|c|c|}
\hline \multicolumn{5}{|c|}{$\begin{array}{c}\text { Verluste absolut in Euro } \\
\text { im Vergleich zum simulierten Vermögen } 2008 \\
\text { ohne Finanzkrise }\end{array}$} & \multicolumn{4}{|c|}{$\begin{array}{c}\text { Relative Verluste } \\
\text { im Vergleich zum simulierten Vermögen } 2008 \\
\text { ohne Finanzkrise }\end{array}$} \\
\hline & \multicolumn{2}{|c|}{ Portfoliostruktur 2007} & \multicolumn{2}{|c|}{$\begin{array}{c}\text { Portfoliostruktur } \\
2008 \\
\end{array}$} & \multicolumn{2}{|c|}{ Portfoliostruktur 2007} & \multicolumn{2}{|c|}{$\begin{array}{c}\text { Portfoliostruktur } \\
2008 \\
\end{array}$} \\
\hline $\begin{array}{l}\text { Alters- } \\
\text { klassen }\end{array}$ & $\begin{array}{l}\text { Alters- } \\
\text { vorsorge- } \\
\text { vermögen }\end{array}$ & $\begin{array}{l}\text { Finanz- } \\
\text { vermögen }\end{array}$ & $\begin{array}{l}\text { Alters- } \\
\text { vorsorge- } \\
\text { vermögen }\end{array}$ & $\begin{array}{l}\text { Finanz- } \\
\text { ver- } \\
\text { mögen }\end{array}$ & \begin{tabular}{|l|} 
Alters- \\
vorsorge- \\
vermögen
\end{tabular} & $\begin{array}{l}\text { Finanz- } \\
\text { vermögen }\end{array}$ & $\begin{array}{l}\text { Alters- } \\
\text { vorsorge- } \\
\text { vermögen }\end{array}$ & $\begin{array}{l}\text { Finanz- } \\
\text { ver- } \\
\text { mögen }\end{array}$ \\
\hline$<=30$ & -145 & -550 & -176 & -786 & $-2,6 \%$ & $-4,4 \%$ & $-3,2 \%$ & $-6,3 \%$ \\
\hline $31-40$ & -320 & -2.113 & -363 & -1.341 & $-2,8 \%$ & $-7,8 \%$ & $-3,2 \%$ & $-5,0 \%$ \\
\hline $41-50$ & -579 & -2.840 & -628 & -1.861 & $-3,2 \%$ & $-7,9 \%$ & $-3,5 \%$ & $-5,2 \%$ \\
\hline $51-60$ & -480 & -3.956 & -612 & -3.211 & $-2,5 \%$ & $-8,8 \%$ & $-3,2 \%$ & $-7,2 \%$ \\
\hline $61-70$ & -202 & -5.084 & -245 & -3.448 & $-2,1 \%$ & $-8,6 \%$ & $-2,6 \%$ & $-5,8 \%$ \\
\hline$>70$ & -111 & -4.153 & -62 & -4.192 & $-3,4 \%$ & $-10,6 \%$ & $-1,9 \%$ & $-10,7 \%$ \\
\hline Gesamt & -335 & -3.159 & -379 & -2.488 & $-2,8 \%$ & $-8,5 \%$ & $-3,2 \%$ & $-6,7 \%$ \\
\hline $\begin{array}{l}\text { Ein- } \\
\text { kommens- } \\
\text { quintile }\end{array}$ & $\begin{array}{l}\text { Alters- } \\
\text { vorsorge- } \\
\text { vermögen }\end{array}$ & $\begin{array}{l}\text { Finanz- } \\
\text { vermögen }\end{array}$ & \begin{tabular}{|l|} 
Alters- \\
vorsorge- \\
vermögen \\
\end{tabular} & \begin{tabular}{|l|} 
Finanz- \\
ver- \\
mögen \\
\end{tabular} & $\begin{array}{l}\text { Altersvor- } \\
\text { sorge- } \\
\text { vermögen }\end{array}$ & $\begin{array}{l}\text { Finanz- } \\
\text { vermögen }\end{array}$ & \begin{tabular}{|l} 
Alters- \\
vorsorge- \\
vermögen \\
\end{tabular} & $\begin{array}{l}\text { Finanz- } \\
\text { ver- } \\
\text { mögen }\end{array}$ \\
\hline Q1 & -43 & -439 & -44 & -404 & $-1,9 \%$ & $-5,1 \%$ & $-1,9 \%$ & $-4,7 \%$ \\
\hline Q2 & -110 & -1.397 & -170 & -794 & $-1,9 \%$ & $-5,4 \%$ & $-3,0 \%$ & $-3,1 \%$ \\
\hline Q3 & -235 & -2.304 & -297 & -1.992 & $-2,3 \%$ & $-7,5 \%$ & $-2,9 \%$ & $-6,5 \%$ \\
\hline Q4 & -351 & -2.989 & -426 & -3.338 & $-2,7 \%$ & $-7,2 \%$ & $-3,3 \%$ & $-8,1 \%$ \\
\hline Q5 & -952 & -8.817 & -963 & -6.174 & $-3,3 \%$ & $-10,8 \%$ & $-3,3 \%$ & $-7,6 \%$ \\
\hline Gesa & -335 & -3.159 & -379 & -2.488 & $-2,8 \%$ & $-8,5 \%$ & $-3,2 \%$ & $-6,7 \%$ \\
\hline $\begin{array}{l}\text { Ver- } \\
\text { mögens- } \\
\text { quintile }\end{array}$ & $\begin{array}{l}\text { Alters- } \\
\text { vorsorge- } \\
\text { vermögen }\end{array}$ & $\begin{array}{l}\text { Finanz- } \\
\text { vermögen }\end{array}$ & \begin{tabular}{|l|} 
Alters- \\
vorsorge- \\
vermögen \\
\end{tabular} & \begin{tabular}{|l|} 
Finanz- \\
ver- \\
mögen \\
\end{tabular} & \begin{tabular}{|l|} 
Altersvor- \\
sorge- \\
vermögen
\end{tabular} & $\begin{array}{l}\text { Finanz- } \\
\text { vermögen }\end{array}$ & \begin{tabular}{|l} 
Alters- \\
vorsorge- \\
vermögen \\
\end{tabular} & $\begin{array}{l}\text { Finanz- } \\
\text { ver- } \\
\text { mögen } \\
\end{array}$ \\
\hline Q1 & -41 & -187 & -50 & -157 & $-2,9 \%$ & $-6,6 \%$ & $-3,5 \%$ & $-5,6 \%$ \\
\hline Q2 & -93 & -360 & -115 & -268 & $-2,8 \%$ & $-4,7 \%$ & $-3,4 \%$ & $-3,5 \%$ \\
\hline Q3 & -271 & -1.514 & -320 & -1.310 & $-2,6 \%$ & $-5,5 \%$ & $-3,1 \%$ & $-4,7 \%$ \\
\hline Q4 & -348 & -2.635 & -397 & -2.163 & $-2,5 \%$ & $-6,8 \%$ & $-2,9 \%$ & $-5,6 \%$ \\
\hline Q5 & -927 & -11.141 & -1.017 & -8.460 & $-3,0 \%$ & $-10,1 \%$ & $-3,3 \%$ & $-7,7 \%$ \\
\hline Gesamt & -335 & -3.159 & -379 & -2.488 & $-2,8 \%$ & $-8,5 \%$ & $-3,2 \%$ & $-6,7 \%$ \\
\hline
\end{tabular}

Quelle: SAVE, eigene Berechnungen.

\subsection{Langfristige Auswirkungen der Finanzkrise}

Die grundsätzlichen Anmerkungen in Abschnitt 3 haben gezeigt, dass durch die Langfristigkeit der Altervorsorgeanlage Renditeschwankungen geglättet und kurzfristige Verluste ausgeglichen werden können. Diese Eigenschaft der Altersvorsorgeanlage kann auch für die deutschen Haushalte demonstriert werden. Dazu werden die Portfolios der Jahre 2007 nicht nur bis zum Jahr 2008 fortgeschrieben, sondern über einen längeren Zeitraum. Für die Berechnungen werden den einzelnen Anlageformen unterschiedliche Renditepfade mit und ohne Finanzkrise unterstellt (Abbildung 22). Dabei wird für alle Kapitalanlagen angenommen, dass 
sich langfristig aufgrund der demographischen Entwicklung ein Renditerückgang gibt. ${ }^{33}$ Für die Wertentwicklung von Aktienanlagen wird unterstellt, dass es nach dem Einbruch in Höhe von -40\% in 2008 im Jahr 2009 zu einer Gegenbewegung von $+16 \%$ kommt. Danach wird unterstellt, dass sich der Aktienindex gemäß seiner langjährigen durchschnittlichen Wachstumsrate im Zeitraum 1970 bis 2007 von 8,15\% entwickelt. Um den Auswirkungen der demographischen Entwicklung auf die Kapitalrendite Rechnung zu tragen, wird bis zum Jahr 2050 davon jährlich ein Renditeabschlag genommen, der sich bis zum Jahr 2050 auf einen Prozentpunkt aufbaut, so dass die Rendite bis 2050 auf 7,15\% sinkt. Die Entwicklung der Renditen ist annahmegemäß ab 2010 mit und ohne Krise identisch. Somit wird hier unterstellt, dass es nicht zu einer strukturellen Renditereduktion durch die Finanzkrise kommt. Dies entspricht dem Szenario 2 (siehe Abschnitt 3).

Auch für die anderen Anlageformen wird ebenfalls ein demographisch bedingter Renditerückgang unterstellt (Abbildung 22). Für die Kapitallebensversicherungen beispielsweise wird angenommen, dass auch noch im Jahr 2009 die Nettoverzinsung mit 4,0\% unterhalb der Verzinsung ohne Krise liegen wird. Im Jahr 2010 wird aber der ursprüngliche Renditepfad ohne Krise wieder erreicht. Bis 2050 sinkt annahmegemäß die Nettoverzinsung der Kapitallebensversicherungen auf 3,7\%. Aus diesen unterschiedlichen Renditeentwicklungen für die einzelnen Anlageklassen wird jeweils eine mit den Portfolioanteilen des Jahres 2007 gewichtete Durchschnittsrendite für die drei Vermögenskategorien (Geldvermögen, Finanzvermögen und Altersvorsorgevermögen) ermittelt ${ }^{34}$ und die Vermögen entsprechend dieser Verzinsung über das Jahr 2008 hinaus fortgeschrieben. ${ }^{35}$

\footnotetext{
${ }^{33}$ Vgl. Börsch-Supan, Heiss,Ludwig und Winter(2003) oder Krüger und Ludwig (2007).

${ }^{34}$ Dieses Vorgehen impliziert die Annahme, dass die Portfoliostruktur der Neuanlage der Portfoliostruktur des Vermögens im Ausgangsjahr 2007 entspricht.

${ }^{35}$ Vgl. Zinsentwicklung in Abbildung 27 ab dem Jahr 2009.
} 
Abbildung 22: Angenommene Renditeentwicklung für die verschiedenen Anlageformen

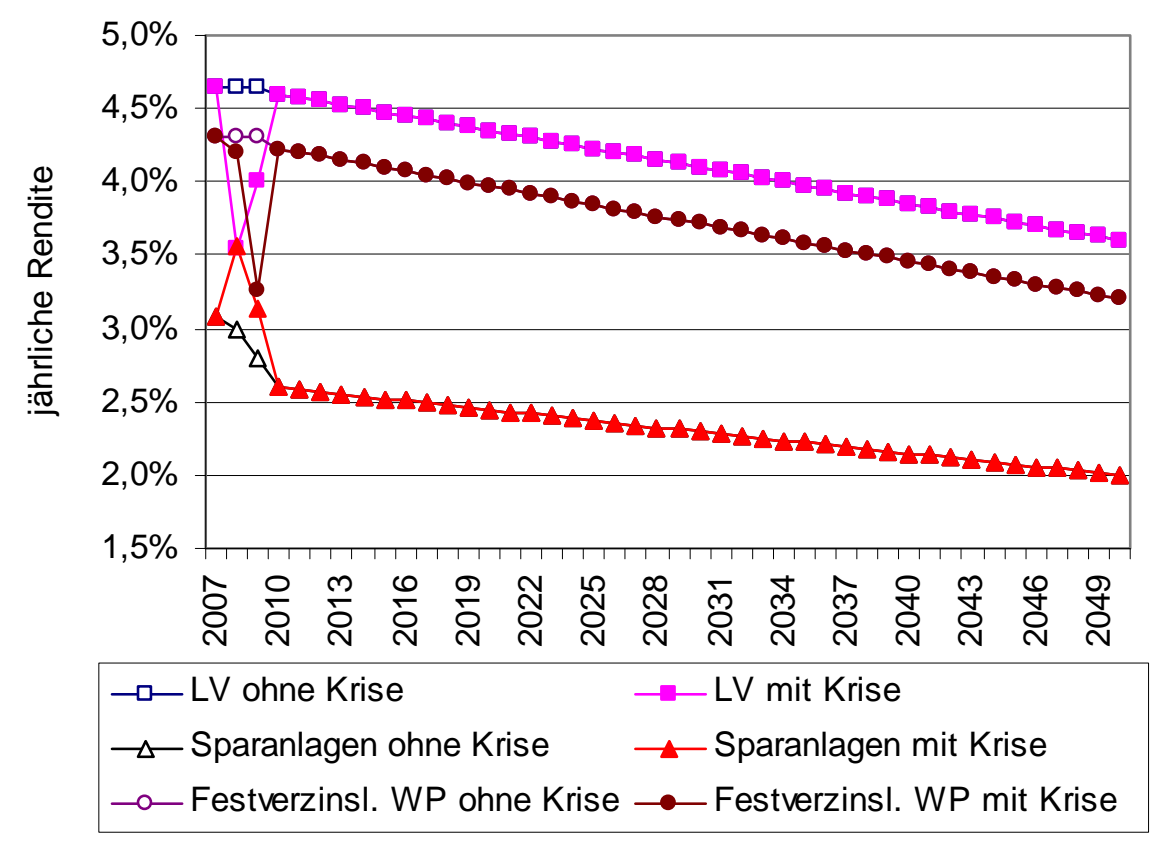

Quelle: Eigene Berechnungen.

Zunächst wird die Entwicklung der durchschnittlichen jährlichen Rendite betrachtet, wenn der Anlagehorizont des Vermögens aus dem Jahr 2007 nicht nur wie in den Berechnungen oben bis 2008 reicht, sondern weiter über 2008 hinausgeht. Die Rendite berechnet sich dann als durchschnittliche jährliche Rendite ab Ende 2007 bis zum Ende des Anlagezeitraums (Abbildung 23). Es zeigt sich, dass die Rendite mit Ausweitung des Anlagehorizonts wieder ansteigt und dass die Renditedifferenz zwischen der Situation mit Krise und der Situation ohne Krise im Zeitverlauf abnimmt. Dies liegt daran, dass für die Berechnung der Durchschnittsrendite nun immer mehr Zinssätze relevant sind und die Bedeutung des Renditeeinbruchs im Jahr 2008 nachlässt. Damit kann man auch hier die Rendite glättende Eigenschaft der Langfristanlage beobachten. Es zeigt sich aber auch, dass die Effekte der Finanzkrise permanent erhalten bleiben. Sie werden zwar mit der Zeit kleiner, verschwinden aber nie. Für den Vermögensbestand zum Zeitpunkt der Krise gibt es also einen permanenten Effekt. Für Neuanlagen nach der Krise gibt es keine Renditeunterschiede, wenn - wie hier angenommen - die Kapitalrendite wieder auf den gleichen Pfad einschwenkt wie ohne Krise.

Der Gesamteffekt hängt mithin davon ab, wie sich z.B. zum Renteneintritt das Vermögen aus Vermögen bis zur Krise und aus nach der Krise erworbenen Vermögen zusammensetzt. Insofern erhält man einen völlig analogen Effekt wie bei der Gesetzlichen Rentenversicherung. Auch dort sind diejenigen am stärksten betroffen, die zum Zeitpunkt der Finanzkrise schon viel „Vermögen“ in Form von Entgeltpunkten angesammelt hatten, also die rentennahen Al- 
tersklassen. Jüngere Altersklassen mit wenig angesammelten Entgeltpunkten sind weniger stark betroffen und diejenigen, die nach der Finanzkrise eine Erwerbstätigkeit aufnehmen, sind gar nicht betroffen. ${ }^{36}$ Das Gleiche gilt bei der privaten Vorsorge: Fängt man erst nach der Krise mit der Vermögensbildung an, hat die Finanzkrise ebenfalls keine Auswirkungen.

\section{Abbildung 23: Durchschnittliche jährliche Rendite des Altersvorsorge- und des Finanz- vermögens bei längerem Anlagehorizont}

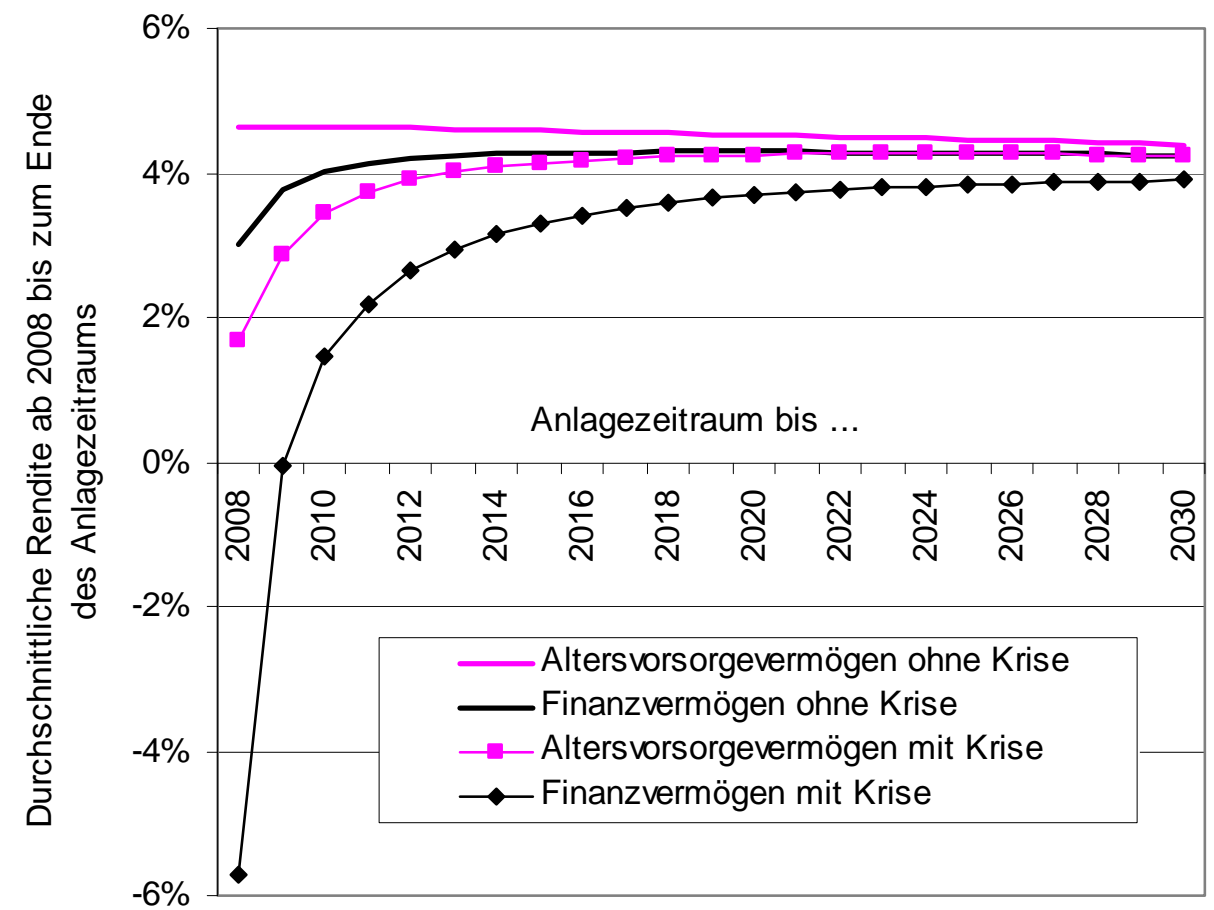

Quelle: Eigene Berechnungen.

Deutlich wird damit aber auch, dass der Renditeeinbruch durch die Finanzkrise vor allem für Ältere ein Problem darstellt, da diese einen kürzeren Anlagehorizont bzw. weniger Zeit haben, um die Krise „auszusitzen“. So braucht es für die 51- bis 60-Jährigen schon drei Jahre, bis sie den Finanzvermögensverlust durch die Finanzkrise wieder ausgeglichen haben und das Finanzvermögens-Portfolio für den Zeitraum seit 2007 eine positive Rendite aufweist, also den Wert von 2007 wieder erreicht hat (Abbildung 24). Weitere fünf Anlagejahre sind erforderlich, bis die Rendite des aufgrund des höheren Aktienanteils risikoreicheren Portfolios der 51- bis 60-Jährigen die Durchschnittsrendite des Portfolios der unter 30-Jährigen mit dem geringeren Aktienanteil eingeholt hat. Auch die Lücke zwischen der Rendite ohne Krise und der Rendite mit Krise schließt sich bei den Älteren langsamer (Abbildung 24).

\footnotetext{
${ }^{36}$ Vgl. Börsch-Supan, Gasche und Wilke (2009).
} 


\section{Abbildung 24: Durchschnittliche jährliche Rendite des Finanzvermögens bei längerem Anlagehorizont am Beispiel zweier Altersklassen}

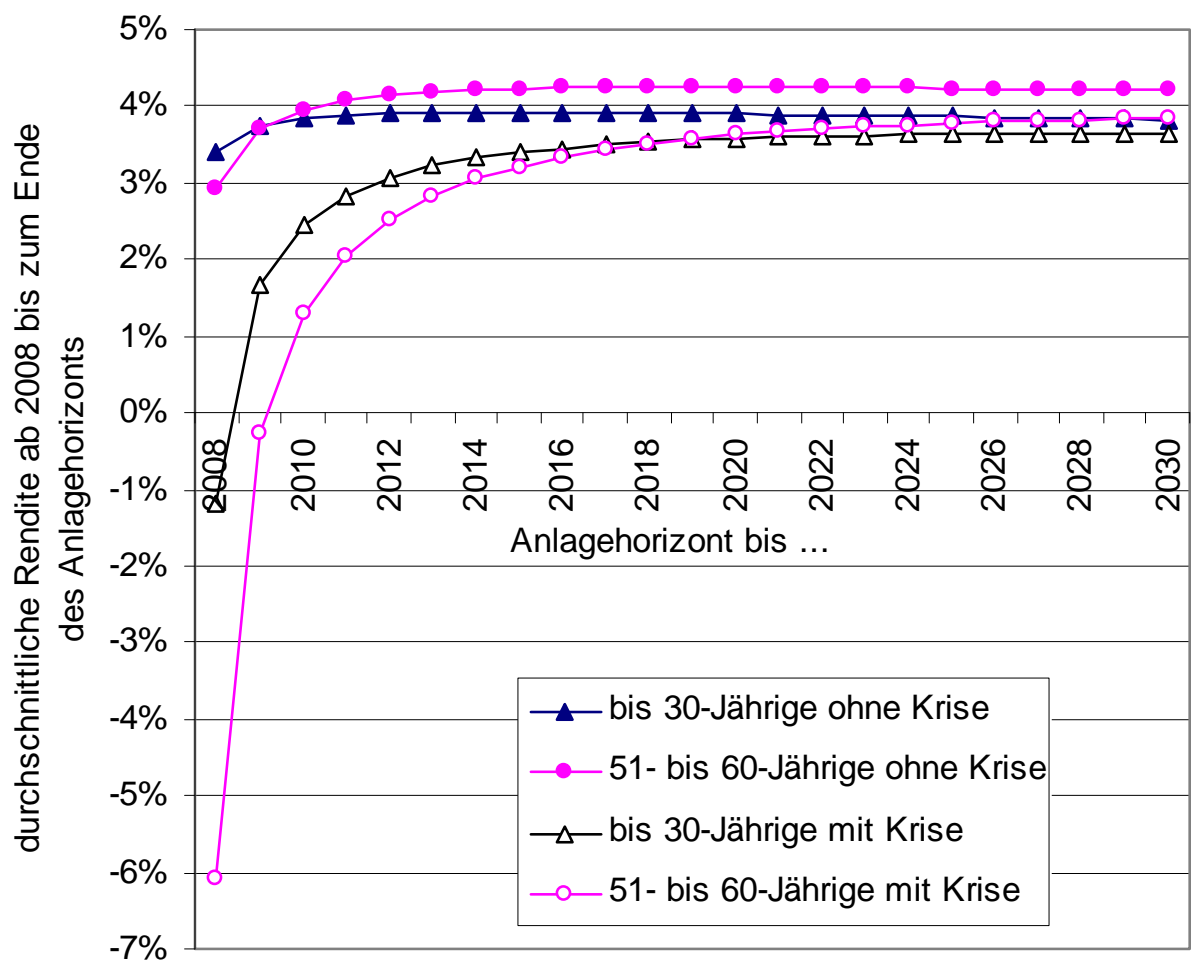

Quelle: Eigene Berechnungen.

Die Auswirkungen der Krise und die Bedeutung der verbleibenden Zeit, um die Verluste wieder auszugleichen kann man anhand der Frage veranschaulichen, wie viel die Haushalte zusätzlich jährlich sparen müssten, um die im Vergleich zur Situation ohne Krise erlittenen Vermögensverluste wieder auszugleichen. ${ }^{37}$ Hier kommt es zu zwei gegenläufigen Effekten: Einerseits greift der naheliegende Zusammenhang, dass man jährlich umso weniger sparen muss, je mehr Zeit man noch zur Verfügung hat, einen bestimmten Betrag anzusparen. Man kann dann den Zinseszinseffekt der Anlagen nutzen und vor allem den „Zielsparbetrag“ gleichsam auf mehrere Perioden aufteilen. Dieser Degression des jährlichen Sparbetrags wirkt andererseits entgegen, dass der Zielsparbetrag, also der absolute Verlust im Vergleich zur Situation ohne Krise im Zeitablauf zunimmt. Dies ist mit einem Zinseszinseffekt zu begründen, der die Differenz zwischen dem Vermögen mit Krise und dem Vermögen ohne Krise in Eurobeträgen immer größer werden lässt. Insgesamt bewirken die gegenläufigen Effekte, dass der zusätzlich erforderliche jährliche Sparbetrag sich mit zunehmenden Anlagehorizont asymptotisch an einen bestimmten Wert annähert (Abbildung 25). So hatten die Haushalte im Jahr 2008 einen Finanzvermögensverlust von rund 3.160 Euro zu verzeichnen. Hätten sie die-

\footnotetext{
${ }^{37}$ Angenommen wird dabei, dass sich die Anlage mit der durchschnittlichen Portfoliorendite verzinst, d.h. dass die Portfoliostruktur der Neuanlage der Portfoliostruktur des Vermögens im Ausgangsjahr 2007 entspricht.
} 
sen Verlust schon bis 2010 aufholen wollen, hätten sie jedes Jahr 745 Euro zusätzlich zurücklegen müssen. Der erforderliche zusätzliche jährliche Sparbetrag sinkt dann mit dem Anlagehorizont bis auf 409 Euro, wenn man den Verlust bis 2015 aufgeholt haben will und auf 190 Euro, wenn man sich bis 2030 Zeit lässt ${ }^{38}$ (Abbildung 25).

\section{Abbildung 25: Zusätzlich nötiger jährlicher Sparbetrag zum Ausgleich der Finanzver- mögensverluste in Abhängigkeit vom Ansparzeitraum}

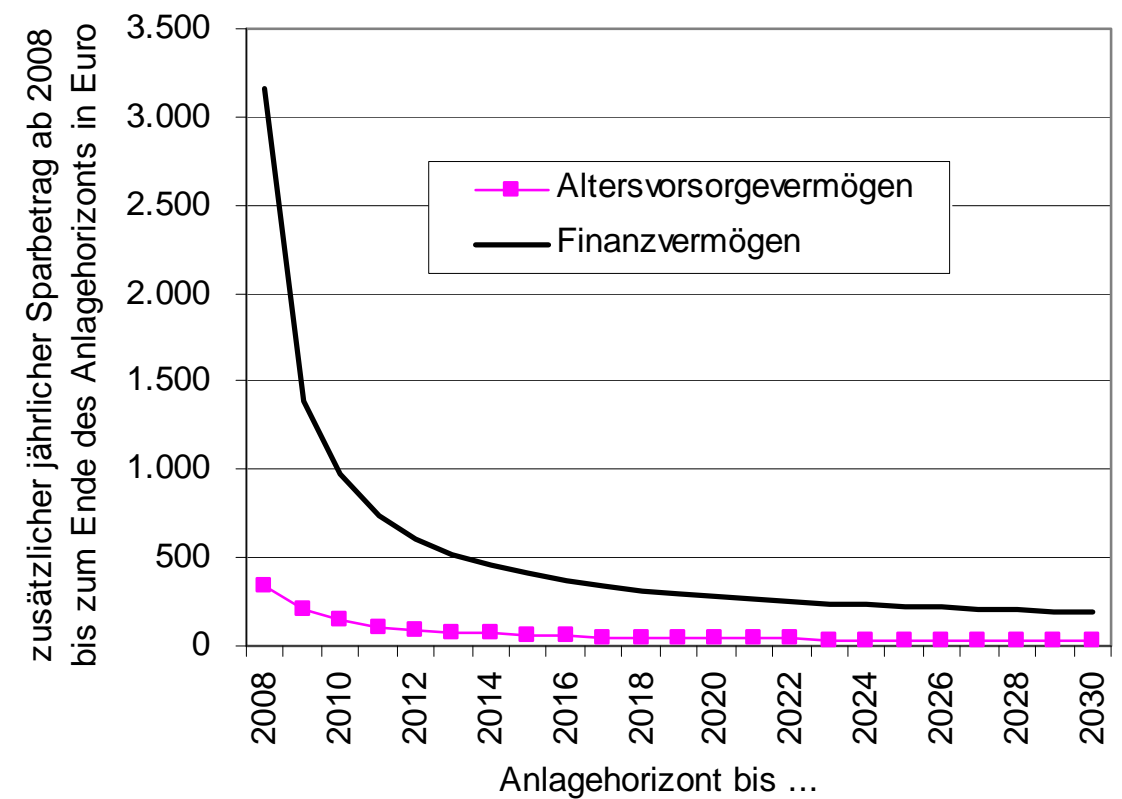

Quelle: Eigene Berechnungen.

Für die Älteren kommt nicht nur die Tatsache zum Tragen, dass ihnen zum Aufholen der Verluste weniger Zeit bleibt und deshalb der erforderliche zusätzliche Sparbetrag höher ist, sondern auch der Umstand, dass sie höhere Verluste erlitten haben und deshalb mehr aufholen müssen. So haben die Haushalte der Altersklasse 51 bis 60 Jahre einen Verlust von durchschnittlich 3.900 Euro hinnehmen müssen, während die bis 30-Jährigen im Vergleich zur Situation ohne Krise nur 550 Euro eingebüßt haben. Da die 51- bis 60-Jährigen mehr aufholen müssen und ihnen bis zum Renteneintritt höchstens 15 Jahre verbleiben, müssen sie entsprechend höhere Zahlungen leisten als die unter 30-Jährigen, deren Anlagehorizont bis zum Renteneintritt noch mindestens 35 Jahre beträgt (Abbildung 26).

\footnotetext{
${ }^{38}$ Der asymptotische Wert liegt in diesem Beispielfall bei etwa 120 Euro jährlich.
} 
Abbildung 26: Zusätzlich nötiger jährlicher Sparbetrag zum Ausgleich der Finanzvermögensverluste in Abhängigkeit vom Ansparzeitraum für verschiedene Altersklassen

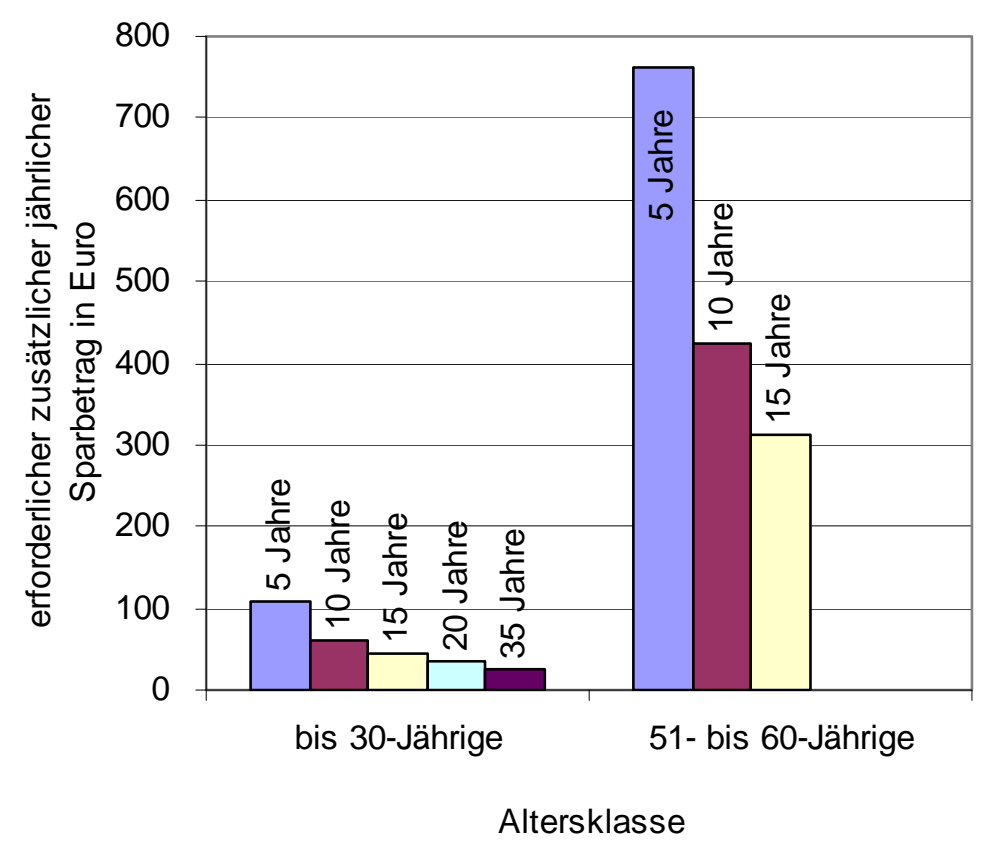

Quelle: SAVE, eigene Berechnung.

\section{Auswirkungen der Finanzkrise auf die Rendite der privaten Al- tersvorsorge}

Bisher wurden die Renditeverluste bezogen auf ein Jahr oder bezogen auf einen längeren in die Zukunft gerichteten Zeitraum berechnet. Um aber eine generelle Aussage über die Auswirkungen der Finanzkrise auf die Rendite der privaten Altersvorsorge machen zu können, sind die Sparleistungen in der Vergangenheit und der Zeitraum, in dem diese Zahlungen vor der Finanzkrise geleistet wurden, von großer Relevanz. Dies hängt im Wesentlichen vom Alter einer Person zum Zeitpunkt der Krise ab. Deshalb wird nun die Renditeentwicklung für verschiedene Geburtsjahrgänge betrachtet und die kohortenspezifischen Renditeeinbußen durch die Finanzkrise abgeschätzt.

Berechnet wird der interne Zinssatz einer Zahlungsreihe, bestehend aus den Sparbeiträgen und den aus dem akkumulierten Vermögen gezahlten Renten. Diesen Renditeberechnungen werden die folgenden Annahmen zugrunde gelegt: Unterstellt wird ein durchschnittlicher SAVE-Sparer, der im Alter von 20 Jahren beginnt Vorsorgevermögen zu bilden und in jedem 
Jahr 4\% des in diesem Jahr gültigen Durchschnittseinkommens ${ }^{39}$ spart. Die Portfoliozusammensetzung und damit auch die Zusammensetzung seiner Sparbeiträge entspricht derjenigen der SAVE-Haushalte Ende des Jahres 2007. Er geht jeweils zum gültigen gesetzlichen Renteneintrittsalter in Rente. Die Rentenbezugsdauer entspricht der ferneren Lebenserwartung gemäß der 11. koordinierten Bevölkerungsvorausberechnung des Statistischen Bundesamts. Für die Verzinsung des so angesparten Kapitalstocks wird der sich aus der angenommenen Portfoliozusammensetzung ergebende Durchschnittszinssatz für das Altersvorsorgevermögen und das gesamte Finanzvermögens abzüglich eines jährlichen Abschlags von 20\% zur Berücksichtigung der Kosten von kapitalgedeckten Vorsorgeprodukten unterstellt. ${ }^{40}$ Die jährliche Verzinsung der kapitalgedeckten Altersvorsorge (ohne Kosten) liegt dann für das Finanzvermögen - allerdings unter enormen Schwankungen - zwischen 8,9\% im Jahr 1960 und knapp 3,7\% im Jahr 2050 und für das Altersvorsorgevermögen bei einem deutlich stabileren Zinspfad zwischen 5,8\% und 3,6\% (Abbildung 27). ${ }^{41}$ Es wird angenommen, dass der angesparte Kapitalstock am Ende der Beitragszeit zu Rentenzahlungen in gleich hohen Annuitäten führt. Die Rentenzahlungen werden so kalkuliert, dass das bis zum Rentenalter angesammelte Vermögen am Ende des Lebens aufgebraucht ist. ${ }^{42}$

\footnotetext{
${ }^{39}$ Es wurde das für die Gesetzliche Rentenversicherung relevante Durchschnittseinkommen unterstellt. Für vergangene Jahre werden die tatsächlichen Zuwachsraten herangezogen, für die Zukunft werden die Raten der mittleren Variante im Rentenversicherungsbericht 2008 unterstellt.

${ }^{40}$ Damit wird die Rendite der kapitalgedeckten Anlage sehr vorsichtig kalkuliert, zumal z.B. Sparanlagen keine zusätzlichen Kosten verursachen, die Kosten vielmehr implizit schon mit der geringeren Verzinsung der Sparanlagen berücksichtigt sind. Zudem wird die stark renditeerhöhend wirkende Förderung bei den Riester-Verträgen nicht berücksichtigt.

${ }^{41}$ Die Verzinsung des Geldvermögens und des Altersvorsorgevermögens und damit auch des gesamten Finanzvermögens haben im Projektionszeitraum ein sehr ähnliches Niveau (Werte ab 2009 in Abbildung 27), weil im Geldvermögen niedrig verzinslichen Spareinlagen einen großen Anteil haben und sie den renditeerhöhenden Effekt der Aktienanlagen derart kompensieren, dass sich im Durchschnitt über alle Arten des Geldvermögens eine ähnliche Verzinsung wie bei den festverzinslichen Wertpapieren bzw. wie beim Altersvorsorgevermögen ergibt.

${ }^{42}$ Damit werden Erbschaften ausgeschlossen. Da von einer Restlebenserwartung gemäß der Bevölkerungsvorausberechnung des Statistischen Bundesamtes ausgegangen wird und nicht von einer höheren Lebenserwartung, die beispielsweise den Sterbetafeln von Versicherungen zugrunde liegt, wird die Rendite an dieser Stelle etwas zu optimistisch ausgewiesen. Dies wird allerdings durch die eher pessimistischen Annahmen bezüglich der Verwaltungskosten in etwa kompensiert.
} 


\section{Abbildung 27: Verzinsung der verschiedenen Vermögensanlagen in den Simulationen}

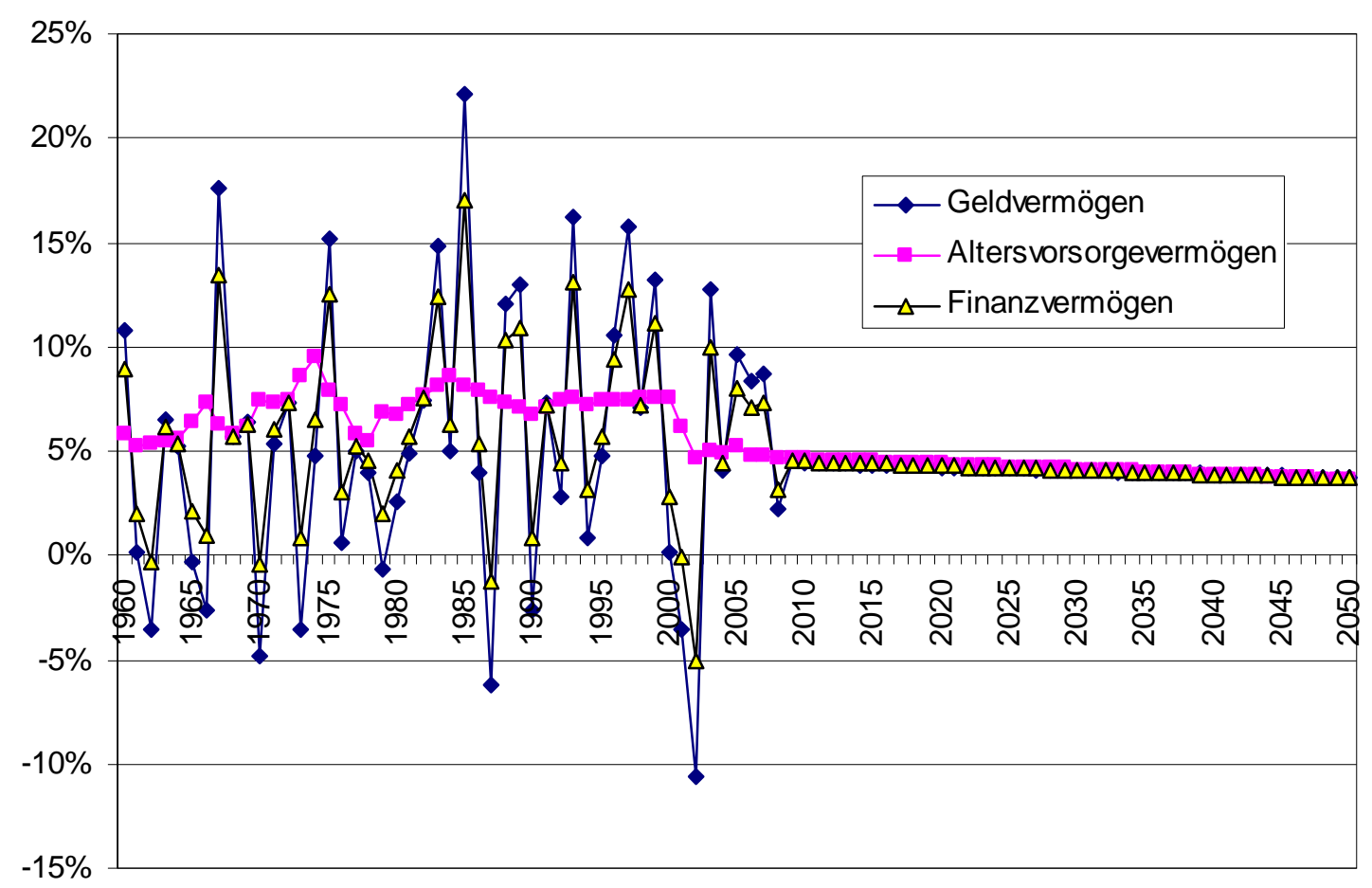

Quelle: eigene Darstellung.

Betrachtet werden vier Szenarien, die sich an den Szenarien des Abschnitts 3 orientieren:

- Im Szenario 1 (Referenzszenario) wird davon ausgegangen, dass es die Finanzkrise nicht gegeben hätte und die oben schon verwendeten Renditeverläufe für die einzelnen Vermögensklassen unterstellt.

- Im Szenario 2 (zentrales Szenario) werden vor allem für das Jahr 2008 niedrigere Renditen angenommen (siehe Tabelle 3). Danach schwenken die Renditen auf den Pfad ohne Krise ein (siehe Abbildung 22).

- Im Szenario 3 (pessimistisches Szenario) wird angenommen, dass die Krise einen langfristigen, strukturellen Rückgang der Kapitalrenditen bewirkt. Deshalb wird angenommen, dass die durchschnittliche Rendite ab 2010 in jedem Jahr um ein Zehntel geringer ist als im Szenario 2. Es kommt also zu dauerhaften Renditeeinbußen im Vergleich zum Referenzszenario.

- Im Szenario 4 (optimistisches Szenario) wird unterstellt, dass nach dem Renditeeinbruch eine Gegenbewegung mit überproportional hohen Kapitalrenditen stattfindet, so dass ab dem Jahr 2011 nicht nur die Renditen des Referenzszenarios wieder aufgeholt sind, sondern auch der Vermögensverlust komplett beseitigt ist. 
Für das Referenzszenario zeigt sich, dass bei der kapitalgedeckten Altersvorsorge die Rendite für den Jahrgang 1940 am größten ist (Abbildung 28), weil dieser Jahrgang am meisten von den hohen Zinssätzen der Vergangenheit profitieren konnte. Dann sinkt die kohortenspezifische Rendite der kapitalgedeckten Altersvorsorge, da auch die Kapitalmarktrendite eine sinkende Tendenz aufweist. Insgesamt liegt die Rendite der Altersvorsorge im Referenzszenario ohne Finanzkrise zwischen 5,1 \% (Jahrgang 1940) und 3,0 \% (Jahrgang 2000). Für das Finanzvermögen insgesamt liegen die Renditen zwischen 4,7\% und 3,0\%. Die etwas geringere Rendite für das Finanzvermögen ist darauf zurückzuführen, dass die niedrig verzinslichen Sparanlagen rund 30\% des Finanzvermögens ausmachen und somit die durchschnittliche Verzinsung dämpfen.

Das Szenario 2 wird hier als „zentrales Szenario“ betrachtet und deshalb ausführlich analysiert. Die Finanzkrise führt für die Geburtsjahrgänge 1940 bis 1990 zu Renditeeinbußen von maximal 0,1 Prozentpunkten für das Altersvorsorgevermögen und maximal 0,2 Prozentpunkten für das Finanzvermögen. Nach 1990 Geborene beginnen annahmegemäß erst nach 2010, also nach der Finanzkrise mit dem Altersvorsorgesparen und sind deshalb nicht betroffen. Die größten Renditeverluste haben die gerade in die Rente eingetretenen und die rentennahen Jahrgänge, weil sie zum Zeitpunkt der Krise schon viel Vermögen angesammelt haben und deshalb die größten Verluste erleiden. Ihnen bleibt kaum Zeit, um die Verluste zu kompensieren. Die späteren Geburtsjahrgänge hatten noch nicht so viel Vermögen angesammelt, so dass die Verluste bezogen auf die Sparleistung über das gesamte Leben klein ausfallen. Die stärkere Betroffenheit der älteren Jahrgänge darf aber nicht ohne Berücksichtigung der Renditeniveaus betrachtet werden. Denn selbst mit Finanzkrise können die älteren Jahrgänge noch immer weit höhere Renditen verzeichnen als die jüngeren Kohorten (Abbildung 28). Die Renditeeinbußen beim Finanzvermögen sind größer als beim Altersvorsorgevermögen, weil sich beim Finanzvermögen die krisenbedingten Einbußen bei den Aktienanlagen stärker bemerkbar machen (Abbildung 29).

Das Szenario 2 ist unmittelbar mit den Szenarien vergleichbar, die in der MEA-Studie zu den Auswirkungen der Finanzkrise auf die Gesetzliche Rentenversicherung simuliert wurden. ${ }^{43}$ Dort wurde unterstellt, dass die Lohnzuwachsraten nach einem Einbruch während der Krise wieder auf die Werte ohne Krise zurückkehren. Dem entspricht in dieser Studie die Annahme, dass die Kapitalrenditen nach einem Einbruch wieder auf ihr Niveau ohne Krise zurückkeh-

\footnotetext{
${ }^{43}$ Vgl. Börsch-Supan, Gasche und Wilke (2009).
} 
ren. Deshalb können die hier berechneten Renditeverluste für das Szenario 2 gut mit Renditeverlusten verglichen werden, die ein Versicherter der Gesetzlichen Rentenversicherung aufgrund der Finanzkrise erlitten hat. Dabei zeigt sich sowohl in qualitativer als auch in quantitativer Hinsicht ein sehr ähnliches Bild. Der maximale Renditeverlust beträgt in der Gesetzlichen Rentenversicherung je nach Szenario zwischen 0,1 und 0,3 Prozentpunkten, ${ }^{44}$ was der Größenordung der hier ermittelten Einbußen entspricht. In der Gesetzlichen Rentenversicherung sind diejenigen am stärkten betroffen, die zum Zeitpunkt der Krise schon viel Vermögen in Form von Entgeltpunkten angesammelt hatten. ${ }^{45}$ In der privaten Altersvorsorge sind diejenigen am stärksten belastet, die viel tatsächliches Kapitalvermögen angespart hatten. Jahrgänge, die nach der Krise erst erwerbstätig werden bzw. erst nach der Krise mit der Vermögensbildung beginnen, bleiben unbeeinflusst. Somit zeigt sich in eindrucksvoller Weise die Parallele zwischen der Altersvorsorge in der Gesetzlichen Rentenversicherung und der privaten Altersvorsorge. Beide Vorsorgearten sind betroffen. Für beide Vorsorgearten hält sich die Betroffenheit aber in Grenzen.

\section{Abbildung 28: Rendite der privaten Vorsorge im Krisenszenario (Szenario 2) und im Referenzszenario ohne Finanzkrise}

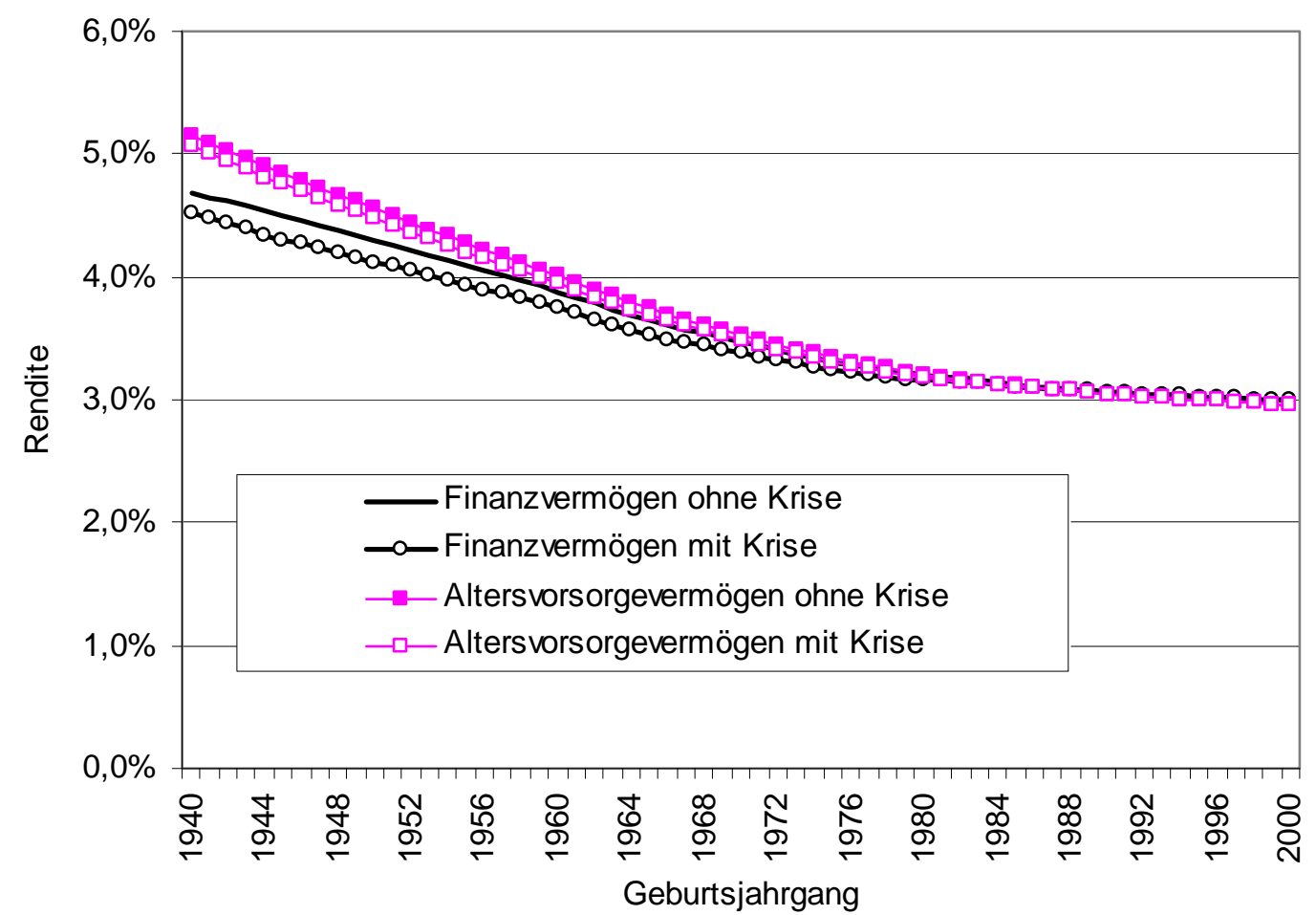

Quelle: SAVE, eigene Berechnung.

\footnotetext{
${ }^{44}$ Vgl. Börsch-Supan, Gasche, Wilke (2009), S. 87, Abbildung 18.

${ }^{45}$ Vgl. Börsch-Supan Gasche, Wilke (2009), Kapitel 7.
} 


\section{Abbildung 29: Kohortenspezifischer Renditeverlust durch die Finanzkrise (Szenario 2) im Vergleich zum Referenzszenario ohne Finanzkrise}

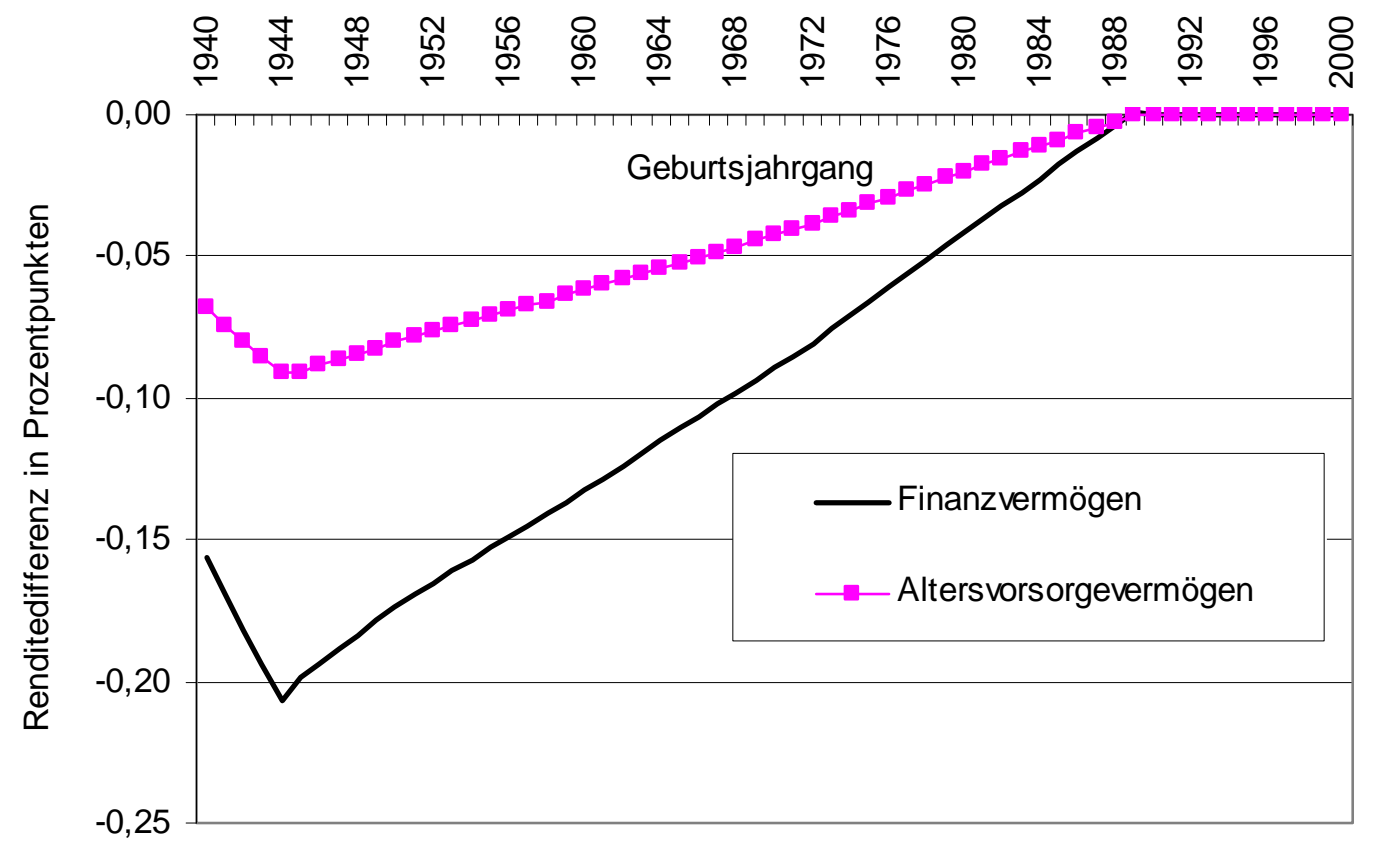

Quelle: SAVE, eigene Berechnung.

Geht man von einem strukturellen Renditerückgang aus (Szenario 3), sind entsprechend auch die Renditen der einzelnen Geburtsjahrgänge für alle Kohorten geringer (Abbildung 30). Die Finanzkrise wirkt sich also auch auf die ganz Jungen aus. Die größten Renditeeinbußen würden die Jahrgänge der 1950er bis 1980er Jahre erleiden, weil sie sowohl voll von der Finanzkrise als auch vom strukturellen Renditerückgang betroffen sind. Die jüngeren Jahrgänge dagegen sind von der Finanzkrise direkt kaum oder gar nicht beeinflusst, müssen aber die langfristigen indirekten Auswirkungen verkraften.

Im Erholungsszenario (Szenario 4) kommt es nur für die Jahrgänge der 1940er Jahre zu leichten Renditeeinbußen (Abbildung 30), was darauf zurückgeführt werden kann, dass diese Jahrgänge - weil sie schon in Rente sind - zur Zeit der Krise Vermögen verzehren mussten und deshalb die Hausse nach der Krise nicht für ihr gesamtes Vermögen zum Tragen kommt. Für die anderen Jahrgänge ergeben sich aufgrund der kompensierenden Wirkungen der Krise und der darauf folgenden Hausse so gut wie keine Auswirkungen. 


\section{Abbildung 30: Kohortenspezifische Renditeverlust des gesamten Finanzvermögens im Vergleich zum Referenzszenario}

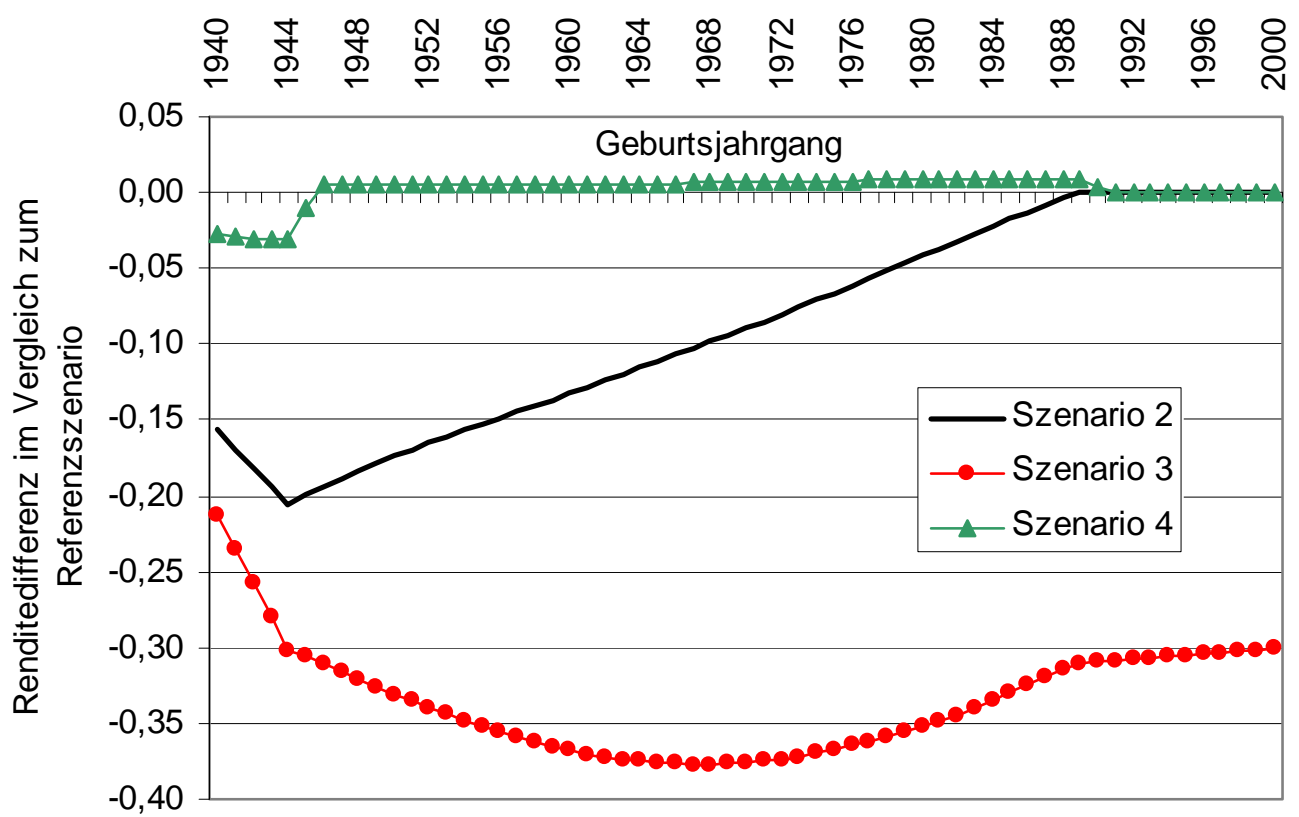

Quelle: SAVE, eigene Berechnung.

Es zeigt sich zudem deutlich, dass für die auf Langfristigkeit angelegte Altersvorsorge langfristige strukturelle Veränderungen wichtiger sind als kurzfristige konjunkturelle Schwankungen, mögen diese auch noch so heftig sein. So sind die Renditeeinbußen der jüngeren Generationen aufgrund des auf die demographische Entwicklung zurückzuführenden strukturellen Rückgangs der Kapitalrendite viel bedeutender als die Renditeeinbußen durch die Finanzkrise. So beträgt die Renditedifferenz zwischen dem Jahrgang 1940, der vom demographiebedingten Rückgang der Kapitalrenditen fast gar nicht betroffen ist, und dem Jahrgang 2000 der voll getroffen wird, über 2 Prozentpunkte (Abbildung 28). Die Finanzkrise dagegen kann selbst im schlimmsten Fall des Szenarios 3 nur zu Renditeeinbußen von 0,4 Prozentpunkten führen (Abbildung 29).

\section{Fazit}

Die Finanzkrise wird auch für private Vermögen langfristige Spuren hinterlassen. Die Vermögensverluste im Jahr 2008 betragen im Vergleich zu einer Situation ohne Krise durchschnittlich rund 3.000 Euro oder durchschnittlich 8,5\% des Finanzvermögens. Die Verluste sind dabei umso höher, je größer der Aktienanteil in den Portfolios der Haushalte war. Entsprechend sind Haushalte mit höherem Einkommen und höheren Vermögen sowie Haushalte mit älteren Personen und Personen mittleren Alters am stärksten betroffen. 
Das Altersvorsorgevermögen ist insgesamt jedoch weniger stark beeinträchtigt. Hier liegt der relative Verlust bei 3\%. Dies liegt vor allem daran, dass der Aktienanteil in der privaten Altersvorsorge relativ gering war. Zweitens gleicht die langfristige Anlage typischer Altersvorsorgeprodukte auch große, aber kurzfristige Schocks weitgehend aus. Drittens bewirken die über eine lange Zeit gleichmäßigen Ein- und oft auch Auszahlungen von Kapitallebensversicherungen, Rentenversicherungen und Sparplänen eine zusätzliche Glättung.

Während sich die Verluste im Durchschnitt der Haushalte also in Grenzen halten, gibt es doch einige, die sehr stark von der Krise gebeutelt wurden. So verloren in 2008 14\% der Haushalte mindestens 10\% ihres Finanzvermögens und 4,8\% der Haushalte mussten Verluste von mindestens 25\% des Finanzvermögens hinnehmen. Auch ältere Haushalte wurden überdurchschnittlich von Verlusten betroffen. Dies ist deshalb bedenklich, weil ihnen nur noch wenig Zeit bleibt, um durch zusätzliche Ersparnis die Verluste wieder auszugleichen.

Die Analyse der gesamten kohortenspezifischen Altersvorsorgerendite mit und ohne Finanzkrise zeigt einen moderaten Renditeverlust von maximal 0,2 Prozentpunkten für das Finanzvermögen. Am stärksten sind die Rentnerjahrgänge und die rentennahen Jahrgänge betroffen - allerdings ist ihre Rendite auch mit Krise noch immer deutlich höher als die Rendite der jungen Jahrgänge, weil der strukturelle demographiebedingte Rückgang der Kapitalrendite deutlich stärker ist als die Auswirkungen der Finanzkrise.

Diese Ergebnisse legen eine bemerkenswerte Symmetrie mit der Analyse der Auswirkungen der Finanzkrise auf die Gesetzliche Rentenversicherung offen. Auch dort waren permanente Vermögensverluste in Form der Abwertung von Entgeltpunkten in Höhe von 5\% bis 9\% zu verzeichnen, was mit den hier berechneten Verlusten von 3\% (Altersvorsorgevermögen) und 8,5\% (Finanzvermögen) vergleichbar ist. Der maximale Verlust der impliziten Rendite der Gesetzlichen Rentenversicherung durch die Krise wurde je nach Szenario zwischen 0,1 und 0,3 Prozentpunkte quantifiziert, was mit den hier berechneten Verlusten von 0,1 Prozentpunkten (Altersvorsorgevermögen) und 0,2 Prozentpunkten (Finanzvermögen) verglichen werden kann. Beide Analysen zeigen die stärkste Betroffenheit bei den Rentnerjahrgängen und den rentennahen Jahrgängen, weil diese Jahrgänge zum Zeitpunkt der Krise schon viel Vermögen angesammelt hatten, entweder in Form von Entgeltpunkten oder in Form von Finanzkapital. 
Somit zeigt sich in eindrucksvoller Weise, dass keines der Altersvorsorgesysteme von der Krise verschont geblieben ist. Insofern sitzen alle in einem Boot. Man kann aber auch feststellen, dass sich die Effekte insgesamt in Grenzen halten und die Finanzkrise in Deutschland nicht zu einer Krise der Altersvorsorge geführt hat. Die symmetrische Betroffenheit aller Systeme stärkt die Einsicht, dass der Einzelne mit einer Mischung aus Kapitaldeckung und Umlagesystem den demographischen Herausforderungen am besten begegnet werden kann. Die Auswirkungen der Finanzkrise ändern an dieser Erkenntnis nichts. 


\section{Literatur}

Benz, T., B. Raffelhüschen und Vatter, J. (2009): Finanzmarktkrise und Altersvorsorge - Wie groß sind die Verluste wirklich? Deutsches Institut für Altersvorsorge, Köln.

Börsch-Supan, A., T. Bucher-Koenen, M. Gasche und M. Ziegelmeyer (2009): Deutsche Privathaushalte in der Finanz- und Wirtschaftskrise - Betroffenheit und Reaktionen, MEAStudie, Nr. 10. Mannheim.

(http://www.mea.uni-mannheim.de/mea_neu/pages/files/polstudies/gt72y8j6zb776ehg_MEA_Study_10_WEB.pdf)

Börsch-Supan, A., M. Coppola, L. Essig, A. Eymann und D. Schunk (2009): The German SAVE Study Design and Results, MEA-Studie Nr. 6, Mannheim.

http://www.mea.uni-mannheim.de/mea_neu/pages/files/polstudies/3aferngy0iaowiys_MEA_Study_6.pdf

Börsch-Supan, A., M. Gasche und C. Wilke (2009): Auswirkungen der Finanzkrise auf die Gesetzliche Rentenversicherung, ihr Beitragszahler und ihre Rentner, MEA-Studie Nr. 9, Mannheim. (http://www.mea.uni-mannheim.de/mea_neu/pages/files/polstudies/egiti5udjt0001rn_MEAStudy09.pdf)

Börsch-Supan, A., F. Heiss, A. Ludwig und J. Winter (2003): Pension Reform, Capital Markets, in: German Economic Review, 4(2), S. 151-181.

Gesamtverband der deutschen Versicherungswirtschaft (GDV) (2009): Bericht zur Geschäftsentwicklung 2008.

GVG - Gesellschaft für Versicherungswissenschaft und -gestaltung e.V. (Hrsg.) (2009): Auswirkungen der Wirtschafts- und Finanzkrise auf die Alterssicherung, Informationsdienst Nr. 328, Köln, September 2009.

Krüger, D. und A. Ludwig (2007): On the Consequences of Demographic Change for Rates of Returns to Capital, and the Distribution of Wealth and Welfare, in: Journal of Monetary Economics, 54(1), S. 49-87.

Langer, T. und N. Nauhauser (2003): Gibt es einen Cost-Average Effekt? Working Paper, Universität Mannheim.

OECD (2009): Pensions at a Glance 2009, Paris.

Schunk, D. (2008): A Markov Chain Monte Carlo Algorithm for Multiple Imputation in Large Surveys, Advances in Statistical Analysis, 92, S. 101-114.

Ziegelmeyer, M. (2009): Documentation of the logical imputation using the panel structure of the 2003-2008 German SAVE Survey, MEA Discussion Paper 173-09, MEA Mannheim. http://www.mea.uni-mannheim.de/publications/meadp_173-09.pdf 


\section{Discussion Paper Series}

Mannheim Research Institute for the Economics of Aging, Universität Mannheim

To order copies, please direct your request to the author of the title in question.

\begin{tabular}{|c|c|c|c|}
\hline Nr. & Autoren & Titel & Jahr \\
\hline $181-09$ & $\begin{array}{l}\text { Steffen Reinhold, } \\
\text { Hendrik Jürges }\end{array}$ & $\begin{array}{l}\text { Secondary School Fees and the Causal Effect } \\
\text { of Schooling on Health Behaviour }\end{array}$ & 09 \\
\hline $182-09$ & $\begin{array}{l}\text { Steffen Reinhold, } \\
\text { Kevin Thom }\end{array}$ & $\begin{array}{l}\text { Temporary Migration and Skill Upgrading: } \\
\text { Evidence from Mexican Migrants }\end{array}$ & 09 \\
\hline $183-09$ & $\begin{array}{l}\text { Hendrik Jürges, } \\
\text { Eberhard Kruk, } \\
\text { Steffen Reinhold }\end{array}$ & $\begin{array}{l}\text { The effect of compulsory schooling on health - } \\
\text { evidence from biomarkers }\end{array}$ & 09 \\
\hline $184-09$ & $\begin{array}{l}\text { Nicola Fuchs- } \\
\text { Schündeln, Dirk } \\
\text { Krüger, Mathias } \\
\text { Sommer }\end{array}$ & $\begin{array}{l}\text { Inequality Trends for Germany in the Last Two } \\
\text { Decades: A Tale of Two Countries }\end{array}$ & 09 \\
\hline $185-09$ & $\begin{array}{l}\text { Francesco Cinnirella, } \\
\text { Joachim Winter }\end{array}$ & $\begin{array}{l}\text { Size Matters! Body Height and Labor Market } \\
\text { Discrimination: A Cross-European Analysis }\end{array}$ & 09 \\
\hline $186-09$ & $\begin{array}{l}\text { Hendrik Jürges, } \\
\text { Steffen Reinhold, } \\
\text { Martin Salm }\end{array}$ & $\begin{array}{l}\text { Does Schooling Affect Health Behavior? } \\
\text { Evidence from Educational Expansion in } \\
\text { Western Germany }\end{array}$ & 09 \\
\hline $187-09$ & Michael Ziegelmeyer & $\begin{array}{l}\text { Das Altersvorsorge-Verhalten von } \\
\text { Selbständigen - eine Analyse auf Basis der } \\
\text { SAVE-Daten }\end{array}$ & 09 \\
\hline $188-09$ & $\begin{array}{l}\text { Beatrice Scheubel, } \\
\text { Daniel Schunk, } \\
\text { Joachim Winter }\end{array}$ & $\begin{array}{l}\text { Don't raise the retirement age! An experiment } \\
\text { on opposition to pension reforms and East- } \\
\text { West differences in Germany }\end{array}$ & 09 \\
\hline $189-09$ & Martin Gasche & $\begin{array}{l}\text { Die sozialversicherungspflichtig Beschäftigten } \\
\text { im deutschen Sozialversicherungssystem: } \\
\text { Eigenschaften, Beitragsleistungen und } \\
\text { Leistungsbezug }\end{array}$ & 09 \\
\hline $190-09$ & Martin Gasche & $\begin{array}{l}\text { Implizite Besteuerung im deutschen } \\
\text { Sozialversicherungssystem }\end{array}$ & 09 \\
\hline $191-09$ & $\begin{array}{l}\text { Alexander Ludwig, } \\
\text { Alexander Zimper }\end{array}$ & $\begin{array}{l}\text { Biased Bayesian learning and the risk-free } \\
\text { rate puzzle }\end{array}$ & 09 \\
\hline 192-09 & $\begin{array}{l}\text { Tabea Bucher- } \\
\text { Koenen }\end{array}$ & $\begin{array}{l}\text { Financial Literacy and Private Old-age } \\
\text { Provision in Germany - Evidence from SAVE } \\
2008 \text { - }\end{array}$ & 09 \\
\hline 193-09 & $\begin{array}{l}\text { Axel Börsch-Supan, } \\
\text { Martin Gasche, } \\
\text { Michael Ziegelmeyer }\end{array}$ & $\begin{array}{l}\text { Auswirkungen der Finanzkrise auf die private } \\
\text { Altersvorsorge }\end{array}$ & 09 \\
\hline
\end{tabular}

